Natália Rodrigues Guimarães

Diversidade do Gênero Hypnea (Gigartinales, Rhodophyta) do Estado de São Paulo Baseada em Marcadores Moleculares e Morfologia.

VERSÃO REVISADA

São Paulo

2011 
Natália Rodrigues Guimarães

\section{Diversidade do Gênero Hypnea (Gigartinales, Rhodophyta) do Estado de São Paulo Baseada em Marcadores Moleculares e Morfologia.}

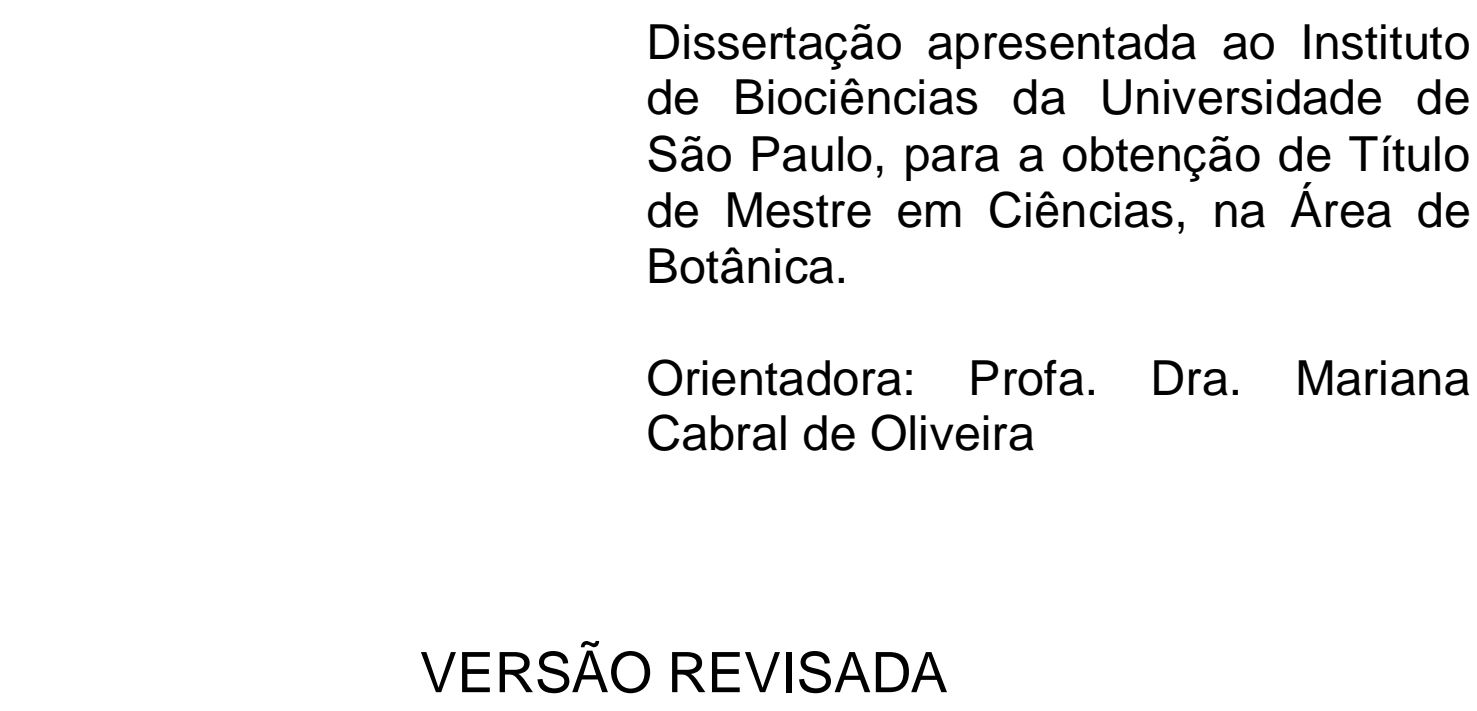

O original desta obra encontra-se disponível na Biblioteca do Instituto de Biociências-USP

São Paulo 2011 
Guimarães, Natália Rodrigues

Diversidade do Gênero Hypnea (Gigartinales, Rhodophyta) do Estado de São Paulo Baseada em Marcadores Moleculares e Morfologia./Natália Rodrigues Guimarães - São Paulo: N.R., 2011. p.: il

Dissertação (Mestrado) - Instituto de Biociências da Universidade de São Paulo. Departamento de Botânica, 2011.

1. cox1, 2."DNA barcoding", 3. Hypnea, 4. filogenia, 5. rbcL, 6. UPA. I. Universidade de São Paulo. Instituto de Biociências. Departamento de Botância. II. Título

\section{Comissão Julgadora:}

Mutue Toyota Fujii

$\operatorname{Prof}(\mathrm{a})$. $\operatorname{Dr}(\mathrm{a})$.
Valéria Cassano

$\operatorname{Prof}(a) . \operatorname{Dr}(a)$.

\section{Mariana Cabral de Oliveira}

Prof(a). Dr.(a).

Orientador(a) 
Aos mestres que me ensinaram o caminho da Ciência: João Petucco, Ciro César Zanini Branco e Mariana Cabral de Oliveira. Aos amigos Manu, Fábio e Carol. 
"The sea, once it casts its spell,

holds one in its net of wonder." Jacques Cousteau 


\section{AGRADECIMENTOS}

Agradeço à FAPESP (Fundação de Amparo à Pesquisa do Estado de São Paulo) pela bolsa cedida ao projeto temático Rhodo-SP (2007/51270-7) e pela bolsa de mestrado (no 2009/01077-1).

À Professora Mariana Cabral de Oliveira, pela orientação e apoio durante os anos de desenvolvimento do projeto e pelo exemplo de mulher/mãe/pesquisadora que foi para $\operatorname{mim}$.

À Professora Nair Yokoya pela colaboração indispensável para o desenvolvimento deste projeto.

Ao Instituto de Biociências da USP, em especial ao Departamento de Botânica, pelo programa de pós-graduação.

Aos professores e mestres do Departamento de Botânica do Instituto de Biociências da USP: Eurico, Estela, Fungyi, Valéria, Lúcia e Salatino; e da Seção de Ficologia do Instituto de Botânica de São Paulo: Mutuê, Silvia Pitta e Diclá, que, durante o desenvolvimento deste trabalho, se dispuseram inúmeras vezes a me ajudar e incentivar.

Aos técnicos, alunos e funcionários da Seção de Ficologia do Instituto de Botânica pela ajuda e amizade durante o desenvolvimento da pesquisa.

Aos técnicos do Laboratório de Algas Marinhas (LAM) da USP: Rosário Petti, Henrique Lauand e Carolina Franco, pelo apoio e colaboração em todos os momentos da minha pesquisa.

A todos que me ajudaram nas coletas realizadas para que este trabalho pudesse se concretizar.

Aos amigos Fábio e Manu, pelos ensinamentos iniciais de bancada no "LAM".

Aos "LAMigos" e agregados pela companhia, almoços, amigos secretos, aniversários ... Enfim, pelos momentos de descontração e pela paciência comigo nos últimos dois anos e meio.

À minha família e amigos pelo apoio incondicional e risadas quando mais precisei.

Este trabalho é o resultado de todas essas amizades e todos os ensinamentos que carregarei comigo para as próximas etapas da minha vida.

Muito obrigada! 
Lista de Tabelas flNDICE

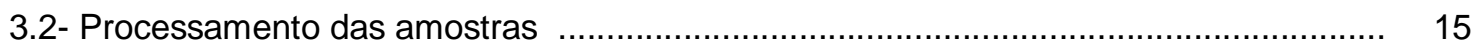

3.3- Extração de DNA e amplificação dos marcadores moleculares ................................ 21

3.4- Sequenciamento de DNA e análises filogenéticas ................................................. 23

3.5- Submissão de sequências nos bancos de dados ....................................................... 26

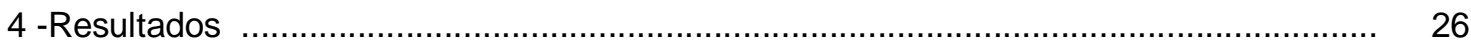

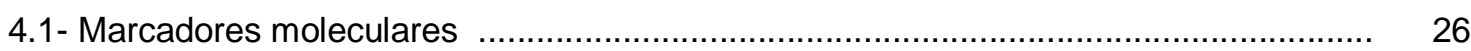

4.2- Análises Filogenéticas ...................................................................................... 31

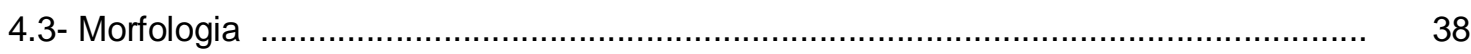

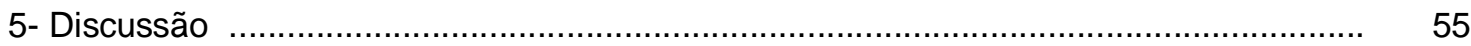

5.1- Marcadores Moleculares e Filogenia

5.2- H.cervicornis X H.spinella ............................................................................ 58

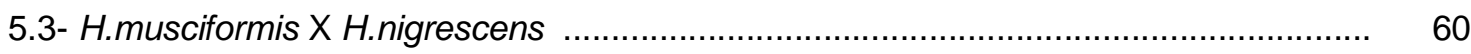

5.4- Hypnea flexicaulis .................................................................................... 61

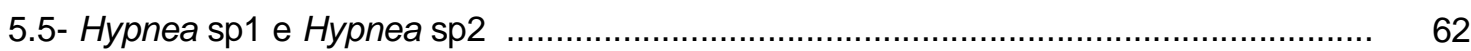

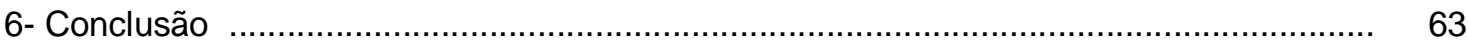

Referências

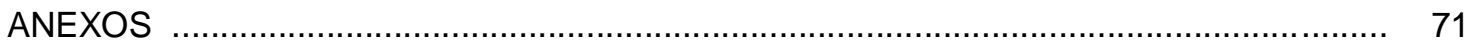




\section{니STA DE TABELAS}

TABELA

Tabela 1. Espécies do gênero Hypnea citadas para região do Atlântico (modificada de Lúcio, 2006).............

Tabela 2. Espécies e sinonímias das espécies de Hypnea referidas para o Brasil.

Tabela 3. Espécies do gênero Hypnea citadas por diferentes autores para o estado de São Paulo e/ou para o Brasil. " $X$ " representa as espécies presentes e "0" representa as não presentes segundo a fonte citada. [ ] indicam sinonímias.

Tabela 4. Marcadores moleculares usados no gênero Hypnea, com sequências depositadas no GenBank e suas referências.

Tabela 5. Listagem das amostras de Hypnea (numeradas de acordo com o projeto Rhodo-SP) e dados da coleta.

Tabela 6. Caracteres morfológicos utilizados nas análises morfológicas das espécies de Hypnea (baseado em Masuda, 1997 e Lúcio, 2009).

Tabela 7. "Primers" para PCR e sequenciamento para os diferentes marcadores moleculares. Nos primers do marcador rbcL, $r=$ A ou $\mathrm{G} ; \mathrm{y}=\mathrm{C}$ ou $\mathrm{T} ; \mathrm{w}=\mathrm{A}$ ou $\mathrm{T}$.

Tabela 8. Sequências do marcador cox1 obtidas do GenBank utilizadas nas análises.

Tabela 9. Sequências do marcador $r b c L$ do GenBank utilizadas nas análises filogenéticas.

Tabela 10. Espécies do gênero Hypnea analisadas neste trabalho agrupadas de acordo com as sequências obtidas para o marcador cox1. Número das amostras de acordo com a Tabela 5.

Tabela 11. Porcentagem de identidade (no triângulo da porção inferior) e número absoluto de nucleotídeos divergentes (no triângulo superior em negrito) entre as sequências do cox1 as espécies e haplótipos estudados do gênero Hypnea. H. musciformis: IBC0098, IBC0138, IBC0188; H. cervicornis: BOT004, IBC0028, IBC0186, IBC0194, IBC0200; H. spinella: IBC0041; H. flexicaulis: IBC0190; H.sp1: IBC0212; H.sp2: BOT0003. Número das amostras de acordo com a Tabela 5.

Tabela 12. Porcentagem de identidade (no triângulo inferior) e número absoluto de nucleotídeos divergentes (no triângulo superior) entre as sequências do UPA dos espécimes estudados do gênero Hypnea. $H$. cervicornis: IBC0028, IBC0064 e IBC0247; H. musciformis: IBC0040, IBC0098 e IBC0185; H. spinella: IBC0129; H. flexicaulis: IBC0190; H.sp1: IBC0212; H.sp2: BOT0003. Número das amostras de acordo com a Tabela 5.

Tabela 13. Porcentagem de identidade (no triângulo inferior) e número absoluto de nucleotídeos divergentes (no triângulo superior em negrito) entre as sequências de $r b c L$ dos espécimes estudados do gênero Hypnea H. cervicornis: IBC0028, IBC0064, IBC0245; H. musciformis: IBC0040, IBC0098, IBC0185; H. spinella: IBC0129; H. flexicaulis: IBC0190; H.sp1: IBC0212; H.sp2: BOT0003. Número das amostras de acordo com a Tabela 5.

Tabela 14. . Divergências interespecíficas e intraespecíficas paras os marcadores cox1, UPA e rbcL entre as amostras do gênero Hypnea sequenciadas para este estudo.

Tabela 15. Características morfológicas das espécies do gênero Hypnea analisadas neste trabalho.

Tabela 16. Amostras identificadas pelo número de projeto (№Rhodo-SP), indicando local de coleta e número do voucher depositado nos herbários SP ou SPF. ${ }^{* *}$ indicam voucher não localizados.

Tabela 17. Comparação entre divergências inter e intraespecíficas com espécies do gênero Hypnea e para Rhodophyta em geral. Sublinhados os valores obtidos utilizando somente as amostras deste estudo. 


\section{LISTA DE FIGURAS}

FIGURA

Figura 1. Composição de táxons de Rhodophyta (a), Florideophyceae (b) e Gigartinales (c). Árvores a e b modificadas, respectivamente, de Yoon et al. (2006) e Tree of Life (http://tolweb.org/Florideophyceae/21781) e lista de famílias de Gigartinales s.s. (c) retirada de Saunders (2004).

Figura 2. Ciclos para PCR dos três marcadores utilizados neste trabalho retirados, de a) Freshwater et al. (1994), b) Saunders (2005) e c) Sherwood \& Presting (2007).

Figura 3. Análise de Neighbor-Joining (NJ) para as sequências de cox1 obtidas de espécies do gênero Hypnea; a sequência de Chondracanthus teedi foi utilizada como grupo externo. Nos ramos estão plotados os valores de bootstrap de duas matrizes analisadas. Apenas valores maiores do que 0,62 foram plotados. As sequências retiradas do GenBank estão seguidas do $n^{\circ}$ de acesso e localidade geográfica. As amostras de São Paulo estão destacadas em negrito.

Figura 4. Análise de Neighbor-Joining (NJ) para as sequências do marcador UPA, mostrando o agrupamento de espécies do gênero Hypnea. Nos ramos estão plotados os valores de bootstrap. Apenas valores maiores do que 70 foram plotados. As sequências retiradas do GenBank estão seguidas do $n^{\circ}$ de acesso. As amostras de São Paulo estão destacadas em negrito.

Figura 5. Análise Bayesiana (MB) de sequências de rbcL mostrando as relações filogenéticas de espécies do gênero Hypnea. Nos ramos estão plotados os valores de bootstrap para análise de Neighbor-Joining (NJ) e Máxima Parsimônia (MP) - NJ/MP. As probabilidades a posteriori (pp) estão representadas na espessura dos ramos, segundo a legenda da figura. Apenas valores maiores do que 0,70 ou 70 foram plotados. As sequências retiradas do GenBank estão seguidas do $n^{\circ}$ de acesso. As amostras de São Paulo estão destacadas em negrito.

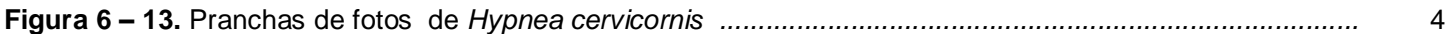

Figura 14 - 17. Pranchas de fotos de Hypnea flexicaulis. ........................................................................

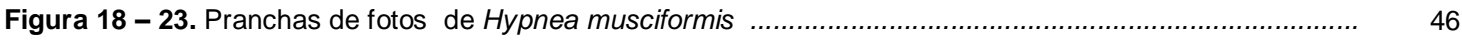

Figura 24 - 29. Pranchas de fotos de Hypnea spinella ........................................................................ 48

Figura 30 - 34. Pranchas de fotos de Hypnea sp. 1 ....................................................................... 50

Figura 35 - 39. Pranchas de fotos de Hypnea sp. 2 ................................................................................ 52

ANEXO I. Matriz de sequências de cox1 das espécies de Hypnea sequenciadas neste estudo. As amostras estão identificadas de acordo com a Tabela 5

ANEXO II. Matriz de sequências de UPA das espécies de Hypnea sequenciadas neste estudo. As amostras estão identificadas de acordo com a Tabela 5

ANEXO III. Matriz de sequências de rbcL das espécies de Hypnea sequenciadas neste estudo. As amostras estão identificadas de acordo com a Tabela 5

ANEXO IV. Matriz de identidade do marcador cox 1 das sequências obtidas neste e estudo e das sequências retiradas do banco de dados. Amostras numeradas de acordo com as Tabelas 5, 8 e 9

ANEXO V. Matriz de identidade do marcador rbcL1 das sequências obtidas neste e estudo e das sequências retiradas do banco de dados. Amostras numeradas de acordo com as Tabelas 5, 8 e 9 


\section{RESUMO}

O gênero Hypnea J.V. Lamouroux (1813) (Cystocloniaceae, Gigartinales), com cerca de 67 espécies descritas, apresenta ampla distribuição geográfica pelas costas marinhas de águas quentes ao redor do mundo. Algumas espécies de Hypnea são usadas para a produção de carragenanas, hidrocolóides de grande importância na indústria atual. A taxonomia do gênero é bastante problemática e a identificação das espécies é complicada devido a uma morfologia relativamente simples que muitas vezes é influenciada pelas condições do habitat onde se encontram. Apesar das revisões regionais já realizadas, o número certo de espécies e o status de algumas delas permanece em dúvida. Estudos moleculares já foram realizados com o gênero Hypnea principalmente para região da Ásia. A técnica do "DNA barcoding" tem sido testada em Rhodophyta com sucesso para identificação rápida de espécies, utilizando a região $5^{\prime}$ do gene mitocondrial da citocromo $c$ oxidase subunidade $\mathrm{I}$, o marcador cox1. Outro marcador recentemente testado como "DNA barcode" é o domínio $V$ do gene plastidial 23S, o marcador UPA. Além destes, o marcador plastidial $r b c \mathrm{~L}$ tem sido utilizado como ferramenta para estudos filogenéticos do gênero Hypnea. No presente trabalho, foram sequenciadas para o marcador cox1, 49 amostras provenientes do no litoral do estado de São Paulo, uma amostra proveniente do estado do Rio de Janeiro e cinco amostras mantidas em cultura provenientes dos litorais dos estados de São Paulo e Espírito Santo. Foram identificados seis grupos taxonômicos diferentes segundo o marcador cox1. Representantes de cada um desses grupos foram sequenciados para os marcadores UPA e rbcL. A divergência interespecífica encontrada entre as amostras sequenciadas neste estudo para o marcador cox1 foi 62 - 100 pb (10,1 - 16,3\%); para o marcador UPA foi 9 - 16 pb $(2,5-4,4 \%)$ e para 0 marcador $r b c L$ foi $42-88$ pb (3,2 - 6,7\%). As divergências intraespecíficas das amostras obtidas neste estudo foram, $0-5 \mathrm{pb}(0-0,9 \%)$ para o marcador cox $1,0-1$ $\mathrm{pb}(0-0,3 \%)$ para o marcador UPA e $0-6 \mathrm{pb}(0-0,5 \%)$ para o marcador $r b c \mathrm{~L}$. As divergências observadas corroboram a existência de seis entidades taxonômicas diferentes. Após análise da morfologia e comparação com sequências disponíveis no GenBank as espécies do gênero Hypnea foram nomeadas como: $H$. cervicornis, $H$. flexicaulis, $H$. musciformis, $H$. spinella, Hypnea sp.1 e Hypnea sp.2. Sendo a espécie Hypnea flexicaulis a primeira citação para o Oceano Atlântico. Baseado nos estudos moleculares e morfológicos, concluímos que a espécie $H$. nigrescens, anteriormente citada para o Estado de São Paulo, é na verdade uma variação morfológica de $H$. musciformis. Ainda, concluímos que as espécies de $H$. cervicornis e $H$. spinella não devem ser colocadas em sinonímia uma vez que suas características morfológicas e as diferenças nas sequências obtidas através dos três marcadores utilizados mostram que são duas espécies distintas. 


\section{ABSTRACT}

The genus J.V. Lamouroux (1813) (Cystocloniaceae, Gigartinales), comprises 67 described species, has a wide geographical distribution on the tropical shores around the world. Some species of Hypnea are used for the production of carrageenan, hydrocolloids of great importance in today's industry. The taxonomy of the genus is very problematic and Hypnea species identification is complicated by a relatively simple morphology that is often influenced by the conditions of the habitat. Although some regional reviews have been carried out, the right number of species and the status of some species remain in doubt. Molecular studies have been carried out mainly dealing with species from Asia. The technique of "DNA barcoding" has been successfully tested in Rhodophyta for rapid identification of species using the 5 'region of the mitochondrial gene cytochrome $c$ oxidase subunit I, the marker cox 1 . Recently, another marker tested as "DNA barcode" is the domain $\mathrm{V}$ of the plastidial $23 \mathrm{~S}$ gene, the marker UPA. In addition, the plastidial marker $r b c \mathrm{~L}$ has been used as a tool for phylogenetic studies of the genus Hypnea. In this study, were sequenced for the marker cox1, 49 samples from the coast of São Paulo State, a sample from the State of Rio de Janeiro and five samples maintained in culture from the coastal states from the States of São Paulo and Espirito Santo. We identified six different taxonomic groups according to the marker cox1. Representatives of each of these groups were sequenced for the UPA and $r b c L$ markers. The divergence found among the cox 1 sequences in this study was from 62 to $100 \mathrm{bp}(10.1-16.3 \%)$, for the UPA marker was from 9 to $16 \mathrm{bp}$ (2.5 to $4.4 \%$ ), and for the rbcL marker was 42 to $88 \mathrm{bp}$ (3.2 - 6.7\%). The intraspecific divergences for the samples sequenced in this study were $0-5 \mathrm{bp}(0$ $0.9 \%)$ for the cox $1,0-1 \mathrm{bp}(0-0.3 \%)$ for the UPA and $0-6 \mathrm{bp}(0-0.5 \%)$ for the rbcL. The observed divergences for the three molecular markers confirm the existence of six different taxonomic entities. After analysis of the morphology and comparison with sequences available in GenBank for the genus Hypnea these taxonomic entities were named as: $H$. cervicornis, $H$. flexicaulis, $H$. musciformis, $H$. spinella, Hypnea sp. 1 and sp2. As the species Hypnea flexicaulis this is the first citation to the Atlantic Ocean. Based on morphological and molecular studies, we conclude that the species $H$. nigrescens, quoted earlier for the State of São Paulo, is actually a morphological variation of $H$. musciformis. Still, we conclude that the species $H$. cervicornis and $H$. spinella should not be placed in synonymy since its morphological characteristics and differences in the sequences obtained from the three molecular markers show that they are two distinct species. 


\section{1- Introdução}

\section{1- Filo Rhodophyta}

As algas vermelhas (Rhodophyta), macro e microalgas, estão distribuidas em ambientes continentais e marinhos, de regiões tropicais a polares. O Filo Rhodophyta forma uma das principais linhagens monofiléticas dentro dos eucariotos e apresenta caracteres químicos, ultra-estruturais e reprodutivos que as separam de outros grupos de algas (Ragan et al.1994, Freshwater et al. 1994). Os organismos deste filo possuem clorofila a e pigmentos acessórios, aloficocianina, ficocianina e ficoeritrina na forma de ficobilissomas, localizados em tilacóides não empilhados, assim como pigmentos fotoprotetores, os carotenóides; não possuem flagelos ou centríolos em nenhuma fase de seu ciclo de vida; produzem o amido das florídeas, depositado no citoplasma (Garbary \& Gabrielson 1990, Graham \& Wilcox 2009). Acredita-se, ainda, que 0 ancestral comum das algas vermelhas, verdes e glaucófitas sofreu um evento de endossimbiose primária com uma cianobactéria (Bhattacharya \& Medlin 1995, Delwiche et al. 1995, Cavalier-Smith 1998, McFadden 1999, Bhattacharya et al. 2004, Rodríguez-Ezpeleta et al. 2005) originando o plastídeo desse grupo, que é envolvido por duas membranas.

Assim como as outras algas, as Rhodophyta possuem um importante papel na produção primária, como fonte de alimento, produção de oxigênio e nos ciclos de carbono e nitrogênio na natureza (Graham \& Wilcox 2009). As Rhodophyta, no contexto da vida moderna, apresentam grande importância econômica, principalmente na indústria de alimentos e na indústria química. Algumas espécies de algas vermelhas são cultivadas como fonte de alimento (i.e. Porphyra C.Agardh) ou para extração de hidrocolóides como o ágar-ágar e as carragenanas (i.e. Gracilaria Greville e Kappaphycus Doty, respectivamente) que são imprescindíveis para certas aplicações tecnológicas e industriais (Crichley \& Ohno 1998).

As Rhodophyta representam mais de $60 \%$ das espécies de macroalgas presentes no ambiente marinho (Norton et al. 1996), sendo o filo mais diverso entre as algas bentônicas. Segundo Graham \& Wilcox (2009), são estimados de 500 a 600 gêneros e pouco mais de 6000 espécies de algas vermelhas, e acredita-se que 0 número de espécies possa chegar a 20.000 (Norton et al.1996), devido às recentes descobertas de espécies crípticas.

No Brasil, as Rhodophyta são representadas, segundo Horta et al. (2001) por 388 espécies dentro das 643 espécies de macroalgas marinhas conhecidas no país 
(http://www.ib.usp.br/algaemaris/ AlgaemarisBrasilis.html) e, recentemente, Fujii et al. (2008) afirmam que existe um total de 482 táxons infragenéricos de Rhodophyta dentre os 774 conhecidos para o Brasil.

O filo Rhodophyta era tradicionalmente dividido em duas classes ou subclasses: Florideophycidae e Bangiophycidae (Garbary \& Gabrielson 1990). Recentemente a classificação do grupo tem sofrido revisões. Saunders \& Hommersand (2004) propuseram o subreino Rhodoplantae, com dois filos: Cyanidiophyta e Rhodophyta. Yoon et al. (2006) propuseram, baseado em resultado de múltiplos marcadores moleculares, que existem sete linhagens de Rhodophyta, que devem ser reconhecidas como classes (Fig.1a). Afirma, ainda, que a criação de um subreino e dois filos não é necessária, já que as Cyanidiophyta compartilham muitas características com as Rhodophyta. Assim, baseado no fato de que as Cyanidiophyceae divergiram primeiramente na evolução das algas vermelhas e são separadas das outras linhagens, foi proposta a criação de um subfilo, Cyanidiophytina, e do subfilo Rhodophytina, agrupando todas as outras linhagens de algas vermelhas. Rhodophytina, nessa classificação, contém seis classes: Bangiophyceae, Compsopogonophyceae, Florideophyceae, Porphyridiophyceae, Rhodellophyceae, e Stylonematophyceae, sendo Bangiophyceae e Florideophyceae mais proximamente relacionadas, formando um grupo monofilético (Yoon et al. 2006).

A classe Florideophyceae inclui, aproximadamente, 6000 espécies, cerca de 99\% das espécies conhecidas (Grahan \& Wilcox 2009), que foram divididas, segundo Le Gall \& Saunders (2007) em cinco subclasses: Hildenbrandiophycidae, Nemaliophycidae, Corallinophycidae, Rhodimeniophycidae e Ahnfeltiophycidae. Conforme o autor, o número de ordens na classe varia de 16 (Yoon et al. 2006) a 23 (Le Gall \& Saunders 2007) (Fig. 1b).

Os membros da classe Florideophyceae crescem por meio de células apicais e consistem inteiramente de filamentos ramificados nos quais as células estão ligadas por "pit-connections", que são conexões estruturais entre células adjacentes (Graham \& Wilcox 2009). Tradicionalmente, as Florideophycidae foram classificadas em ordens e famílias com base no ciclo de vida e modo de reprodução sexuada. A constituição química da parede celular (ágar ou carragenana) também é uma característica determinante na caracterização de algumas ordens de algas vermelhas (Freshwater et al. 1994).

Entre as ordens de Florideophyceae, a ordem Gigartinales proposta, em 1892 por Schmitz, é uma das principais (Saunders et al. 2004). Kylin (1956) sugeriu a união das ordens Gigartinales e Cryptonemiales, que foi validada posteriormente por Kraft \& Robins (1985). Assim, a ordem Gigartinales sensu lato (s.l) passou a ter 
aproximadamente 40 famílias. Trabalhos em relação à morfologia e anatomia deste grupo (Pueschel \& Cole 1982, Silva \& Johansen 1986, Fredericq \& Hommersand 1989, Maggs \& Pueschel 1989), assim como o posterior uso de ferramentas moleculares (Freshwater et al. 1994; Saunders \& Kraft 1994,1996,2002; Harper \& Saunders 2001), reduziram a heterogeneidade da ordem, tendo grande impacto no entendimento da composição e das relações entre os membros das Gigartinales (Saunders et al. 2004). Saunders et al. (2004), além de elucidar todas as mudanças pelas quais as Gigartinales já haviam passado, apresentou um estudo com membros das 40 famílias então incluídas na ordem, delineando Gigartinales sensu stricto (s.s.) , com 29 famílias, baseado em relações inferidas a partir do uso de um marcador molecular (Fig. 1c).

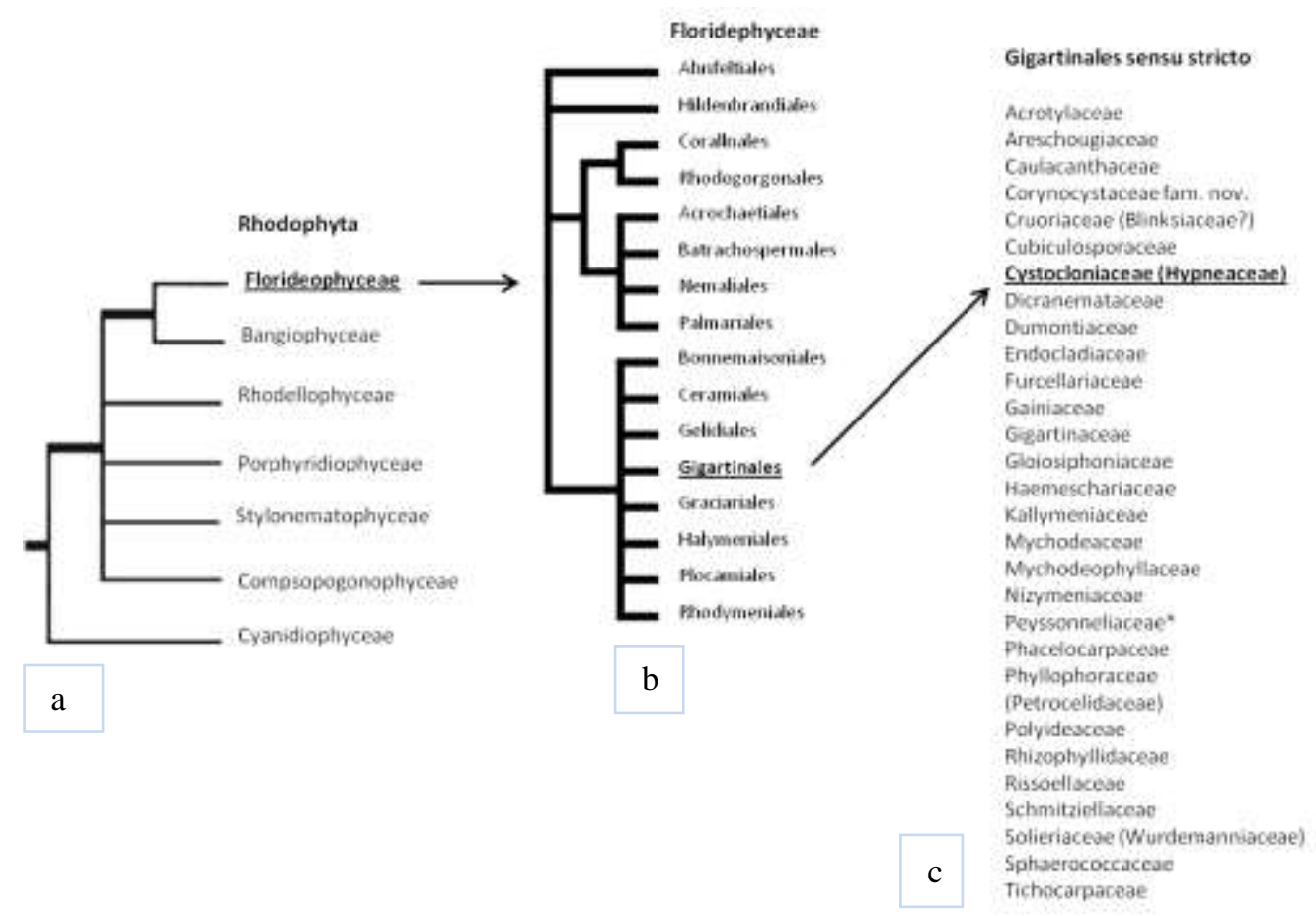

Figura 1. Composição de táxons de Rhodophyta (a), Florideophyceae (b) e Gigartinales (c). Árvores a e b foram modificadas, respectivamente, de Yoon et al. (2006) e Tree of Life (http://tolweb.org/Florideophyceae/21781) e lista de famílias de Gigartinales s.s. (c) retirada de Saunders (2004).

A família Cystocloniaceae, dentro de Gigartinales s.l., era formada pelos gêneros: Hypnea J.V. Lamouroux (1813), Hypneocolax Boergesen e Rhodoatilis J.Agardh. Kylin (1930) acrescentou Calliblepharis na família Hypneaceae e então em 1932 moveu Calliblepharis para as Cystocloniaceae, distinguindo essa família de Hypneaceae baseado em análises morfológicas do carposporângio. Min-Thein e Womersley (1976) questionaram essa mudança, observando que outros aspectos vegetativos e reprodutivos eram virtualmente idênticos nos dois grupos. 
Em 2004, Saunders et al.propõe a união das famílias Hypneaceae (incluindo os gêneros Hypnea e Hypneocolax) e Cystocloniaceae, baseado em resultados de marcadores moleculares obtidos por Fredericq et al. (1996a) (Fig.1c).

\section{2- O gênero Hypnea}

O gênero Hypnea foi estabelecido por Lamouroux (1813) baseado em seis espécies, sendo sua espécie tipo, H. musciformis (Wulfen) J. V. Lamouroux (Kylin 1930, Papenfuss 1968), que recebeu esse nome por sua semelhança com um musgo Hypnum Linné (Lúcio 2006 e Geraldino et al. 2010). O gênero Hypnea possui cerca de 67 espécies descritas (Geraldino et al. 2010) que variam no tamanho do talo de pequenos (menor do que $3 \mathrm{~cm}$ ) a grandes (maior do que $50 \mathrm{~cm}$ ) e se encontram distribuídas nas costas tropicais e subtropicais do mundo (Geraldino et al. 2009).

O gênero Hypnea é bastante conhecido dentro da família Cystocloniaceae (Saunders et al. 2004), ordem Gigartinales, por sua ampla distribuição geográfica, elevado número de espécies e importância econômica. O gênero é caracterizado por um talo cilíndrico a achatado, com muitas ramificações, ramos laterais curtos, cistocarpos globulares, e tetrasporângios zonados (Lamouroux 1813, Mshigeni 1978a, Womersley 1994). Depois do trabalho de Lamouroux (1813), muitas espécies foram descritas. J. Agardh (1852) descreveu 19 espécies e classificou-as em três sessões com base do hábito do talo: Virgatae, Spinuligerae e Pulvinatae. Apesar de alguns ficólogos terem aceitado e seguido essa divisão, atualmente ela não é reconhecida (e.g.Mshigeni 1978 a, b; Masuda et al. 1997; Geraldino et al. 2010).

Algumas espécies de Hypnea são usadas como alimento e como matéria prima para a produção de carragenanas (Greer et al. 1984), um hidrocolóide que apresenta uma grande importância na indústria de alimentos e cosmética. Contrário ao que era afirmado sobre a família Hypneaceae, que esta produzia somente K-carragenana (cf. Chiovitti et al. 1998 e referências neste citadas), hoje sabe-se que os dois tipos de carragenanas, L- carragenana e K-carragenana, coexistem em muitas espécies de Hypnea (Greer et al. 1984; Knutsen et al. 1995).

Devido a esse interesse econômico, estudos de maricultura para espécies de Hypnea já foram realizados no Brasil (Berchez \& Oliveira 1989; Reis et al. 2006). Além de estudos de maricultura, outros estudos abordando aspectos fisiológicos, bioquímicos (Schenkman 1980; Saito \& Oliveira 1990; Bravin \& Yoneshigui-Valentin 
2002) e biogeográficos (Haroun \& Prud'Homme van Reine 1993; Hommersand \& Fredericq 2003) já foram realizados com o gênero.

Schenkman (1980) estudou, entre outros fatores, a fenologia e o crescimento em diferentes condições de maricultura de Hypnea musciformis. Em seu trabalho de 1986, aprofundou o estudo em relação à frequência da fase tetrasporofítica e gametofítica e à ausência de plantas masculinas na natureza. Estudou os aspectos de reprodução em condições de laboratório e tentou esclarecer as dúvidas taxonômicas e o número de espécies existentes do Estado de São Paulo. Em sua discussão, Schenkman (1986) concluiu que algumas dificuldades taxonômicas do grupo são evidentes, como a plasticidade fenotípica, causando confusão na identificação das espécies, as quais são separadas por diferenças tênues.

Apesar da importância do gênero, sua taxonomia é bastante problemática e confusa. Isabella Abbot, em sua introdução para a revisão de Masuda et al. (1997) faz comentários sobre as dificuldades de trabalho com o gênero. Por ter uma distribuição cosmopolita e exibir uma variação morfológica muito grande, muitas vezes influenciada pelas condições do habitat onde se encontram, existe uma dificuldade na discriminação das espécies (Geraldino et al. 2010). Ainda, a não uniformidade das descrições das espécies do gênero causam mais confusão taxonômica (Yamagishi \& Masuda 2000) e o status de algumas espécies descritas no século 19 ainda não está bem estabelecido, o que, assim como as diferentes descrições já feitas, podem levar a erros classificatórios (Masuda et al. 1997). Por fim, não está estabelecido o real valor taxonômico dos caracteres morfológicos utilizados na identificação das espécies (Masuda et al. 1997).

A Tabela 1 mostra algumas revisões realizadas para o gênero Hypnea para o Oceano Atlântico. 
Tabela 1. Espécies do gênero Hypnea citadas para região do Atlântico (modificada de Lúcio, 2006)

\begin{tabular}{|c|c|c|c|c|}
\hline $\begin{array}{l}\text { Mshigeni \& Chapman (1994): } \\
\text { para o Oceano Atlântico }\end{array}$ & $\begin{array}{l}\text { Littler \& Littler (2000): } \\
\text { para o Caribe e costas } \\
\text { temperadas do Atlântico } \\
\text { Americano }\end{array}$ & $\begin{array}{l}\text { John et al. (2004): para zonas } \\
\text { ocidentais da África }\end{array}$ & $\begin{array}{l}\text { Creed et al. (2010): para o } \\
\text { Barsil }\end{array}$ & $\begin{array}{l}\text { Wynne (2011): Atlântico } \\
\text { tropical e subtropical }\end{array}$ \\
\hline H. alopecuroides Kützing 1868 & H. musciformis & H. arbuscula & H. cenomyce & H. cenomyce \\
\hline H. arbuscula P. Dangeard 1952 & H. spinella & H. cenomyce & H. cornuta & H. cervicornis \\
\hline H. cenomyce J. Agardh 1851 & H. valentiae & H. ceramioides & H. musciformis & H. cornuta \\
\hline H. ceramioides Kützing 1849 & & H. divaricata (C.Agardh) Greville 1870 & H. nigrescens & H. krugiana Hauck 1888 \\
\hline H. cervicornis J. Agardh 1851 & & H. eckloni Suhr 1836 & H. spinella & H. musciformis \\
\hline $\begin{array}{l}\text { H. cornuta (Kützing) J. Agardh } \\
1851\end{array}$ & & H. flagelliformis & H. valentiae & H. nigrescens \\
\hline $\begin{array}{l}\text { H. flagelliformis Greville ex J. } \\
\text { Agardh } 1851\end{array}$ & & H. musciformis & H. volubilis (Searles) & H.spinella \\
\hline $\begin{array}{l}\text { H. hamulosa (Esper) J.V. } \\
\text { Lamouroux } 1913\end{array}$ & & H. pannosa & & H.valentiae \\
\hline $\begin{array}{l}\text { H. musciformis (Wulfen) J.V. } \\
\text { Lamouroux } 1813\end{array}$ & & H. setacea Kützing 1847 & & $\begin{array}{l}\text { H.volubilis Searles in C.W. } \\
\text { Schneider \& Searles } 1976\end{array}$ \\
\hline H. pannosa J. Agardh 1847 & & H. spicifera (Suhr) Harvey 1938 & & \\
\hline $\begin{array}{l}\text { H. spinella (C. Agardh) Kützing } \\
1847 \\
\text { H. valentiae (Turner) Montagne } \\
1841\end{array}$ & & $\begin{array}{l}\text { H. spinella } \\
\text { H. tenuis Kylin } 1938\end{array}$ & & \\
\hline & & $\begin{array}{l}\text { H. unilateralis P. Dangeard } 1952 \\
\text { H. valentiae }\end{array}$ & & \\
\hline
\end{tabular}


No Brasil são referidas oito espécies de Hypnea (http://www.ib.usp.br/algaemaris/ algaemarisbrasilis.html; Schenkman 1986, Guimarães 2006 e Creed 2010), listadas na Tabela 2. Sendo que para o Estado de São Paulo o número de espécies citadas permanece em dúvida, como comentado abaixo.

Tabela 2. Espécies e sinonímias de Hypnea referidas para o Brasil.

\begin{tabular}{lll}
\hline Espécie & Localidade tipo * & Sinonímia \\
\hline Hypnea cenomyce & Costa da Holanda & \\
Hypnea cervicornis & Ilhas Maurício & \\
Hypnea cornuta & Costa de Nova Guiné & \\
Hypnea musciformis & Trieste, Italia & Hypnea arborescens \\
Hypnea nigrescens & Índia & \\
Hypnea spinella & "Indiae occidentalis" & Hypnea cervicornis \\
Hypnea valentiae & Mar Vermelho & Hypnea gracilarioides \\
Hypnea volubilis & & \\
\hline
\end{tabular}

*fonte: algaebase

Em seu trabalho de 1993, Haroun \& Prud'Homme van Reine sugeriram que as espécies Hypnea cervicornis (J. Agardh) e Hypnea spinella (C. Agardh) Kützing fossem colocadas em sinonímia, pois, baseado em caracteres morfológicos, foram encontradas formas intermediárias entre essas duas espécies. Sendo então a $H$. cervicornis uma forma presente em habitat mais calmo e submerso, enquanto que $H$. spinella seria a forma da espécie encontrada em um habitat com maior hidrodinamismo, ação das ondas e marés. A espécie foi então designada $H$. spinella (C. Agardh) Kützing devido à prioridade de publicação. Porém, alguns autores (Abbott 1999) não aceitaram a proposta e continuam a separar as espécies $H$. spinella e $H$. cervicornis. No Brasil, Guimarães (2006) mantém a separação das espécies, baseado no fato de seus talos apresentarem morfologias distintas. Na revisão realizada por Wynne em 2011, como citado acima, para o Atlântico tropical e subtropical essa sinonímia não é aceita, baseado em Guimarães (2006).

Ainda, a presença de Hypnea nigrescens no litoral do estado de São Paulo possui apenas uma citação, Schenkman (1986). E para o Brasil, uma citação é feita por Guimarães (2006). Na revisão feita por Wynne (2011) para o Atlântico tropical e subtropical a espécie é citada como presente para essa região.

A presença das espécies acima citadas fica, portanto, mais difícil de ser definida para o estado de São Paulo. A Tabela 3 mostra algumas referências de citações para espécies do estado de São Paulo e para o Brasil. 
Tabela 3. Espécies do gênero Hypnea citadas por diferentes autores para o estado de São Paulo e/ou para o Brasil. "X" representa as espécies presentes e "0" representa as não presentes segundo a fonte citada. [ ] indica sinonímias.

\begin{tabular}{|c|c|c|c|c|}
\hline \multirow{2}{*}{$\begin{array}{c}\text { Espécies } \\
\text { Fonte }\end{array}$} & \multicolumn{2}{|c|}{ São Paulo } & \multicolumn{2}{|c|}{ Brasil } \\
\hline & $\begin{array}{l}\text { Schenkman } \\
\text { (1986) }\end{array}$ & $\begin{array}{l}\text { Algaemaris }^{1} \\
\text { (2007) }\end{array}$ & Algaebase $^{2}$ & $\begin{array}{l}\text { Lúcio } \\
\text { (2006) }\end{array}$ \\
\hline $\begin{array}{l}\text { Hypnea } \\
\text { cenomyce }\end{array}$ & 0 & 0 & $\mathrm{x}$ & 0 \\
\hline H. cervicornis & $x$ & 0 & 0 & 0 \\
\hline $\begin{array}{l}\text { H.cornuta } \\
\text { J.Agardh }\end{array}$ & $x$ & 0 & $x$ & 0 \\
\hline H. nigrescens & $x$ & 0 & $x$ & $x$ \\
\hline H.musciformis & $x$ & $\begin{array}{c}\mathrm{X} \\
{[\text { H.arborescens] }}\end{array}$ & $x$ & $x$ \\
\hline H. spinella & $x$ & $\begin{array}{c}\mathrm{X} \\
{[\text { H.cervicornis] }}\end{array}$ & $\begin{array}{c}\mathrm{X} \\
\text { [H.cervicornis] }\end{array}$ & $x$ \\
\hline H. valentiae & $x$ & $\frac{\mathrm{X}}{\text { [H.gracilarioides] }}$ & $x$ & 0 \\
\hline H. volubilis & 0 & 0 & $x$ & 0 \\
\hline
\end{tabular}

1- http://www.algaemarisbrasilis.ccb.ufsc.br/algaemarisbrasilis.html; 2- http://www.algaebase.org

A difícil identificação a nível específico somada à falta de precisão e certeza das descrições e localidades tipo encontradas na literatura, faz das espécies de Hypnea alvo potencial de estudos moleculares que possam auxiliar na resolução de dúvidas taxonômicas.

\section{3- Marcadores moleculares e o Método "DNA barcoding"}

As Rhodophyta possuem muitas espécies não descritas, e o exato número destas ainda é uma dúvida. Isso ocorre, porque a morfologia dessas algas pode ser muito variável, dentro da mesma espécie e entre espécies diferentes. Sua morfologia ainda pode ser convergente e muito influenciada pelo habitat, o que leva a ocorrência de espécies crípticas. A identificação morfológica também pode ser ainda mais 
dificultada, pois o ciclo de vida dessas algas é complexo e muitas vezes as fases são morfologicamente distintas e são confundidas e descritas como espécies e até gêneros diferentes (Robba et al. 2006).

$\mathrm{Na}$ década de 1980, com intuito de auxiliar na resolução desses problemas taxonômicos, técnicas moleculares foram adotadas nos estudos das algas vermelhas e, utilizadas em conjunto com a morfologia e cultura, permitiram a distinção de espécies e avanços no entendimento de suas relações filogenéticas (Robba et al. 2006). Pesquisadores têm utilizado cada vez mais essas ferramentas moleculares para auxílio na taxonomia e biogeografia dessas algas.

Nas Rhodophyta, diferentes regiões têm sido utilizadas como marcadores moleculares, principalmente os genes nucleares que codificam para os RNAs ribossomais (rRNA) ("small subunit rRNA gene" - SSU rDNA e "large subunit rRNA gene"-LSU rDNA) e o espaçador dos genes ribossomais ("internal transcribed spacer" - ITS) (Tai et al. 2001; Ross et al. 2003); o gene do cloroplasto que codifica a subunidade grande $(r b c \mathrm{~L})$ da enzima ribulose-1, 5-bisfosfato carboxilase-oxigenase (Rubisco) (Hughey et al. 2001); e a região espaçadora dos genes mitocondriais para a citocromo oxidase subunidades 2 e 3, cox2-3 (Zucarello et al. 1999).

Enquanto que nas algas verdes (Chlorophyta) e plantas terrestres o gene rbcL está localizado no cloroplasto e o gene que codifica a subunidade pequena ( rbcS) está localizado no núcleo, nas algas vermelhas e nas algas cromófitas (Heterokontophyta) ambos os genes ( $r b c L$ e rbcS) estão no cloroplasto (Hagopian et al. 2004). Nas Rhodophyta os dois genes são separados por uma pequena região espaçadora (espaçador rbcL-S), que devido a uma maior variabilidade é empregada em análises de isolados de diferentes regiões biogeográficas ou em identificações de espécies de algas (Maggs et al. 1992, Goff et al. 1994, Zuccarello \& West 1997). O gene rbcL é também amplamente utilizado para filogenia e identificação de espécies em diferentes grupos de algas vermelhas.

O rápido desenvolvimento das tecnologias computacionais e de sequenciamento de DNA têm transformado essas informações na maior fonte de dados para a compreensão e avanço no entendimento das relações genéticas e evolutivas (Hajibabaei et al. 2007) para estudos de biodiversidade e das interrelações dos diversos grupos de organismos.

As sequências de marcadores moleculares que permitem a identificação de espécies têm sido denominadas de "DNA barcodes", em analogia ao sistema de código de barras usado em produtos manufaturados (Stoeckle 2003). A técnica de "DNA barcoding" é baseada na amplificação por PCR ("Polymerase Chain Reaction") 
de um seguimento de DNA relativamente curto ( 400-700 pb) que pode ser inteiramente sequenciado com os mesmos dois "primers" usados na PCR.

Essa técnica encontra-se entre os estudos filogenéticos e os estudos populacionais. Enquanto estes estudam, respectivamente, as relações evolutivas entre os grupos e a variação entre e dentro das populações, o "DNA barcoding" procura entender as espécies, focando na sua delineação ao invés de suas relações (Hajibabaei et al. 2007).

O sistema de "DNA barcoding" é prático e uniforme para identificação de espécies, além disso, os dados gerados possuem ampla aplicação, com grande utilidade em levantamentos de biodiversidade e em conservação.

Proposto por Herbert et al. (2003), o "DNA barcoding" foi primeiramente utilizado para estudar a separação de espécies de animais. Muitos genes têm sido utilizados na sistemática, entretanto, o "DNA barcoding" pede um padrão global, que permita a comparação entre todos os seres vivos submetidos à técnica. Assim, um fragmento de $\sim 650 \mathrm{pb}$ do gene mitocondrial da citocromo $c$ oxidase subunidade I (COI ou cox1) tem sido escolhido como o principal marcador para o "DNA barcoding" (Hajibabaei et al. 2007).

A escolha do $\operatorname{cox} 1$ foi baseada em duas importantes vantagens relacionadas ao gene: a existência de "primers" universais muito robustos para amplificação de sua região 5' em animais (Folmer et al. 1994; Zhang \& Hewitt 1997) e a distribuição do $\mathrm{COI}$ em um amplo espectro filogenético. Além disso, em relação a outros genes codificantes de proteínas, o COI possui uma alta taxa de substituição na terceira base, o que leva a uma taxa de evolução molecular até três vezes maior do que outros genes mitocondriais como 12S ou 16S rDNA (Knowlton \& Weigt 1998).

O "DNA barcoding" permite, ainda, a detecção de espécies crípticas e fornece dados que ajudam a entender a diversidade da vida e os mecanismos envolvidos nos processos de especiação. Diferentes marcadores ou protocolos podem ser necessários em certos grupos taxonômicos, mas aparentemente não existem barreiras para a aplicação dessa metodologia em nenhum grupo de ser vivo (De Salle et al. 2005; Saunders 2005).

Saunders (2005), baseando-se no fato de que essa técnica foi indicada para resolver problemas com plasticidade fenotípica, espécies crípticas e diferenças morfológicas nos estágio de vida dos animais, e que todos esses problemas também são observados em Rhodophyta, utilizou a região 5' do cox1 em Rhodophyta, cobrindo 15 famílias em 6 ordens e um total de 250 indivíduos verificou que esse marcador se mostrou adequado para a distinção de espécies nos grupos de algas vermelhas estudados. 
Além do cox1, uma região do gene do cloroplasto, o domínio $\mathrm{V}$ do gene $23 \mathrm{~S}$, que codifica o RNA da subunidade grande do ribossomo (23S RNAr), conhecido como "universal plastid amplicon - UPA" (Presting, 2006; Sherwood \& Presting, 2007; Sherwood et al., 2010) tem sido testada como marcador para o "DNA barcoding" de organismos fotossintetizantes. O UPA consiste de uma região de aproximadamente $400 \mathrm{pb}$, flanqueada por sequências conservadas que podem ser usadas como "primers" universais (Presting 2006), ao contrário do cox1, que pode possuir variação de nucleotídeos na região dos "primers".

O "DNA barcoding" não tem como intenção o fim da taxonomia tradicional, mas sim disponibilizar a informação molecular para ser usada mais amplamente pela taxonomia. Isso levará a alteração do número e distribuição das espécies que são reconhecidas nas linhagens das algas. No entanto, não é uma ferramenta que deve ser usada sozinha, e sim em conjunto com observações morfológicas e anatômicas, assim como com outros marcadores moleculares para obtenção de informações filogenéticas (Saunders 2005).

\subsection{2-Marcadores e estudos moleculares em Hypnea}

Relativamente poucos estudos que utilizam dados moleculares abordaram o gênero Hypnea. Alguns estudos já avaliaram a estrutura das Gigartinales, ordem a qual pertence Hypnea, baseando-se em marcadores moleculares (Hommersand et al. 1994; Fredericq et al. 1996; Saunders et al. 2004).

Entre os marcadores moleculares já testados para o gênero Hypnea está o SSU rDNA (Saunders et al. 2004), o cox2-3 (Zucarello \& West 2002) que tem sido utilizado principalmente como um marcador para análises populacionais em Rhodophyta; mas o principal marcador utilizado para espécies do gênero tem sido o $r b c L$. Porém, os focos destes estudos têm sido espécies coletadas na Ásia (Yamagishi \& Masuda 2000; Yamagishi et al. 2003; Geraldino et al. 2006) e na África do Sul (Fredericq \& Hommersand 2003) (Tabela 4). O marcador UPA também foi utilizado recentemente em algas do gênero Hypnea em um levantamento no Havaí (Sherwood et al. 2010). Faltam ainda trabalhos com marcadores moleculares de espécies localizadas em outras regiões geográficas, notadamente a região atlântica da América do Sul. 
Tabela 4. Marcadores moleculares usados no gênero Hypnea, com sequências depositadas no GenBank e suas referências.

\begin{tabular}{|c|c|c|}
\hline Marcador & Referência & País/Região \\
\hline \multirow[t]{7}{*}{$r b c L$} & Freshwater, S. et al., 1994 & $\begin{array}{l}\text { EUA, Oc. } \\
\text { Pacífico e } \\
\text { Atlântico }\end{array}$ \\
\hline & Yamagishi, Y. \& Masuda, M., 2000 & Japão \\
\hline & Yamagishi, Y. et al., 2003 & Malaysia, \\
\hline & Hommersand, M.M. \& Fredericq, S., 2003 & África do Sul \\
\hline & Geraldino et al., 2006 & Coréia \\
\hline & Geraldino et al., 2009 & $\begin{array}{c}\text { Coréia, Japão } \\
\text { e Tawian, }\end{array}$ \\
\hline & Geraldino et al.,2010 & Coréia \\
\hline \multirow[t]{3}{*}{$\operatorname{cox} 1$} & Geraldino et al., 2006 & Coréia \\
\hline & Geraldino et al., 2009 & $\begin{array}{c}\text { Coréia, Japão } \\
\text { e Tawian, }\end{array}$ \\
\hline & Geraldino et al., 2010 & Coréia \\
\hline SSU rDNA & Geraldino et al., 2009 & $\begin{array}{c}\text { Coréia, Japão } \\
e\end{array}$ \\
\hline & & Tawian, \\
\hline UPA & Sherwood et al., 2010 & Havaí, EUA \\
\hline $\cos 2-3$ & Zuccarello \& West, 2002 & $\begin{array}{l}\text { Oceano } \\
\text { Pacífico }\end{array}$ \\
\hline
\end{tabular}

Dada a dificuldade taxonômica relacionada às espécies de Hypnea, tem sido recomendado que revisões regionais sejam efetuadas (Masuda et al. 1997). Além disso, a ausência de estudos moleculares com o gênero Hypnea no Brasil torna esse grupo um excelente alvo para a aplicação de marcadores moleculares. 


\section{2- Objetivos}

Este trabalho tem como objetivo analisar a diversidade e filogenia das espécies de Hypnea (Gigartinales, Rhodophyta) do Estado de São Paulo baseado em marcadores moleculares, incluindo marcadores do tipo "DNA barcode" e morfologia. Para tanto, as seguintes etapas foram executadas:

- Obtenção de amostras georeferenciadas das espécies do gênero Hypnea de ocorrência no estado de São Paulo, formando um banco de material preservado para análises moleculares e exsicatas para incorporação em herbários;

- Identificação das amostras através de caracteres morfológicos e anatômicos;

- Geração de um banco de amostras com o DNA do gênero Hypnea;

- Sequenciamento marcadores moleculares para as amostras coletadas incluindo marcadores do tipo "DNA barcode";

- Analise filogenética para as espécies de Hypnea utilizando o marcador rbcL.

\section{3- Materiais e métodos}

\section{1-Coletas}

As coletas foram realizadas em locais no litoral do Estado de São Paulo, sendo alguns locais pré-determinados pelo projeto "Flora ficológica do estado de São Paulo", do qual também foram utilizadas amostras já preservadas em sílica gel. Estes locais, no sentido norte ao sul, são: Ubatuba: Picinguaba, Ilha das Couves, Ilha da Rapada, Praia da Fortaleza, Praia Brava, Praia Vermelha do Sul, Praia do Lamberto, Praia Dura, Domingas Dias e Praia da Lagoinha; São Sebastião e Ilhabela: Praia das Cigarras, Saco do Poço; Itanhaém: Praia dos Sonhos e Cibratel; Cananéia: Ilha do Bom Abrigo e Ilha do Cardoso. Ainda para enriquecimento das análises, duas amostras do Saco do Mamanguá, Rio de Janeiro e duas do Espírito Santo, foram incluídas. Todas as amostras obtidas foram georeferenciadas com o uso de GPS (Global Positioning System). As coletas foram realizadas no meso e infralitoral, sendo estas realizadas em períodos de maré baixa ou com método de mergulho autônomo (Tabela 5). Ainda, foram analisadas cinco amostras mantidas em cultura por K. Tesima no Laboratório de Cultura de Algas e Cianobactérias "Marilza Cordeiro Marino", do Núcleo de Pesquisas em Ficologia do Instituto de Botânica (Martins et al. 2011). 


\section{2- Processamento das amostras}

As amostras coletadas foram triadas em campo, e/ou em laboratório com lupa. Após a triagem, amostras de Hypnea foram separadas para morfologia e análises moleculares. As amostras destinadas para a morfologia que estavam epifitando outras algas foram mantidas junto ao seu substrato, a fim de enriquecer as análises do material. As amostras destinadas às análises moleculares tiveram sua região apical, mais livre de contaminantes por ser a região de crescimento, limpas e separadas do resto da planta. Esses ápices foram preservados em sílica, sendo isolados da mesma por um papel absorvente, com o objetivo de não se perder nenhum fragmento da amostra seca. O remanescente dos exemplares de onde foram removidas as amostras para DNA foram fixados em formol $4 \%$ para as análises morfológicas e para a confecção de exsicatas. Exsicatas foram feitas e depositadas ou no acervo do herbário SPF (Index Herbariorum: http://207.156.243.8/emu/ih/index.php), localizado na Universidade de São Paulo, ou no acervo do herbário SP, do Instituto de Botânica de São Paulo.

Sempre que possível também foram separadas das amostras uma duplicata para preservação em sílica gel a serem estocadas em condições apropriadas gerando um banco de amostras que ficará disponível para outros estudos. A identificação do material foi feita primeiramente em campo baseada em caracteres morfológicos gerais e hábitos conhecidos das espécies. Os nomes dados as amostras só se tornaram permanentes após os estudos morfológicos e moleculares com as mesmas.

Os estudos morfológicos foram realizados baseando-se nas descrições originais das espécies (Kützing 1849, J. Agardh 1851), visto que muitos dados conflitantes são encontrados na literatura. Abordagens mais atualizadas foram levadas em consideração sempre que necessário (Schenkman 1986, Geraldino et al. 2006, Lucio 2009). As características morfológicas observadas nas amostras estão descritas na Tabela 6. 
Tabela 5. Listagem das amostras de Hypnea (numeradas de acordo com o projeto Rhodo-SP), dados da coleta e marcador sequenciado indicado por " $\mathrm{X}$ "

\begin{tabular}{|c|c|c|c|c|c|c|c|c|c|c|}
\hline $\begin{array}{c}\text { № } \\
\text { RHODO- } \\
\text { SP }\end{array}$ & Coletor & $\begin{array}{l}\text { Data de } \\
\text { coleta }\end{array}$ & & Local de coleta & & \multicolumn{2}{|c|}{$\begin{array}{c}\text { GPS } \\
\text { Latitude/Longitude }\end{array}$} & $\operatorname{cox} 1$ & UPA & $r b c L$ \\
\hline вот0001* & S.P.B.Guimarães & 04.set.1994 & Ponta da Baleia & $\begin{array}{c}\text { Serra,Manguinhos, } \\
\text { ES }\end{array}$ & Meso-litoral & -20.144 .219 & -40.295 .200 & $x$ & & \\
\hline ВОт0002* & S.P.B.Guimarães & 04.set.1994 & Ponta da Baleia & $\begin{array}{c}\text { Serra,Manguinhos, } \\
\text { ES }\end{array}$ & Meso-litoral & -20.144 .219 & -40.295 .200 & $x$ & & \\
\hline Вот0003* & S.P.B.Guimarães & 27.mai.2002 & Praia das Cigarras & São Sebastião,SP & Meso-litoral & -23.436 .790 & -45.157 .910 & $x$ & $x$ & $x$ \\
\hline Вот0004* & S.P.B.Guimarães & 29.mai.2002 & Praia da Fortaleza & Ubatuba,SP & Meso-litoral & - 23.529.591 & -45.157 .910 & $x$ & & \\
\hline ВОт0005* & N. S. Yokoya & 26.out.2004 & Praia da Fortaleza & Ubatuba,SP & Meso-litoral & -23.529 .591 & -45.157 .910 & $x$ & & \\
\hline IBC0028 & E.C.Oliveira & 13.out.2008 & $\begin{array}{l}\text { Praia Vermelha do Sul } \\
\text { - costão direito }\end{array}$ & Ubatuba,SP & Meso-litoral & - 23.512.377 & - 45.172 .014 & $x$ & $x$ & $x$ \\
\hline IBC0040 & E.C.Oliveira & 13.out.2008 & $\begin{array}{l}\text { Praia Vermelha do Sul } \\
\text { - costão esquerdo }\end{array}$ & Ubatuba,SP & Meso-litoral & -23.506 .713 & -45.173 .065 & $x$ & $x$ & $x$ \\
\hline IBC0041 & E.C.Oliveira & 13.out.2008 & $\begin{array}{l}\text { Praia Vermelha do Sul } \\
\text { - costão esquerdo }\end{array}$ & Ubatuba,SP & Meso-litoral & -23.506 .713 & - 45.173 .065 & $x$ & & \\
\hline IBC0051 & E.C.Oliveira/M.C.Oliveira & 13.out.2008 & $\begin{array}{l}\text { Praia Vermelha do Sul } \\
\text { - costão esquerdo }\end{array}$ & Ubatuba,SP & Meso-litoral & - 23.506.713 & - 45.173 .065 & $x$ & & \\
\hline IBC0064 & E.C.Oliveira/M.C.Oliveira & 14.out.2008 & $\begin{array}{c}\text { Praia Dura - costão } \\
\text { esquerdo }\end{array}$ & Ubatuba,SP & Meso-litoral & - 23.495.159 & - 45.165 .038 & $x$ & $x$ & $x$ \\
\hline IBC0067 & E.C.Oliveira/M.C.Oliveira & 14.out.2008 & $\begin{array}{c}\text { Praia Dura - costão } \\
\text { esquerdo }\end{array}$ & Ubatuba,SP & Meso-litoral & -23.495 .159 & - 45.165 .038 & $x$ & & \\
\hline IBC0089 & E.C.Oliveira/M.C.Oliveira & 15.out.2008 & Ponta da Fortaleza & Ubatuba,SP & Meso-litoral & - 23.529.591 & -45.157 .910 & $x$ & & \\
\hline IBC0098 & M.C.Oliveira & 16.out.2008 & $\begin{array}{c}\text { Praia do Costa - lado } \\
\text { esquerdo }\end{array}$ & Ubatuba,SP & Meso-litoral & -23.775 .581 & -45.233 .514 & $x$ & $x$ & $x$ \\
\hline IBC0123 & M.C.Oliveira & 30.out.2008 & Ilha Vitória & São Sebastião,SP & Infralitoral & -23.436 .790 & -45.23 .868 & $x$ & & \\
\hline IBC0129 & M.C.Oliveira & 31.out.2008 & $\begin{array}{c}\text { Saco do Poço - Ilha } \\
\text { Bela }\end{array}$ & São Sebastião,SP & Infralitoral & -23.515 .066 & -45.166 .797 & $x$ & $x$ & $x$ \\
\hline
\end{tabular}

* amostras em cultura no Instituto de Botânica 
Tabela 5. Continuação.

\begin{tabular}{|c|c|c|c|c|c|c|c|c|c|c|}
\hline \multirow{2}{*}{$\begin{array}{c}\text { № } \\
\text { RHODO- } \\
\text { SP } \\
\text { IBC0137 }\end{array}$} & \multirow{2}{*}{$\begin{array}{c}\text { Coletor } \\
\text { M.C.Oliveira }\end{array}$} & \multirow{2}{*}{$\begin{array}{c}\begin{array}{c}\text { Data de } \\
\text { coleta }\end{array} \\
\text { 08.mai.2009 }\end{array}$} & \multicolumn{3}{|c|}{ Local de coleta } & \multicolumn{2}{|c|}{$\begin{array}{c}\text { GPS } \\
\text { Latitude/Longitude }\end{array}$} & \multirow{2}{*}{$\frac{\operatorname{cox} 1}{x}$} & \multirow[t]{2}{*}{ UPA } & \multirow[t]{2}{*}{$r b c L$} \\
\hline & & & $\begin{array}{l}\text { Praia das Cigarras - } \\
\text { costão norte }\end{array}$ & São Sebastião,SP & Meso-litoral & -23.775 .581 & -45.233 .514 & & & \\
\hline IBC0138 & M.C.Oliveira & 08.mai.2009 & $\begin{array}{l}\text { Praia das Cigarras - } \\
\text { costão sul }\end{array}$ & São Sebastião,SP & Meso-litoral & -23.438 .990 & -45.238 .870 & $x$ & & \\
\hline IBC0139 & E.C.Oliveira/ F. Nauer & 08.mai.2009 & Praia Vermelha do Sul & Ubatuba,SP & Meso-litoral & -23.438 .990 & -45.238 .870 & $x$ & & \\
\hline IBC0184 & M.B.Benal & 06.mai.2009 & Praia da Fortaleza & Ubatuba,SP & Meso-litoral & -23.529 .591 & -45.157 .910 & $x$ & & \\
\hline IBC0185 & N.Yokoya & 06.mai.2009 & Praia da Fortaleza & Ubatuba,SP & Meso-litoral & -23.529 .591 & -45.157 .910 & $x$ & $\mathrm{x}$ & $x$ \\
\hline IBC0186 & M.B.Benal & 06.mai/2009 & Praia Brava & Ubatuba,SP & Meso-litoral & -23.300 .870 & -45.101 .620 & $x$ & & \\
\hline IBC0187 & N.R.Guimaraes & 07.mai.2009 & Praia dos Sonhos & Itanhaém,SP & Meso-litoral & -24.175 .703 & -46.748 .017 & $x$ & & \\
\hline IBC0188 & N.R.Guimaraes & 07.mai.2009 & Praia dos Sonhos & Itanhaém,SP & Meso-litoral & -24.175 .703 & -46.748 .017 & $x$ & & \\
\hline IBC0189 & E.C.Oliveira & 20.nov.2009 & Saco do Mamanguá & Paraty, RJ & Infralitoral & -23.263 .633 & -44.636 .397 & $x$ & & \\
\hline IBC0190 & E.C.Oliveira & 20.nov.2009 & Saco do Mamanguá & Paraty, RJ & Infralitoral & -23.263 .633 & -44.636 .397 & $\mathrm{x}$ & $x$ & $x$ \\
\hline IBC0194 & M.C.Oliveira/E. Costa & 17.mar.2010 & $\begin{array}{l}\text { Praia Picinguaba, } \\
\text { Costão Esquerdo }\end{array}$ & Ubatuba, SP & Meso-litoral & -23.380 .032 & -44.840 .732 & $X$ & & \\
\hline IBC0195 & S.M.P.B.Guimarães & 16.mar.2010 & $\begin{array}{l}\text { Domingas Dias, } \\
\text { Costão Direito }\end{array}$ & Ubatuba, SP & Meso-litoral & -23.493 .539 & -45.147 .169 & $x$ & & \\
\hline IBC0196 & M.T.Fujii & 16.mar.2010 & $\begin{array}{l}\text { Domingas Dias, } \\
\text { Costão Direito }\end{array}$ & Ubatuba, SP & Meso-litoral & -23.493 .539 & -45.147 .169 & $x$ & & \\
\hline IBC0197 & N.R.Guimarães & 16.mar.2010 & $\begin{array}{l}\text { Domingas Dias, } \\
\text { Costão Direito }\end{array}$ & Ubatuba, SP & Meso-litoral & -23.493 .539 & -45.147 .169 & $X$ & & \\
\hline IBC0198 & $\underset{\text { Fujii }}{\text { S.M.P.B.Guimarẽes/M.T. }}$ & 16.mar.2010 & $\begin{array}{l}\text { Domingas Dias, } \\
\text { Costão Direito }\end{array}$ & Ubatuba, SP & Meso-litoral & -23.493 .539 & -45.147 .169 & $x$ & & \\
\hline
\end{tabular}


Tabela 5. Continuação.

\begin{tabular}{|c|c|c|c|c|c|c|c|c|c|c|}
\hline \multirow{2}{*}{$\begin{array}{c}\text { № } \\
\text { RHODO- } \\
\text { SP } \\
\text { IBC0199 }\end{array}$} & \multirow{2}{*}{ 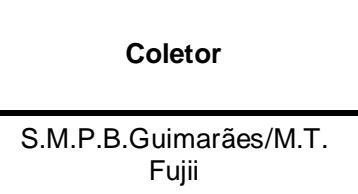 } & \multirow{2}{*}{$\begin{array}{c}\begin{array}{c}\text { Data de } \\
\text { coleta }\end{array} \\
\text { 16.mar.2010 }\end{array}$} & \multicolumn{3}{|c|}{ Local de coleta } & \multicolumn{2}{|c|}{$\begin{array}{c}\text { GPS } \\
\text { Latitude/Longitude }\end{array}$} & \multirow{2}{*}{$\frac{\operatorname{cox} 1}{x}$} & \multirow[t]{2}{*}{ UPA } & \multirow[t]{2}{*}{$r b c L$} \\
\hline & & & $\begin{array}{c}\text { Domingas Dias, Costão } \\
\text { Direito }\end{array}$ & Ubatuba, SP & Meso-litoral & -23.493 .539 & -45.147 .169 & & & \\
\hline IBC0200 & M.C.Oliveira/E. Costa & 17.mar.2010 & $\begin{array}{c}\text { Domingas Dias, Costão } \\
\text { Direito }\end{array}$ & Ubatuba, SP & Meso-litoral & -23.493 .539 & -45.147 .169 & $\mathrm{x}$ & & \\
\hline IBC0201 & $\begin{array}{l}\text { S.M.P.B.Guimarães/M.T. } \\
\text { Fujii }\end{array}$ & 16.mar.2010 & $\begin{array}{c}\text { Domingas Dias, Costão } \\
\text { Direito }\end{array}$ & Ubatuba, SP & Meso-litoral & -23.493 .539 & -45.147 .169 & $x$ & & \\
\hline IBC0202 & $\begin{array}{l}\text { S.M.P.B.Guimarães/M.T. } \\
\text { Fujii }\end{array}$ & 16.mar.2010 & $\begin{array}{l}\text { Domingas Dias, Costão } \\
\text { Direito }\end{array}$ & Ubatuba, SP & Meso-litoral & -23.493 .539 & -45.147 .169 & $\mathrm{x}$ & & \\
\hline IBC0203 & $\begin{array}{l}\text { S.M.P.B.Guimarães/M.T. } \\
\text { Fujii }\end{array}$ & 16.mar.2010 & $\begin{array}{c}\text { Domingas Dias, Costão } \\
\text { Direito }\end{array}$ & Ubatuba, SP & Meso-litoral & -23.493 .539 & -45.147 .169 & $\mathrm{x}$ & & \\
\hline IBC0204 & $\begin{array}{l}\text { S.M.P.B.Guimarães/M.T. } \\
\text { Fujii }\end{array}$ & 16.mar.2010 & $\begin{array}{c}\text { Domingas Dias, Costão } \\
\text { Direito }\end{array}$ & Ubatuba, SP & Meso-litoral & -23.493 .539 & -45.147 .169 & $\mathrm{x}$ & & \\
\hline IBC0205 & N.R.Guimarães & 16.mar.2010 & $\begin{array}{l}\text { Praia do Laberto, } \\
\text { Int.Ocenográfico }\end{array}$ & Ubatuba, SP & Meso-litoral & -23.499 .961 & -45.117 .014 & $\mathrm{X}$ & & \\
\hline IBC0206 & N.R.Guimarães & 16.mar.2010 & $\begin{array}{l}\text { Praia do Laberto, } \\
\text { Int.Ocenográfico }\end{array}$ & Ubatuba, SP & Meso-litoral & -23.499 .961 & -45.117 .014 & $\mathrm{x}$ & & \\
\hline IBC0210 & M.C.Oliveira/M.B.B.Barreto & 17.mar.2010 & $\begin{array}{l}\text { Praia Picinguaba, } \\
\text { Costão Esquerdo }\end{array}$ & Ubatuba, SP & Infralitoral & -23.380 .032 & -44.840 .732 & $x$ & & \\
\hline IBC0211 & M.C.Oliveira/M.B.B.Barreto & 17.mar.2010 & $\begin{array}{l}\text { Praia Picinguaba, } \\
\text { Costão Esquerdo }\end{array}$ & Ubatuba, SP & Infralitoral & -23.380 .032 & -44.840 .732 & $\mathrm{x}$ & & \\
\hline IBC0212 & N.R.Guimarães & 18.mar.2010 & $\begin{array}{l}\text { Praia Vermelha do Sul- } \\
\text { Costão esq. }\end{array}$ & Ubatuba, SP & Meso-litoral & -23.506 .713 & -45.173 .065 & $\mathrm{x}$ & $\mathrm{x}$ & $\mathrm{x}$ \\
\hline IBC0213 & N.R.Guimarães & 18.mar.2010 & $\begin{array}{l}\text { Praia Vermelha do Sul- } \\
\text { Costão esq. }\end{array}$ & Ubatuba, SP & Meso-litoral & -23.506 .713 & -45.173 .065 & $x$ & & \\
\hline IBC0214 & M.C.Oliveira & 18.mar.2010 & Ilha das Couves & Ubatuba, SP & Infralitoral & -23.425 .330 & -44.904 .491 & $x$ & & \\
\hline IBC0216 & M.C.Oliveira & 18.mar.2010 & Ilha das Couves & Ubatuba, SP & Infralitoral & -23.425 .330 & -44.904 .491 & $x$ & & \\
\hline IBC0217 & M.C.Oliveira & 18.mar.2010 & Ilha das Couves & Ubatuba, SP & Infralitoral & -23.425 .330 & -44.904 .491 & $x$ & & \\
\hline
\end{tabular}


Tabela 5. Continuação.

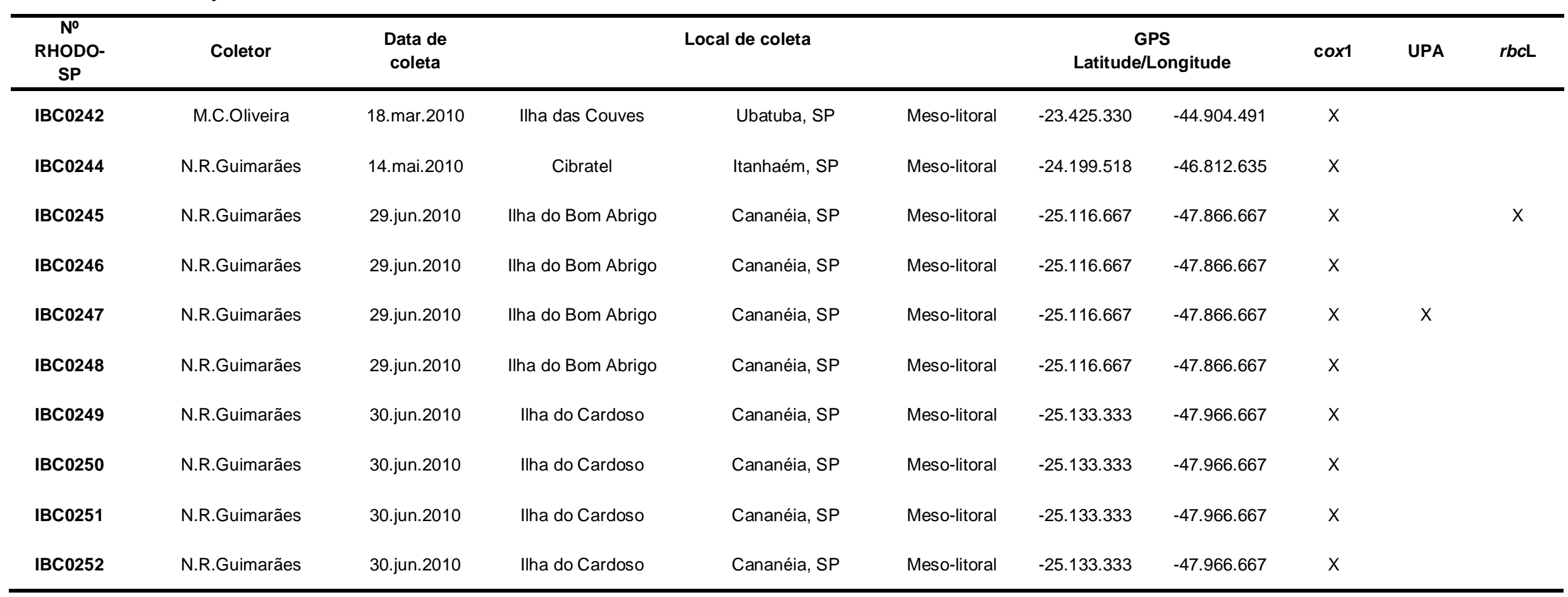


Tabela 6. Caracteres morfológicos utilizados nas análises morfológicas das espécies de Hypnea (baseado em Masuda, 1997 e Lúcio, 2006).

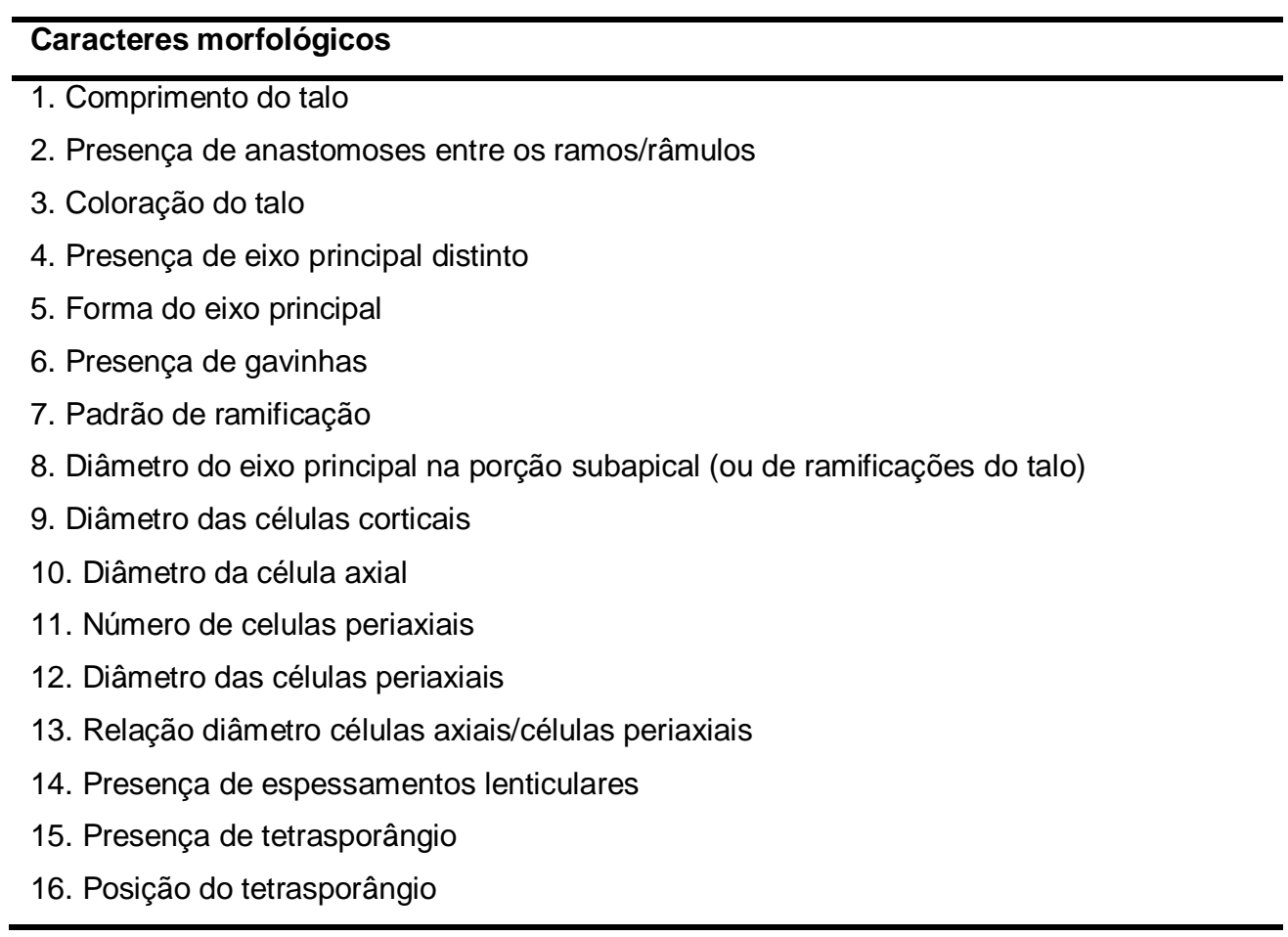

Os cortes anatômicos foram realizados no laboratório de Algas Marinhas do Instituto de Biociências da USP, feitos à mão-livre com auxílio de lâmina de barbear e corados com azul de anilina a 1\%, acidificada com $\mathrm{HCl} 1 \mathrm{~N}$. Os aspectos gerais e os caracteres diagnósticos de cada espécie foram obtidos com sistema digital de captura e análise de imagens Leica DM4000-B.

\section{3- Extracão de DNA e amplificacão dos marcadores moleculares}

Para a extração do DNA, o material algal mantido em sílica gel foi macerado em nitrogênio líquido. Após a maceração das amostras, o DNA foi extraído utilizando-se o protocolo do kit NucleoSpin Plant II (Macherey-Nagel - Düren, Alemanha). O DNA total foi submetido à eletroforese em gel de agarose 0,7\%, em tampão tris-borato-EDTA, corado com GelRed diluído em água na proporção 1:500 ("GelRed Nucleic Acid Gel Stain" Biotium, Hayward, CA, USA), para averiguação da presença, qualidade e quantidade de DNA extraído (Sambrook et al. 1989).

O DNA extraído foi utilizado para a amplificação da sequência alvo usando-se "primers" específicos para os diferentes marcadores moleculares (Tabela 7) através da "Polymerase Chain Reaction" ou PCR (Sambrook et al. 1989). Os "primers" (IDT- lowa, 
EUA) descritos para o marcador cox1 foram retirados de Saunders (2005), os "primers" para o marcador rbcL (internos e externos) estão descritos em Freshwater et al. (1994), e os "primers" do marcador UPA estão descritos em Sherwood \& Presting (2007).

As PCRs foram realizadas utilizando-se o kit da Promega (Madison, WI - EUA). Após a PCR, os produtos foram analisados por eletroforese em gel de agarose a 0,7\%, com marcador de tamanho (1 Kb DNA Ladder- Invitrogen, Carlsbad, CA, USA), para verificar os tamanhos dos fragmentos amplificados, corados com corante GelRed na concentração 1:500. Os ciclos utilizados para a amplificação dos marcadores estão descritos da Figura 2. Os termocicladores utilizados para a realização da reação de PCR foram: Techne TC-512e Techne TC-4000 (Bibby Scientific Ltd., Staffordshire, UK). Os produtos de PCR foram purificados utilizando a coluna GTX ${ }^{\text {TM }}$ PCR DNA and Gel Band Purification Kit (GE Healthcare, Burckinghamshire, UK), quantificados com o uso do aparelho NanoDrop 2000 Spechtophotometer (Wilmington, DE - EUA), e diretamente sequenciados.

Tabela 7. "primers" para PCR e sequenciamento para os diferentes marcadores moleculares. Nos "primers"do marcador rbcL, $r=A$ ou $G ; y=C$ ou T; w = A ou T.

\begin{tabular}{cccc}
\hline “primers” & Sequência 5'- 3' & $\begin{array}{c}\text { Marcador } \\
(\mathbf{p b})\end{array}$ & Referência \\
\hline GazF1 & TCAACAAATCATAAAGATATTGG & $\begin{array}{c}\text { cox1 } \\
(\sim 710)\end{array}$ & Saunders 2005 \\
GazR1 & ACTTCTGGATGTCCAAAAAAyCA & & \\
F-rbcL start & ATGTCTAACTCTGTAGAA & & \\
R753a & GCTCTTTCrTACTCyTC & & \\
F492a & CGyATGGAyAAATTTGGACG & & rbcL \\
R1150 & GCAATTTGCrCRCArTGAATACC & $(\sim 1500)$ & $\begin{array}{c}\text { Freshwater et } \\
\text { al. 1994 }\end{array}$ \\
F993 & GGTACTGTTGGTAAATTwGAAGG & & \\
R-rbcS start & GTTCTTTGTGTTAATCTCAC & & \\
P23SrV R1 & TCAGCCTGTTATCCCTAGAG & UPA & Sherwood \& \\
P23SrV F1 & GGA CAG AAA GACCCT ATG AA & $(\sim 400)$ & Presting 2007 \\
\hline
\end{tabular}

Após a obtenção dos marcadores moleculares, as amostras de DNA foram catalogadas, precipitadas em etanol e estocadas a $-80^{\circ} \mathrm{C}$ formando um banco que ficará disponível para outros estudos (Chase et al. 2005). 


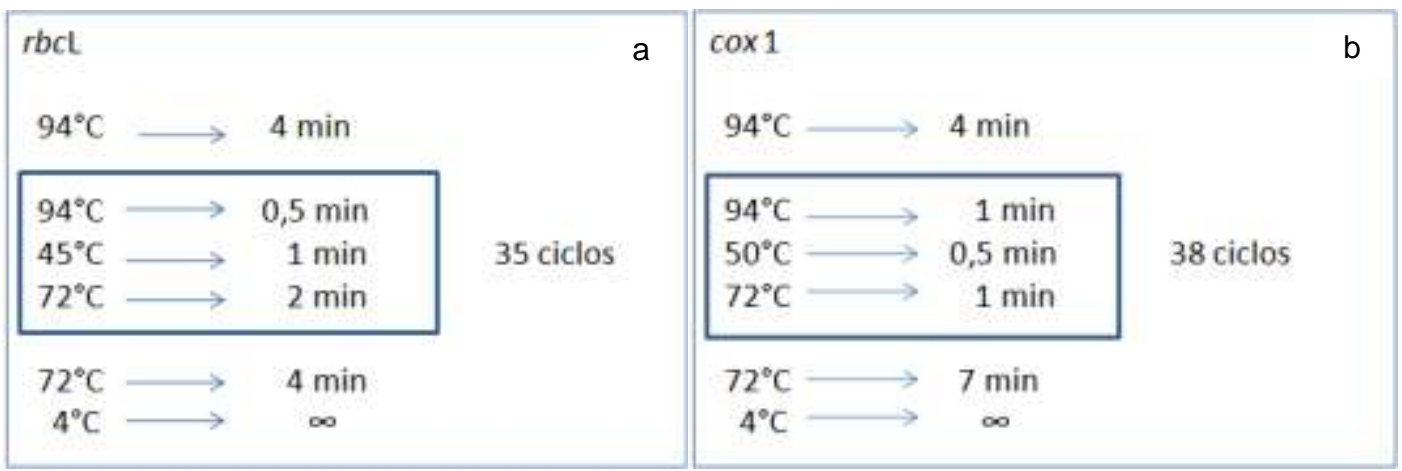

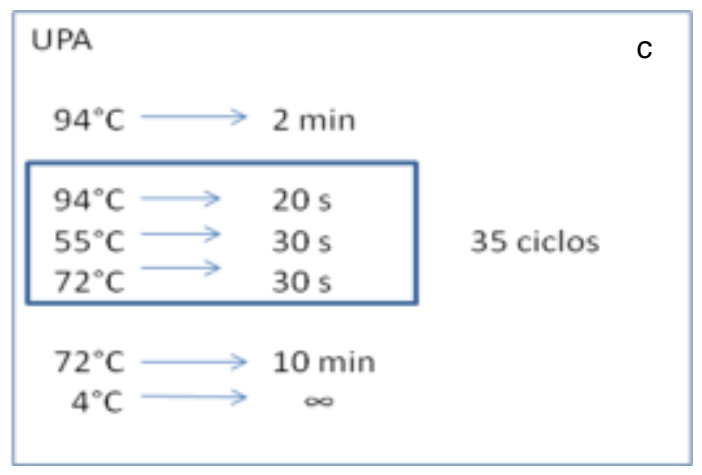

Figura 2. Ciclos para PCR dos três marcadores utilizados neste trabalho retirados, de a) Freshwater et al. (1994), b) Saunders (2005) e c) Sherwood \& Presting (2007).

\section{4- Sequenciamento de DNA e análises filogenéticas}

O sequenciamento dos marcadores moleculares a partir do produto de PCR purificado e quantificado (variação da quantificação $=10,6$ - $30 \mathrm{ng} \mathrm{DNA} / \mu \mathrm{L}$ ) foi realizado no sequenciador automático (ABI PRISM 3100) usando-se o kit "Cycle Sequencing, Big-Dye Terminator" (Applied Biosystems, Carlsbad, California-EUA), conforme instruções do fornecedor, utilizando os mesmos "primers" da PCR. Para o rbcL, os "primers" internos listados na Tabela 7 também foram usados para o sequenciamento. As sequências consenso para cada marcador de amostra foram montadas usando o programa BioEdit (Hall 1999) a partir das sequências obtidas nas direções direta e reversa. Nucleotídeos divergentes ocorrendo na mesma posição foram verificados nos cromatogramas das sequências. As sequências consenso obtidas foram comparadas com as sequências disponíveis no GenBank (http://www.ncbi.nlm.nih.gov) com o uso do programa BLAST (Altschul et al. 1997).

As sequências consenso, assim como outras sequências obtidas no banco de dados foram alinhadas utilizando-se o Clustal-W no programa BioEdit. Para todas as matrizes de alinhamento foram removidas as regiões dos "primers" de PCR das pontas 5'e 3'.

A matriz de UPA com 369 nucleotídeos foi construída utilizando-se 18 sequências do banco de dados, dez sequências obtidas neste trabalho e uma sequência de 
Chondrachantus acicularis (Gigartinaceae, Gigartinales), utilizada como grupo externo. Todas as sequências retiradas do banco de dados pertencem ao trabalho de Sherwood et al. 2010, e são provenientes do Havaí. Para as sequências de cox1 foram geradas duas matrizes, uma com 466 nucleotídeos e outra com 617 nucleotídeos. As matrizes de cox1 foram construídas utilizando-se 27 sequências do banco de dados (Tabela 8), 55 sequências deste trabalho e uma de Chondracantus teedei (Mertens ex Roth) Kützing, utilizada como grupo externo. As divergências para esse marcador foram calculadas utilizando-se a matriz com 617 nucleotídeos. A matriz de rbcL com 1317 nucleotídeos foi construída utilizando-se 28 sequências do banco de dados (Tabela 9), dez sequências deste trabalho e uma sequência de Calliblepharis fimbriata (Greville) Kützing (Cystocloniaceae, Gigartinales) e outra de Craspedocarpus venosus (Kützing) Mint-Thein \& Womerseley (Cystocloniaceae, Gigartinales), utilizadas como grupo externo.

Tabela 8. Sequências do marcador cox1 obtidas do GenBank utilizadas nas análises.

\begin{tabular}{|c|c|c|c|}
\hline Espécie & $\begin{array}{c}\text { Acesso } \\
\text { GenBank }\end{array}$ & $\begin{array}{l}\text { País de } \\
\text { origem }\end{array}$ & Referência \\
\hline H.boergesenii & EU345983 & Coréia & Geraldino et al. (2009) \\
\hline H.cervicornis & HQ422674 & Havaí & Sherwood. et al.(2010) \\
\hline H.charoides & EU240822 & Austrália & Geraldino et al. (2009) \\
\hline H.cornuta & HQ422721 & Havaí & Sherwood et al. (2010) \\
\hline H.flexicaulis & EF136611 & Coréia & Geraldino et al. (2006) \\
\hline H.flexicaulis & EF136601 & Coréia & Geraldino et al. (2006) \\
\hline H.flexicaulis & EF136591 & Coréia & Geraldino et al. (2006) \\
\hline H.japonica & EU345989 & Taiwan & Geraldino et al. (2009) \\
\hline H.musciformis & HQ422876 & Havaí & Sherwood et al. (2010) \\
\hline H.musciformis & HQ422683 & Havaí & Sherwood et al. (2010) \\
\hline H.nidulans & FJ694913 & Filipinas & Geraldino et al. (2010) \\
\hline H.pannosa & FJ694912 & Filipinas & Geraldino et al. (2010) \\
\hline H.pannosa & FJ694892 & México & Geraldino et al. (2010) \\
\hline H.pannosa & FJ694910 & Filipinas & Geraldino et al. (2010) \\
\hline H.spinella & EU240818 & Vietnã & Geraldino et al. (2009) \\
\hline H.spinella & HQ422681 & Havaí & Sherwood et al. (2010) \\
\hline H.stellulifera & EU345985 & Filipinas & Geraldino et al. (2006) \\
\hline H.valentiae & HQ422901 & Havaí & Sherwood et al. (2010) \\
\hline H.valentiae & HQ422680 & Havaí & Sherwood et al. (2010) \\
\hline H. viridis & FJ694908 & África do Sul & Geraldino et al. (2010) \\
\hline H.sp."asiatica" & EU345981 & Taiwan & Geraldino et al. (2009) \\
\hline Hypnea sp. & HQ422958 & Havaí & Sherwood et al. (2010) \\
\hline Hypnea sp. & HQ422951 & Havaí & Sherwood et al.(2010) \\
\hline Hypnea sp. & HQ422905 & Havaí & Sherwood et al.. (2010) \\
\hline Hypnea sp. & HQ422821 & Havaí & Sherwood et al. (2010) \\
\hline Hypnea sp. & HQ422812 & Havaí & Sherwood et al. (2010) \\
\hline
\end{tabular}


Tabela 9. Sequências do marcador $r b c L$ do GenBank utilizadas nas análises filogenéticas.

\begin{tabular}{|c|c|c|c|}
\hline Espécie & $\begin{array}{l}\text { Acesso } \\
\text { GenBank }\end{array}$ & $\begin{array}{l}\text { País de } \\
\text { origem }\end{array}$ & Referência \\
\hline H.boergesenii & EU346010 & Coréia & Geraldino et al. (2009) \\
\hline H.boergesenii & AF385634 & Taiwan & Hommersand \& Fredericq (2005) \\
\hline H.charoides & EU240843 & Australia & Geraldino et al. (2009) \\
\hline H.charoides & AB033159 & Japão & Yamagishi \& Masuda (2000) \\
\hline H.chordacea & AB033160 & Japão & Yamagishi \& Masuda (2000) \\
\hline H.cornuta & EU345993 & Indonésia & Geraldino et al. (2009) \\
\hline H.cornuta & AB095912 & Itália & Yamagishi et al. (2006) \\
\hline H.flagelliformis & AB033162 & Japão & Yamagishi \& Masuda (2000) \\
\hline H.flexicaulis & EF136632 & Filipinas & Geraldino et al. (2006) \\
\hline H.flexicaulis & AB033163 & Japão & Yamagishi \& Masuda (2000) \\
\hline H.japonica & EU346002 & Coréia & Geraldino et al. (2009) \\
\hline H.japonica & DQ095823 & - & Kim et al. (2005) \\
\hline H.musciformis & EU346014 & França & Geraldino et al. (2009) \\
\hline H.musciformis & U04179 & EUA & Freshwater et al. (1994) \\
\hline H. nidifica & FJ694932 & Cingapura & Geraldino et al. (2010) \\
\hline H.nidulans & FJ694947 & Filipinas & Geraldino et al. (2010) \\
\hline H.pannosa & AB033165 & Japão & Yamagishi \& Masuda (2000) \\
\hline H.pannosa & FJ694959 & México & Geraldino et al. (2010) \\
\hline H.rosea & FJ694935 & África do Sul & Geraldino et al. (2010) \\
\hline H.spinella & EU240849 & Vietnã & Geraldino et al. (2009) \\
\hline H.spinella & AB033166 & Japão & Yamagishi \& Masuda (2000) \\
\hline H.stellulifera & EU346004 & Filipinas & Geraldino et al. (2009) \\
\hline H.tenuis & FJ694934 & África do Sul & Geraldino et al. (2010) \\
\hline H.valentiae & FJ694933 & Indonésia & Geraldino et al. (2010) \\
\hline H. viridis & FJ694930 & África do Sul & Geraldino et al. (2010) \\
\hline H.sp."asiática" & EU345998 & Coréia & Geraldino et al. (2009) \\
\hline H.sp IzuH1 & AB033167 & Japão & Yamagishi \& Masuda (2000) \\
\hline $\begin{array}{c}\text { H.sp PJLG- } \\
2009\end{array}$ & FJ694945 & Cingapura & Geraldino et al. (2010) \\
\hline $\begin{array}{c}\text { H.sp PJLG- } \\
2009\end{array}$ & FJ694944 & Cingapura & Geraldino et al.(2010) \\
\hline
\end{tabular}

As árvores filogenéticas foram contruídas usando o método de distância (neighborjoining, NJ) para cox1, UPA e rbcL. Os métodos de máxima parcimônia (MP) e análise Bayesiana $(\mathrm{MB})$ também foram utilizados para o rbcL. Os modelos evolutivos para as análises filogenéticas de rbcL foram obtidos através do programa MrModeltest 2.2 (Nylander 2004) usando Akaike Information Criterion (AIC). Para MP e NJ foi utilizado o programa PAUP 4.0b10 (Swoford 2002). A análise de MP foi realizada sob busca heurística com 2000 réplicas de bootstrap (Felsestein 1985) para MP e NJ. A análise Bayesiana foi realizada através do programa Mr.Bayes 3.1.2 (Huelsenbeck \& Ronquist 2001). Uma corrida com quatro cadeias de MCMC foram realizadas com 1 milhão de gerações, com amostragem a cada 100 gerações. Foram descartadas as primeiras 100.000 gerações como "burn-in" para a construção da árvore consenso.

Para todas as análises realizadas foi considerada a seguinte escala arbitrária para descrever porcentagens de suporte nos ramos: 50-69, baixo; 70-85, moderado e 86-100, 
alto. Nas árvores foram plotados apenas os valores maiores que $70 \%$ para bootstrap e maiores que 0,7 para probabilidades a posteriori. Em todas as análises os "gaps" foram considerados como dados ausentes e o modelo evolutivo de substituição nucleotídica selecionado foi o $\mathrm{GTR}+\mathrm{l}+\mathrm{G}$, onde se assume o modelo Geral de Reversão ao Longo do Tempo (GTR) com uma proporção de sítios invariáveis (I) e distribuição gamma (G) para acomodar as diferentes taxas para sítios variáveis.

\section{5- Submissão de sequências nos bancos de dados}

Os dados obtidos para os espécimes coletados do gênero Hypnea, assim como o detalhamento das espécies e das coletas foram revisados e organizados para depósito no banco de dados BOLD, Barcoding of Life Data System (http://www.boldsystems.org; Ratnasinghan \& Hebert 2007). Na publicação dos dados as sequências serão depositadas também no GenBanK.

Todo o material gerado para cada amostra (amostras em Si-Gel, amostras de DNA, exsicatas e sequências) está nomeado por um código (número IBC ou número BOT) que permite a pronta recuperação no BOLD. Os marcadores moleculares possuem no mínimo duas sequências (uma na direção direta e outra na reversa), e assim como as sequências consenso, têm sua qualidade avaliada pelo BOLD Systems.

\section{4- Resultados}

\section{1- Marcadores moleculares}

As coletas realizadas reúnem um banco de 50 amostras coletadas e cinco amostras mantidas em cultura no Laboratório de Cultura de Algas e Cianobactérias "Marilza Cordeiro Marino", do Núcleo de Pesquisas em Ficologia do Instituto de Botânica. Foram sequenciadas as 55 amostras para o marcador cox1 (ANEXO I). Após a análise dos agrupamentos obtidos para as sequências de cox1, foram selecionadas 10 amostras, representando cada grupo e seus diferentes haplótipos, para o sequenciamento dos marcadores UPA (ANEXO II) e rbcL (ANEXO III).

As sequências obtidas para o cox1 mostraram a existência de seis grupos diferentes (Tabela 10) com divergências de 10,1 - 16,3\% (Tabela 11). 
Tabela 10. Espécies do gênero Hypnea analisadas neste trabalho agrupadas de acordo com as sequências obtidas para o marcador cox 1 . Número das amostras de acordo com a Tabela 5.

\begin{tabular}{cccccc}
\hline $\begin{array}{c}\text { Hypnea } \\
\text { cervicornis }\end{array}$ & $\begin{array}{c}\text { Hypnea } \\
\text { flexicaulis }\end{array}$ & $\begin{array}{c}\text { Hypnea } \\
\text { musciformis }\end{array}$ & $\begin{array}{c}\text { Hypnea } \\
\text { spinella }\end{array}$ & $\begin{array}{c}\text { Hypnea } \\
\text { sp.1 }\end{array}$ & $\begin{array}{c}\text { Hypnea } \\
\text { sp.2 }\end{array}$ \\
\hline $\mathrm{BOT} 0004$ & $\mathrm{IBC} 0190$ & $\mathrm{BOT} 0001$ & $\mathrm{IBC} 0041$ & $\mathrm{IBC} 0211$ & $\mathrm{BOT} 0003$ \\
$\mathrm{IBC} 0028$ & & $\mathrm{BOT} 0002$ & $\mathrm{IBC} 0129$ & $\mathrm{IBC} 0212$ & \\
$\mathrm{IBC} 0051$ & & $\mathrm{BOT} 0005$ & $\mathrm{IBC} 0184$ & & \\
$\mathrm{IBC} 0064$ & & $\mathrm{IBC} 0040$ & $\mathrm{IBC} 0198$ & & \\
$\mathrm{IBC} 0139$ & & $\mathrm{IBC} 0067$ & $\mathrm{IBC} 0203$ & & \\
$\mathrm{IBC} 0186$ & & $\mathrm{IBC} 0089$ & & & \\
$\mathrm{IBC} 0194$ & & $\mathrm{IBC} 0098$ & & & \\
$\mathrm{IBC} 0195$ & & $\mathrm{IBC} 0123$ & & & \\
$\mathrm{IBC} 0197$ & & $\mathrm{IBC} 0137$ & & & \\
$\mathrm{IBC} 0200$ & & $\mathrm{IBC} 0138$ & & & \\
$\mathrm{IBC} 0201$ & $\mathrm{IBC} 0174$ & & & \\
$\mathrm{IBC} 0204$ & $\mathrm{IBC} 0185$ & & & \\
$\mathrm{IBC} 0205$ & $\mathrm{IBC} 0187$ & & \\
$\mathrm{IBC} 0210$ & $\mathrm{IBC} 0188$ & & \\
$\mathrm{IBC} 0213$ & $\mathrm{IBC} 0189$ & & \\
$\mathrm{IBC} 0214$ & $\mathrm{IBC} 0196$ & & \\
$\mathrm{IBC} 0216$ & $\mathrm{IBC} 0199$ & & \\
$\mathrm{IBC} 0217$ & $\mathrm{IBC} 0202$ & & \\
$\mathrm{IBC} 0242$ & $\mathrm{IBC} 0244$ & & \\
$\mathrm{IBC} 0245$ & $\mathrm{IBC} 0252$ & & \\
$\mathrm{IBC} 0246$ & & & \\
$\mathrm{IBC} 0247$ & & & \\
$\mathrm{IBC} 0248$ & & & \\
$\mathrm{IBC} 0249$ & & & \\
$\mathrm{IBC} 0250$ & & & \\
$\mathrm{IBC} 0251$ & & & & \\
\hline
\end{tabular}

O grupo identificado como $H$. cervicornis possui 26 das 55 sequências obtidas (Tabela 10). Dentro deste grupo foi observada a presença de três haplótipos para o cox1, com uma divergência intraespecífica de 0 a 3 pb (0-0,5\%).

$\mathrm{O}$ grupo identificado como $\mathrm{H}$. musciformis possui 20 das 55 amostras sequenciadas para o cox1 (Tabela 10). Dentro deste grupo de sequências foi observada a presença de três haplótipos, com uma divergência intraespecífica de 0 a 4 pb (0 - 0,7\%).

O grupo identificado como H.spinella possui cinco das 55 sequências. Dentro deste grupo foi observada a presença de apenas um haplótipo (Tabela 10).

O grupo nomeado de Hypnea sp.1 possui duas das 55 sequências, com a presença de um haplótipo.

Hypnea flexicaulis e Hypnea sp.2 possuem, cada uma, apenas uma sequência, sendo assim, um só haplótipo (Tabela 10). 
Tabela 11. Porcentagem de identidade (no triângulo da porção inferior) e número absoluto de nucleotídeos divergentes (no triângulo superior em negrito e itálico) entre as sequências do cox1 as espécies e haplótipos estudados do gênero Hypnea. H. musciformis: IBC0098, IBC0138, IBC0188; H. cervicornis: ВOT004, IBC0028, IBC0186, IBC0200; H. spinella: IBC0041; H. flexicaulis: IBC0190; H.sp1: IBC0212; H.sp2: BOT0003. Número das amostras de acordo com a Tabela 5.

\begin{tabular}{|c|c|c|c|c|c|c|c|c|c|c|c|}
\hline & IBC0098 & IBC0138 & IBC0188 & ВОT0004 & IBC0028 & IBC0186 & IBC0200 & IBC0041 & ВОт0003 & IBC0190 & IBC0212 \\
\hline IBC0098 & ID & 1 & 3 & 95 & 97 & 94 & 99 & 81 & 93 & 75 & 85 \\
\hline IBC0138 & 99,8 & ID & 4 & 97 & 98 & 95 & 100 & 82 & 94 & 76 & 86 \\
\hline IBC0188 & 99,5 & 99,3 & ID & 94 & 95 & 92 & 97 & 79 & 93 & 74 & 85 \\
\hline вот0004 & 84,4 & 84,2 & 84,7 & ID & 1 & 2 & 3 & 78 & 75 & 86 & 76 \\
\hline IBC0028 & 84,2 & 84,1 & 84,6 & 99,8 & ID & 3 & 2 & 79 & 76 & 87 & 77 \\
\hline IBC0186 & 84,7 & 84,6 & 85,0 & 99,6 & 99,5 & ID & 5 & 77 & 74 & 86 & 75 \\
\hline IBC0200 & 83,9 & 83,7 & 84,2 & 99,5 & 99,6 & 99,1 & ID & 81 & 78 & 89 & 79 \\
\hline IBC0041 & 86,8 & 86,7 & 87,1 & 87,3 & 87,1 & 87,5 & 86,8 & ID & 65 & 96 & 62 \\
\hline вот0003 & 84,9 & 84,7 & 84,9 & 87,8 & 87,6 & 88,0 & 87,3 & 89,4 & ID & 86 & 69 \\
\hline IBC0190 & 87,8 & 87,6 & 88,0 & 86,0 & 85,8 & 86,0 & 85,5 & 88,4 & 86,0 & ID & 79 \\
\hline IBC0212 & 86,2 & 86,0 & 86,2 & 87,6 & 87,5 & 87,8 & 87,1 & 89,9 & 88,8 & 87,1 & ID \\
\hline
\end{tabular}

Para o marcador UPA as 10 sequências obtidas mostraram a existência, novamente, das mesmas seis entidades taxonômicas, sendo que no caso dos diferentes haplótipos encontrados para as sequências de cox1, as sequências de UPA foram idênticas, com excecão da amostra IBC0185 que diferiu em um nucleotídeo das duas outras amostras de H. musciformis (IBC0040 e IBC0098). A divergência encontrada entre as seis entidades taxonômicas foi de 2,5 - 4,4\% (Tabela 12). 
Tabela 12. Porcentagem de identidade (no triângulo inferior) e número absoluto de nucleotídeos divergentes (no triângulo superior em negrito e itálico) entre as sequências do UPA dos espécimes estudados do gênero Hypnea. H. cervicornis: IBC0028, IBC0064 e IBC0247; H. musciformis: IBC0040, IBC0098 e IBC0185; H. spinella: IBC0129; H. flexicaulis: IBC0190; H.sp1: IBC0212; H.sp2: BOT0003. Número das amostras de acordo com a Tabela 5 .

\begin{tabular}{llllllllllll}
\hline & IBC0028 & IBC64 & IBC0247 & IBC0040 & IBC98 & IBC185 & IBC129 & IBC190 & BOT003 & IBC212 \\
IBC0028 & ID & $\mathbf{0}$ & $\mathbf{0}$ & $\mathbf{1 0}$ & $\mathbf{1 0}$ & $\mathbf{1 1}$ & $\mathbf{1 1}$ & $\mathbf{1 1}$ & $\mathbf{9}$ & $\mathbf{1 1}$ \\
IBC0064 & 100 & ID & $\mathbf{0}$ & $\mathbf{1 0}$ & $\mathbf{1 0}$ & $\mathbf{1 1}$ & $\mathbf{1 1}$ & $\mathbf{1 1}$ & $\mathbf{9}$ & $\mathbf{1 1}$ \\
IBC0247 & 100 & 100 & ID & $\mathbf{1 0}$ & $\mathbf{1 0}$ & $\mathbf{1 1}$ & $\mathbf{1 1}$ & $\mathbf{1 1}$ & $\mathbf{9}$ & $\mathbf{1 1}$ \\
IBC0040 & 97,2 & 97,2 & 97,2 & ID & $\mathbf{0}$ & $\mathbf{1}$ & $\mathbf{1 4}$ & $\mathbf{1 1}$ & $\mathbf{1 1}$ & $\mathbf{1 5}$ \\
IBC0098 & 97,2 & 97,2 & 97,2 & 100 & ID & $\mathbf{1}$ & $\mathbf{1 4}$ & $\mathbf{1 1}$ & $\mathbf{1 1}$ & $\mathbf{1 5}$ \\
IBC0185 & 97,0 & 97,0 & 97,0 & 99,7 & 99,7 & ID & $\mathbf{1 5}$ & $\mathbf{1 2}$ & $\mathbf{1 2}$ & $\mathbf{2 4}$ \\
IBC0129 & 97,0 & 97,0 & 97,0 & 96,2 & 96,2 & 95,9 & ID & $\mathbf{1 0}$ & $\mathbf{9}$ & $\mathbf{1 1}$ \\
IBC0190 & 97,0 & 97,0 & 97,0 & 97,0 & 97,0 & 96,7 & 97,2 & ID & $\mathbf{1 0}$ & $\mathbf{1 2}$ \\
BOT0003 & 97,5 & 97,5 & 97,5 & 97,0 & 97,0 & 96,7 & 97,5 & 97,2 & ID & $\mathbf{1 2}$ \\
IBC0212 & 97,0 & 97,0 & 97,0 & 95,9 & 95,9 & 95,6 & 97,0 & 96,7 & 96,7 & ID \\
\hline
\end{tabular}

A partir da confirmação dos resultados obtidos com o marcador cox1 e UPA foi sequenciado o marcador $r b c \mathrm{~L}$, uma vez que esse marcador possui um maior números de sequências disponíveis para a comparação no GenBank. O resultado da comparação entre as sequências de $r b c L$ das amostras e as do banco de dados corroboram a existência de seis táxons entre as amostras coletadas, com uma divergência interespecífica para o marcador rbcL de 3,2-6,7\% (Tabela 13). 
Tabela 13. Porcentagem de identidade (no triângulo inferior) e número absoluto de nucleotídeos divergentes (no triângulo superior em negrito e itálico) entre as sequências de $r b c \mathrm{~L}$ dos espécimes estudados do gênero Hypnea H. cervicornis: IBC0028, IBC0064, IBC0245; H. musciformis: IBC0040, IBC0098, IBC0185; H. spinella: IBC0129; H. flexicaulis: IBC0190; H.sp1: IBC0212; H.sp2: BOT0003. Número das amostras de acordo com a Tabela 5.

\begin{tabular}{|c|c|c|c|c|c|c|c|c|c|c|}
\hline & IBC0028 & IBC0064 & IBC0245 & IBC0040 & IBC0098 & IBC0185 & IBC0129 & IBC0190 & IBC0212 & ВОT0003 \\
\hline BC0028 & ID & 0 & 6 & 75 & 75 & 75 & 47 & 79 & 62 & 50 \\
\hline IBC0064 & 100 & ID & 6 & 75 & 75 & 75 & 47 & 79 & 62 & 50 \\
\hline IBC0245 & 99,5 & 99,5 & ID & 80 & 81 & 80 & 53 & 88 & 80 & 56 \\
\hline IBC0040 & 94,3 & 94,3 & 93,9 & ID & 1 & 0 & 84 & 73 & 88 & 79 \\
\hline IBC0098 & 94,3 & 94,3 & 93,8 & 99,9 & ID & 1,3 & 84 & 72 & 88 & 84 \\
\hline IBC0185 & 94,3 & 94,3 & 93,9 & 100 & 99,9 & ID & 84 & 73 & 88 & 79 \\
\hline IBC0129 & 96,4 & 96,4 & 95,9 & 93,6 & 93,6 & 93,6 & ID & 79 & 55 & 42 \\
\hline IBC0190 & 93,7 & 93,7 & 93,3 & 94,4 & 94,5 & 94,4 & 93,7 & ID & 88 & 82 \\
\hline IBC0212 & 95,3 & 95,3 & 94,9 & 93,3 & 93,3 & 93,3 & 95,8 & 93,3 & ID & 42 \\
\hline ВОТ0003 & 96,2 & 96,2 & 95,7 & 93,7 & 93,6 & 93,7 & 96,8 & 93,8 & 96,8 & ID \\
\hline
\end{tabular}




\section{2- ANÁLISES FILOGENÉTICAS}

As análises geradas para o marcador cox1 utilizaram uma porção de 617 nucleotídeos da região 5' do gene, alinhando 82 sequências, referentes a 18 espécies de Hypnea. A árvore segundo a análise de Neighbor Joining (NJ) mostrou a formação de oito agrupamentos principais, a maioria com alto suporte das análises de bootstrap, e espécies isoladas (Figura 3).

No primeiro agrupamento, $H$. flexicaulis (Paraty, RJ) aparece como grupo irmão do clado que contém $H$. flexicaulis (Filipinas) e um agrupamento com dois clados, um contendo $H$. boergesenii (Coréia) e outro com $H$. cervicornis (Havaí), H. flexicaulis (Coréia) e $H$. valentiae (Havaí).

No segundo agrupamento, $H$. stellullifera (Filipinas) aparece como grupo irmão do agrupamento que contém as sequências de $H$. musciformis. Hypnea musciformis do Havaí aparece como um táxon basal ao clado que contém as amostras H.musciformis analisadas neste trabalho. As amostras brasileiras se dividiram em dois grupos, um com três amostras de Itanhaém, SP e o outro contendo as demais amostras incluindo uma outra amostra de Itanhaém. A divergência encontrada no cox1 entre os dois agrupamentos de $H$. musciformis do Brasil foi de $0-4 \mathrm{pb}(0-0,7 \%)$. A divergência encontrada entre a $H$. musciformis do Havaí e as amostras Brasileiras foi de 4,3-4,6\%.

No terceiro agrupamento encontram-se uma amostra de $H$. musciformis e outra de $H$. valentiae ambas do Havaí.

No quarto agrupamento $H$. nidulans (Filipinas) aparece como grupo irmão do clado que contém $H$. pannosa (México), $H$. viridis (África do Sul) e duas outras amostras de $H$. pannosa (Filipinas).

No quinto agrupamento, $H$. spinella (Vietnã) aparece como grupo irmão do agrupamento que contém dois clados; o primeiro com quatro amostras do Havaí (três Hypnea sp e uma $H$. spinella e, o segundo, com as duas amostras de Hypnea sp.1 (São Paulo).

O sexto agrupamento inclui Hypnea sp. "asiática" (Taiwan) como grupo irmão de Hypnea sp. (Havaí).

No sétimo agrupamento estão todas as amostras de H. cervicornis coletadas em São Paulo que se dividem em dois grupos, um contendo quatro amostras de Ubatuba e o outro com as demais amostras, incluindo outras amostras de Ubatuba. A divergência encontrada no cox 1 entre os dois agrupamentos de $H$. cervicornis foi de $1-2 \mathrm{pb}(0,2-0,4 \%)$.

No oitavo agrupamento estão as amostras de $H$. spinella obtidas para o Estado de São Paulo. 
A amostra de Hypnea sp.2 (São Paulo) aparece isolada e não é proximamente relacionada a nenhum dos outros clados.

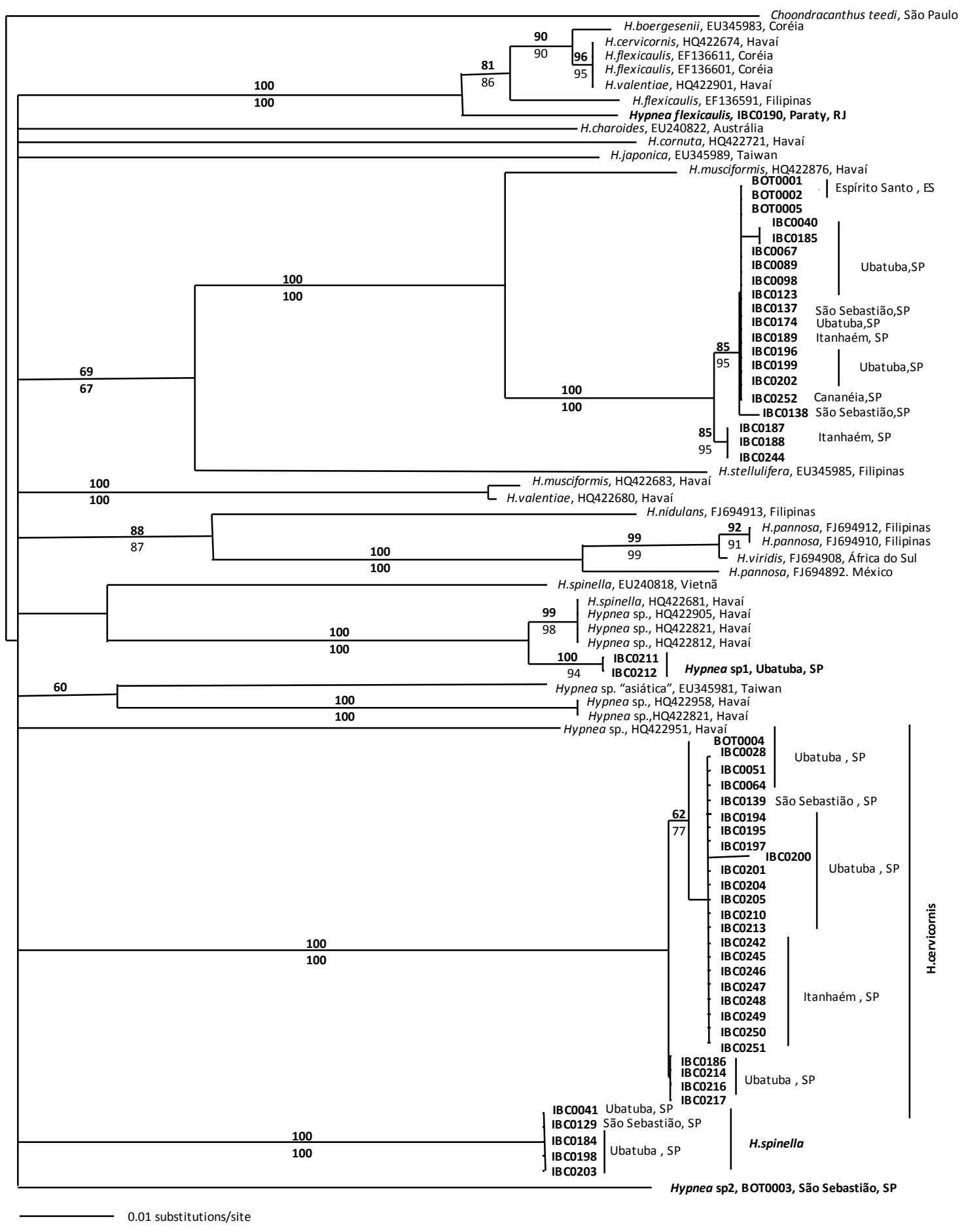

Figura 3. Análise de Neighbor-Joining (NJ) para as sequências de cox1 obtidas de espécies do gênero Hypnea; a sequência de Chondracanthus teedi foi utilizada como grupo externo. Nos ramos estão plotados os valores de bootstrap de duas matrizes analisadas. Apenas valores maiores do que 
60 foram plotados. As sequências retiradas do GenBank estão seguidas do $n^{\circ}$ de acesso e localidade geográfica. As amostras obtidas neste estudo estão destacadas em negrito.

As análises geradas para o marcador UPA utilizaram uma porção de 369 nucleotídeos do gene, alinhando 29 sequências, referentes a 12 espécies de Hypnea (todas as sequências retiradas do banco de dados pertencem ao trabalho de Sherwood et al. 2010, e são provenientes do Havaí). A árvore filogenética segundo a análise de NJ (Figura 4) mostrou a formação de seis agrupamentos e algumas sequências isoladas.

O primeiro agrupamento contém três amostras do Havaí, $H$. cervicornis, $H$. musciformis e $H$. valentiae. No segundo agrupamento, $H$. cornuta e $H$. pannosa, ambas do Havaí, aparecem juntas. O terceiro agrupamento se divide em dois clados. O primeiro com amostras de $H$. musciformis (Havaí) e o segundo com as amostras de $H$. musciformis (São Paulo). A divergência encontrada para o UPA entre esses dois agrupamentos de $H$. musciformis foi de 5 a 7 pb (1,4 - 1,7\%). O quarto agrupamento contém $H$. flexicaulis (Paraty, RJ) como grupo irmão de $H$. nidifica e $H$. valentiae ambas do Havaí. No quinto agrupamento, Hypnea sp (Havaí) aparece como grupo irmão do clado que contém $H$. spinella (Havaí) e Hypnea sp.1 (São Paulo). O sexto agrupamento contém as amostras de H. cervicornis (São Paulo). As sequências de H. spinella (São Paulo) e Hypnea sp.2 (São Paulo) não se agruparam com nenhuma outra sequência disponível. 
Chondracantus acicularis, HQ421634

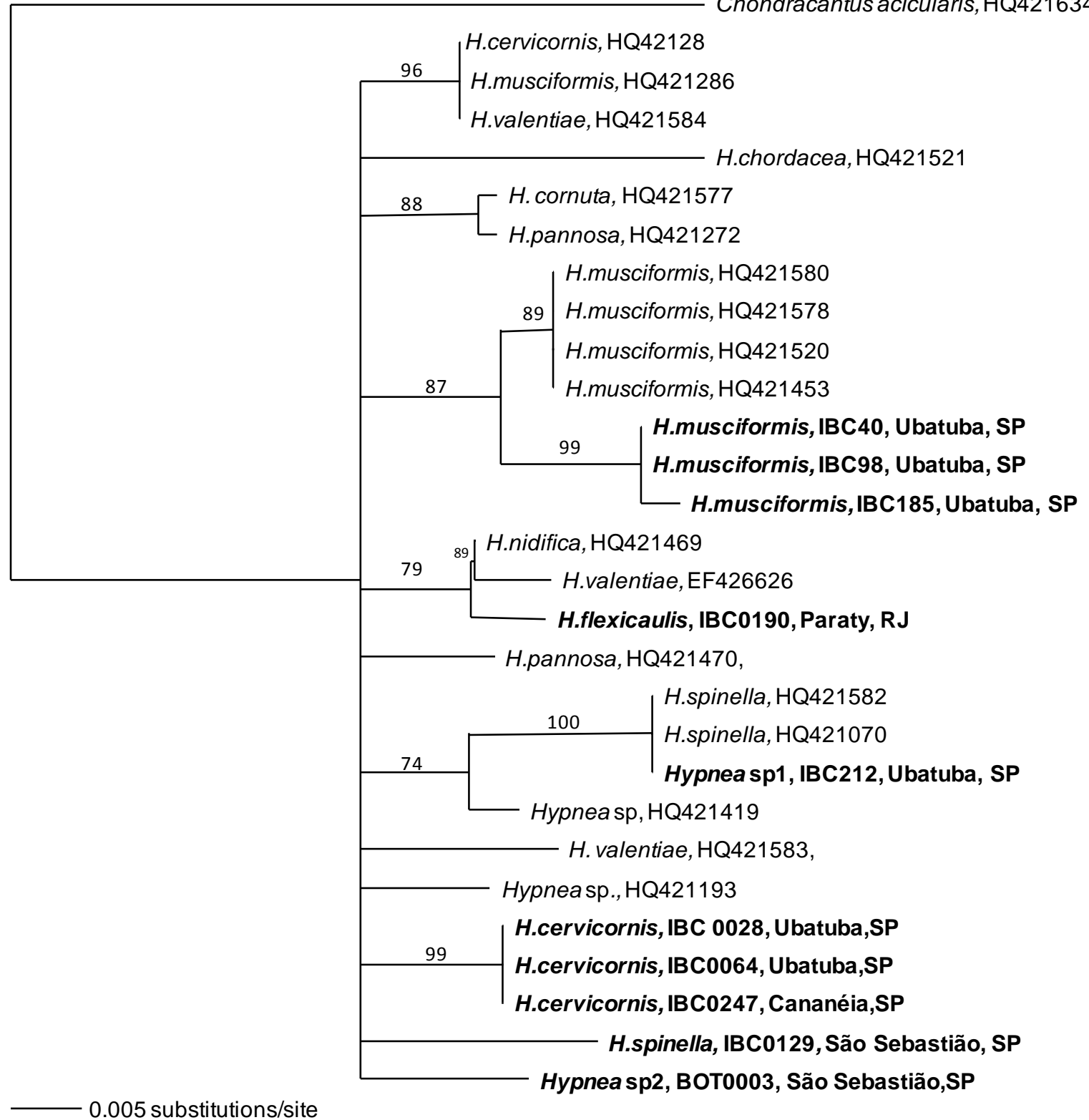

Figura 4. Análise de Neighbor-Joining (NJ) para as sequências do marcador UPA, mostrando o agrupamento de espécies do gênero Hypnea. Nos ramos estão plotados os valores de bootstrap. Apenas valores maiores do que 70 foram plotados. As sequências retiradas do GenBank estão seguidas do $\mathrm{n}^{0}$ de acesso. As amostras de São Paulo estão destacadas em negrito. 
Trinta e nove sequências representando 22 espécies de Hypnea foram alinhadas utilizando uma porção do gene rbcL com 1317 nucleotídeos. A árvore gerada pela análise Bayesiana mostra a relação filogenética das espécies do gênero Hypnea baseada nesse marcador (Figura 5).

As espécies de Hypnea analisadas formaram um agrupamento monofilético com alto suporte em relação aos grupos externos utilizados e se dividiram em dois grandes grupos, mas com um suporte moderado apenas de probabilidade a posteriori.

O primeiro grande grupo se dividiu em dois agrupamentos com suporte de moderado à alto nas análises. O primeiro contém $H$. tenuis (África do Sul) como grupo irmão do clado que contém $H$. flexicaulis (Filipinas e Japão), H. japonica (local desconhecido), H. flexicaulis (Paraty, RJ), H. boergesenii (Taiwan e Coréia). A variação encontrada para esse grupo de H. flexicaulis - H. japônica - H. boergesenii foi de 10 a 79 pb (0,8 - 6\%). O segundo grupo por sua vez se subdivide em alguns clados. Um contendo $H$. chordacea (Japão) e $H$. flagelliformis (Japão) como grupo irmão de $H$. musciformis. As amostras de $H$. musciformis se dividem em dois agrupamentos um com os exemplares da França e EUA, e o outro com as amostras de $H$. musciformis de São Paulo, ambos com alto suporte nos ramos. A variação encontrada para o rbcL entre os dois agrupamentos de H.musciformis foi de 12 pb. O segundo agrupamento contém $H$. stellulifera (Filipinas) como grupo irmão $H$. cornuta da Indonésia e Itália. $O$ outro agrupamento formado, referente ao primeiro grande agrupamento, inclui espécies da Ásia $H$. japonica (Coréia), e $H$. nidulans, $H$. pannosa (Japão), Hypnea sp. PJLG (Cingapura) e uma amostra da África do Sul de H. viridis.

O segundo grande grupo se divide em três agrupamentos. O primeiro, sem suporte nas análises, agrupa $H$. charoides (Austrália) com $H$. rosea (África do Sul). O segundo inclui $H$. nidifica (Cingapura), H. charoides e Hypnea sp. "asiatica" ambas do Japão, e um agrupamento com as amostras de $H$. cervicornis de São Paulo, com alto suporte nos ramos. A divergência observada entre o grupo de $H$. cervicornis e o grupo de espécies da Ásia foi de 5 a 55 pb (0,4 - 4,2\%). O terceiro grupo é formado por dois agrupamentos: um contém Hypnea sp.2 (São Paulo), Hypena sp1 (São Paulo) e H. spinella do Vietnã e do Japão, com uma variação de 40 a 46 pb (3,1 - 3,5\%); o outro agrupa $H$. valentiae (Indonésia), Hypnea sp. IzuH1 (Japão) e H. spinella (São Paulo). A variação encontrada entre esses três últimos táxons para o rbcL foi de 33 a $35 \mathrm{pb}(2,5-2,7 \%)$. 


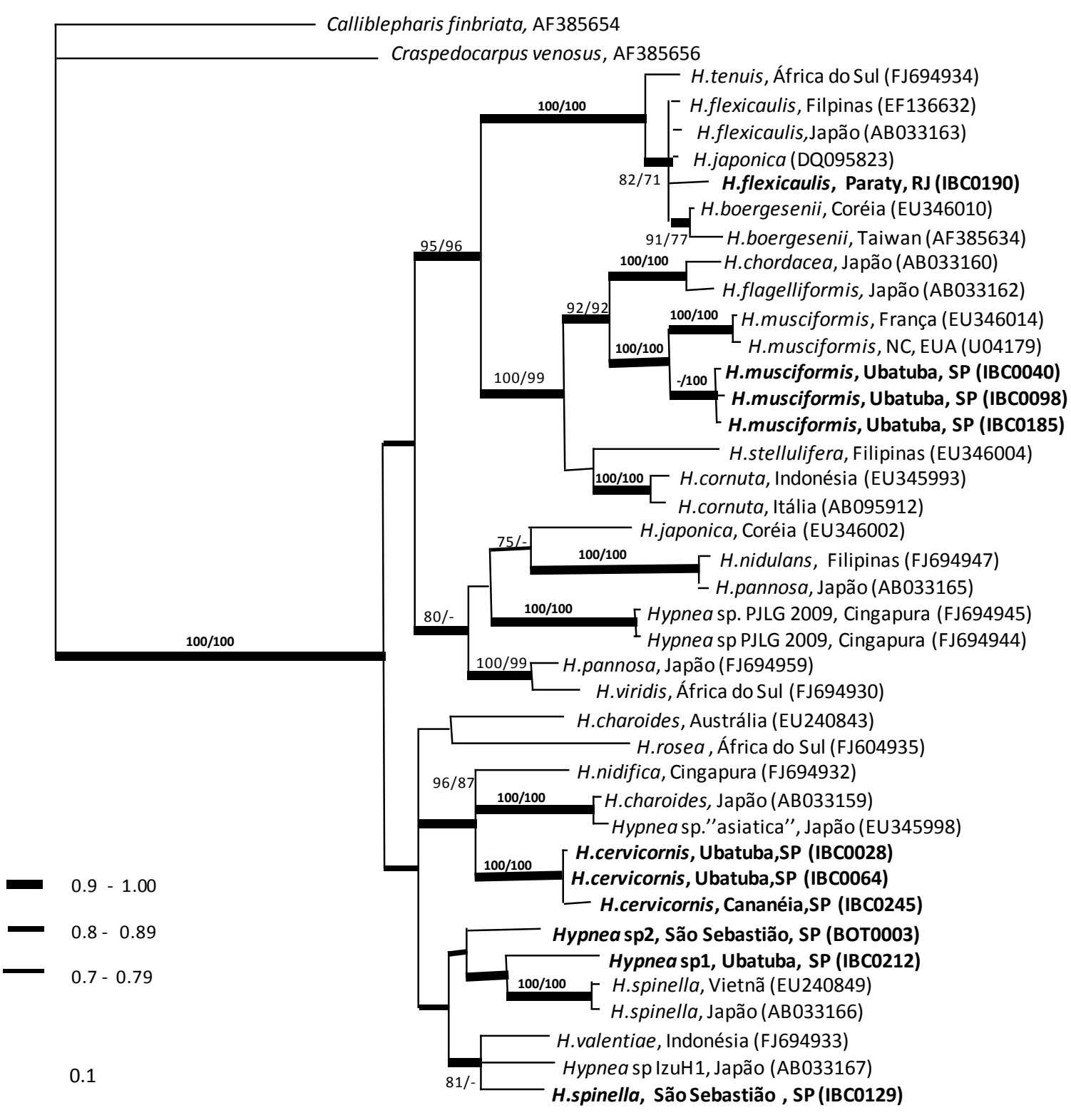

Figura 5. Análise Bayesiana (MB) de sequências de $r b c L$ mostrando as relações filogenéticas de espécies do gênero Hypnea. Nos ramos estão plotados os valores de bootstrap para análise de Neighbor-Joining (NJ) e Máxima Parcimônia (MP) - NJ/MP. As probabilidades a posteriori (pp) estão representadas na espessura dos ramos, segundo a legenda da Figura. Apenas valores maiores do que 70 foram plotados. As sequências retiradas do GenBank estão seguidas do $n^{\circ}$ de acesso. As amostras obtidas neste trabalho estão destacadas em negrito.

Comparando todas as amostras utilizadas nas análises, as divergências interespecíficas, calculadas a partir da matriz com 466 pb, foram de 0 a 74 pb (0 - 15,9\%) para o marcador cox1. Ressaltando que a divergência de 0 pb ocorreu entre $H$. flexicaulis 
da Coréia e H. cervicornis de São Paulo, Brasil. Para o marcador rbcL as divergências interespecíficas foram de 3 a 97 pb $(0,2-7,4 \%)$, sendo que a divergência de 3 pb ocorreu entre $H$. nidulans e $H$. pannosa ambas da Ásia.

Entre as amostras do estado de São Paulo as divergências interespecíficas foram de 62 a 100 pb (10,6\% - 16,3\%) para o marcador cox1; 9 a 15 pb (2,5 - 4,1\%) para o marcador UPA e 42 a 88 pb (3,2 - 6,7 \%) para o marcador rbcL (Tabela14).

Entre as amostras de São Paulo a divergência intraespecífica foi de 0 a 5 pb $(0-0,9$ \%) para o marcador cox 1,0 a 1 pb $(0-0,3 \%)$ para o UPA e 0 a 6 pb (0-0,5\%) para o rbcL. Estes últimos referentes às amostras de $H$. musciformis e $H$. cervicornis, que possuíam mais de uma sequência para essa análise (Tabela14).

Tabela 14. Divergências interespecíficas e intraespecíficas paras os marcadores cox1, UPA e rbcL entre as amostras do gênero Hypnea sequenciadas para este estudo.

\begin{tabular}{ccc}
\hline Marcador & Interespecífica & Intraespecífica \\
\hline cox1 & $62-100 \mathrm{pb}$ & $0-5 \mathrm{pb}$ \\
& $(10,1-16,3 \%)$ & $(0-0,9 \%)$ \\
UPA & $9-16 \mathrm{pb}$ & $0-1 \mathrm{pb}$ \\
& $(2,5-4,4 \%)$ & $(0-0,3 \%)$ \\
rbcL & $42-88 \mathrm{pb}$ & $0-6 \mathrm{pb}$ \\
& $(3,2-6,7 \%)$ & $(0-0,5 \%)$ \\
\hline
\end{tabular}




\section{3- Morfologia}

As amostras coletadas foram separadas segundo as sequências do marcador cox1, e a morfologia destes grupos foram avaliadas separadamente. Caracteres morfológicos (Tabela 6) foram avaliados a fim de encontrar semelhanças nas morfologias dos indivíduos de um mesmo grupo.

Segundo a análise morfológica dos grupos encontrados e separados pelas divergências das sequências de cox1, esses grupos foram denominados de: H.cervicornis, H.flexicaulis, H.musciformis, H.spinella, Hypnea sp. 1 e Hypnea sp. 2.

Segue abaixo a descrição morfológica das espécies encontradas.

1- Hypnea cervicornis J. Agardh, Spec. gen. et ord. algar. 2(2): 337 [bis]-351 [bis] 352-506, 1851.

Localidade tipo: Índia Ocidental ou Ilhas Maurício

Figs. 6 - 13.

Plantas de coloração vermelha-rosada a amarronzada, medindo 1 - $4 \mathrm{~cm}$ de altura (Figuras 6-7). Alguns espécimes apresentaram perda de coloração pelo armazenamento em formol, e apresentaram coloração diferenciada nas fotos (Figura 7). Eixo principal distinguível, cilíndrico, de consistência delicada medindo de $3-5 \mathrm{~cm}$ (Figuras 6-7), apresentando ápice reto e levemente afinado, sem ganchos ou gavinhas (Figura 8). Ramificação em padrão alterno espiralado ou no mesmo plano, inseridas em ângulo agudo ou reto, mais densa nas partes mais basais do talo. Ramos de ordem primária com diâmetro pouco menor que o eixo principal (Figura 8). Ramos de ordem secundária com diâmetro menor que do eixo principal, levemente curvado em diferentes direções (Figura 8). Râmulos espinescentes presentes (Figuras 6-8). Anastomoses pouco frequentes. Em corte transversal na região subapical, diâmetro do eixo principal medindo de 218,9 - 547,5 $\mu \mathrm{m}$ (Figura 9). Talo com uma a duas camadas de células corticais de contorno arredondado (ovalado) com diâmetro de 6,2 -22,1 $\mu \mathrm{m}$. Células axiais medindo de 31,3 - 49,55 $\mu \mathrm{m}$ (Figura 10), 5-6 células periaxiais por célula axial, com diâmetro de (33,8) 52,8 - 72,0 (91,1) um (Figuras. 9-10). Espessamentos lenticulares raros, observados somente em uma amostra (llha do Bom Abrigo, Cananéia, SP - SPF57139) (Figuras 11-12). Tetrasporângios localizados na base de râmulos, zonados (Figura 13). Plantas femininas e masculinas não foram observadas.

Hábitat: Plantas crescendo no infralitoral e em áreas de costão exposto ao impacto de ondas, epilíticas ou epífitas em outras algas. 
Material examinado: São Paulo - Ubatuba: Praia Vermelha do Sul, 13.x.2008, E.C.Oliveira, tetrasporófito (SPF56877); Praia Dura, 14.xi.2008 E.C.Oliveira \& M.C.Oliveira, planta tetraspórica, SPF56881. Cananéia: Ilha do Bom Abrigo, 29.vi.2010, N.R.Guimarães, planta tetraspórica, SPF56887; Ilha do Bom Abrigo, 29.vi.2010, N.R.Guimarães, planta não fértil, SPF57140; Ilha do Bom Abrigo, 29.vi.2010, N.R.Guimarães, planta tetraspórica, SPF57142; Ilha do Cardoso, 30. vi.2010, N.R.Guimarães, planta tetraspórica, SPF57144. 

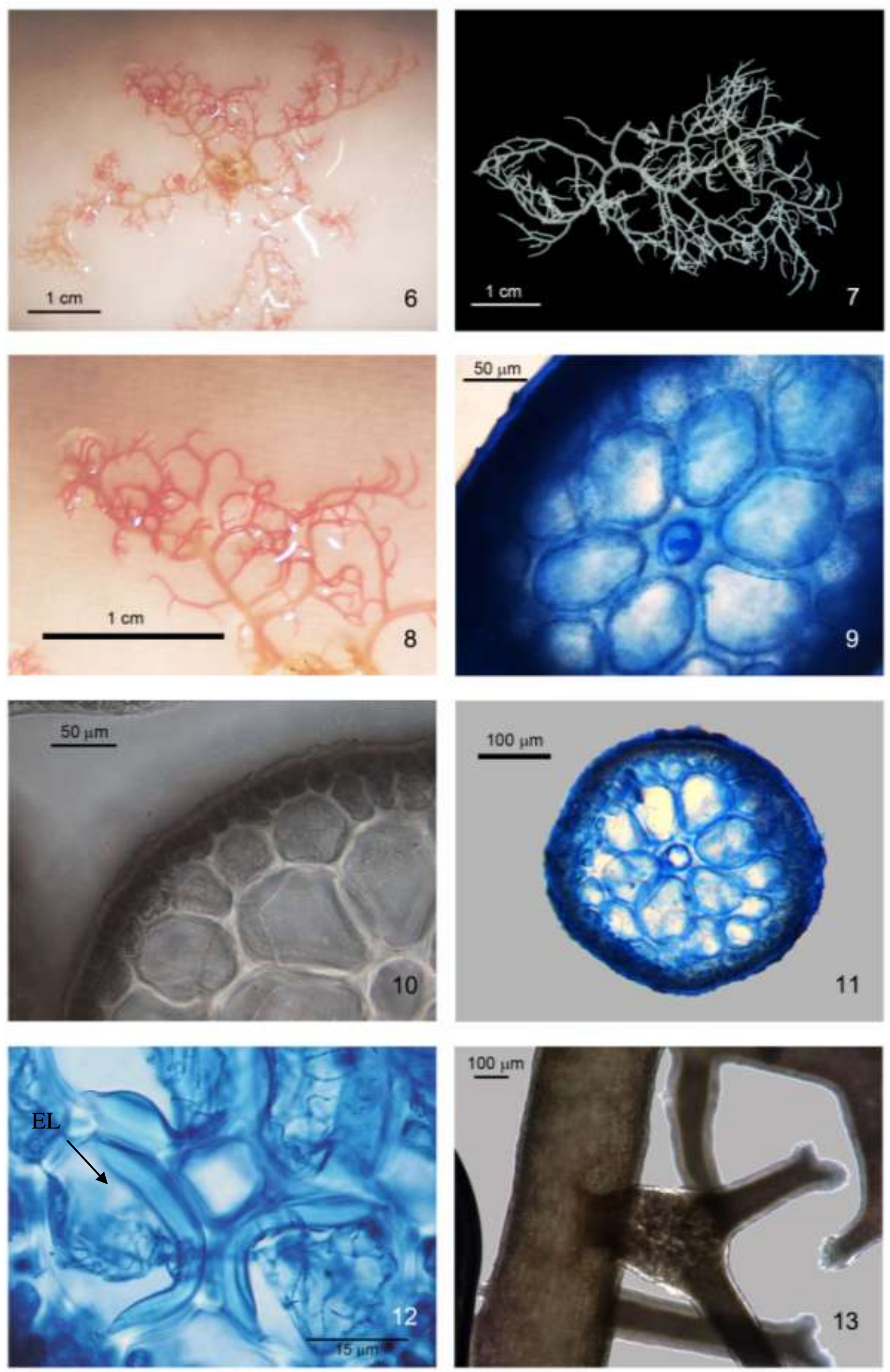
Figuras 6-13. Hypnea cervicornis. Figuras 6 e 7. Aspecto geral do talo de H.cervicornis. Figura 8. Detalhe das ramificações e ápice. Figuras 9-11. Corte transversal da região subapical do talo mostrando células central $(C)$ e pericentral $(P C)$. Figura 12. Detalhe do espessamento lenticular (EL) da amostra SPF57139. Figura 13. Detalhe do râmulo com tetrasporângios. 
2- Hypnea flexicaulis Yamagishi, Y. \& Masuda, M. The species of Hypnea from Japan 6: 135-162, 1997.

Localidade tipo: Ikata, Ehime Prefecture, Japão.

Figs. 14-17.

Plantas de cor vermelho enegrecido, medindo $5-7 \mathrm{~cm}$. Eixo principal distinguível e cilíndrico (Figura 14). Terminação apical tanto dos eixos principais quanto das ramificações secundárias algumas vezes encurvadas, lembrando um gancho ou gavinha (Figura 15). Ramificações primárias com diâmetro pouco menor que o eixo principal, inseridas em ângulo agudo. Pode haver ou não râmulos espinescentes. Ramificações em padrão alterno (Figura 15). Em corte transversal, diâmetro do eixo principal medindo de 457,5 - 530,4 $\mu \mathrm{m}$ na porção subapical do talo. Células axiais medindo de 58,2 - 72,4 $\mu$ m (Figura 16), 6 células periaxiais por célula axial, com diâmetro de 77,4 - 158,1 um (Figuras 16-17). Espessamentos lenticulares ausentes. Plantas tetrasporofíticas, femininas e masculinas férteis não foram observadas.

Hábitat: infralitoral, 2 metros de profundidade.

Material examinado: Rio de Janeiro: Paraty: Saco do Mamanguá, 20.xi.2009, E.C.Oliveira; planta não fértil, SPF56540. 

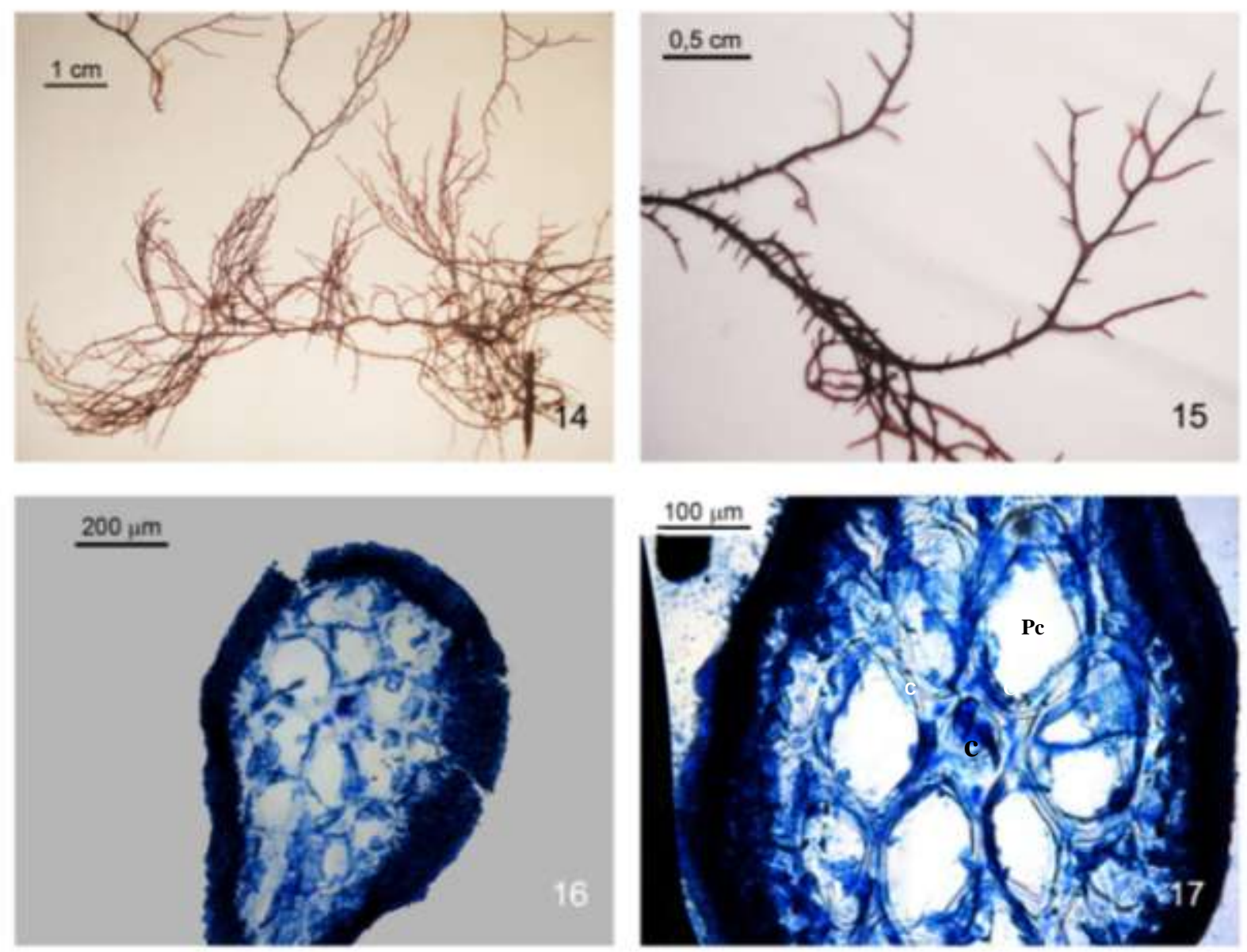

Figuras 14-17. H.flexicaulis. Figura 14. Aspecto geral do talo de H.flexicaulis.

Figura 15. Detalhe das ramificações e ápice. Figuras 16-17. Corte transversal da regiãosubapical do talo mostrando células central $(C)$ e pericentral $(\mathrm{Pc})$. 
3- Hypnea musciformis (Wulfen) J.V.Lamouroux. Annls. Mus. Hist. nat., Paris 20: 21-47, 115-139, 267-293, Figs. 7-13, 1813

Basiônimo: Fucus musciformis (Wulfen in Jacquin), 1791

Localidade tipo: Trieste, Itália.

Figs. 18 - 23

Plantas de coloração esverdeada a vinho-enegrecidas, com 3 - $7 \mathrm{~cm}$ de altura (Figura 1819). Eixos principais distinguíveis, cilíndricos, de consistência rígida ou carnosa, presença de ramos com ápices em forma de ganchos ou gavinhas (Figuras 18-19). Râmulos espinescentes dispostos predominantemente de forma unilateral (Figura 20). Ramificação irregular com predominância de ramificação alterna, em ângulo agudo ou quase reto, com até três ordens de ramificação (Figura 20). Muitas vezes, as ramificações secundárias aparecem de um lado só do ramo primário. Anastomoses ausentes. Em corte transversal da região subapical, diâmetro do eixo principal uniforme, medindo de 266,1 - 622,2 $\mu$ m; 1 a 2 camadas de células corticais oval-arredondadas com diâmetro de 6,0 - 14,8 $\mu \mathrm{m}$ (Figura 21). Células axiais medindo de 42,1 - 83,3 $\mu \mathrm{m}$; 5-8 células periaxiais por célula axial, com diâmetro de 20,0 - 66,9 (79,2) um (Figura 21). Espessamentos lenticulares ausentes. Tetrasporângios localizados na base ou em volta do râmulo, zonados (Figura 22). Cistocarpos globosos medindo 456 - 537,7 $\mu$ m (Figura 23). Plantas masculinas não foram observadas.

Hábitat: Plantas crescendo em locais batidos como epífitas em algas do gênero Sargassum C.Agardh ou em outras espécies de Hypnea, ou ainda epiliticamente.

Material examinado: São Paulo: Ubatuba: Praia Vermelha do Sul, 13.x.2008, E.C.Oliveira, planta tetraspórica, SPF56878; Praia do Costa, 16.x.2008, M.C.Oliveira, planta tetraspórica, SPF56883. São Sebastião: Praia das Cigarras 08.v.2009, M.C.Oliveira, planta tetraspórica, SPF56888. Itanhaém: Praia dos Sonhos, v.2010, N.R.Guimarães, planta feminina, SPF56891.

Comentários: Os espécimes coletados na Praia dos Sonhos, em Itanhaém (Figura 2) foram previamente identificados como Hypnea nigrescens segundo Schenkman (1986). Porém, os estudos moleculares mostraram que os espécimes identificados como $\mathrm{H}$. nigrescens para o Estado de São Paulo correspondem a uma variação morfológica de $H$. musciformis. Os espécimes previamente identificados como $H$. nigrescens apresentam talo com coloração vináceo-enegrecida, vários eixos eretos com o mesmo comprimento, lembrando as cerdas 
de um pincel, e poucos ramos com gavinhas. Estas características foram encontradas em espécimes coletados em locais diretamente expostos ao impacto de ondas. 

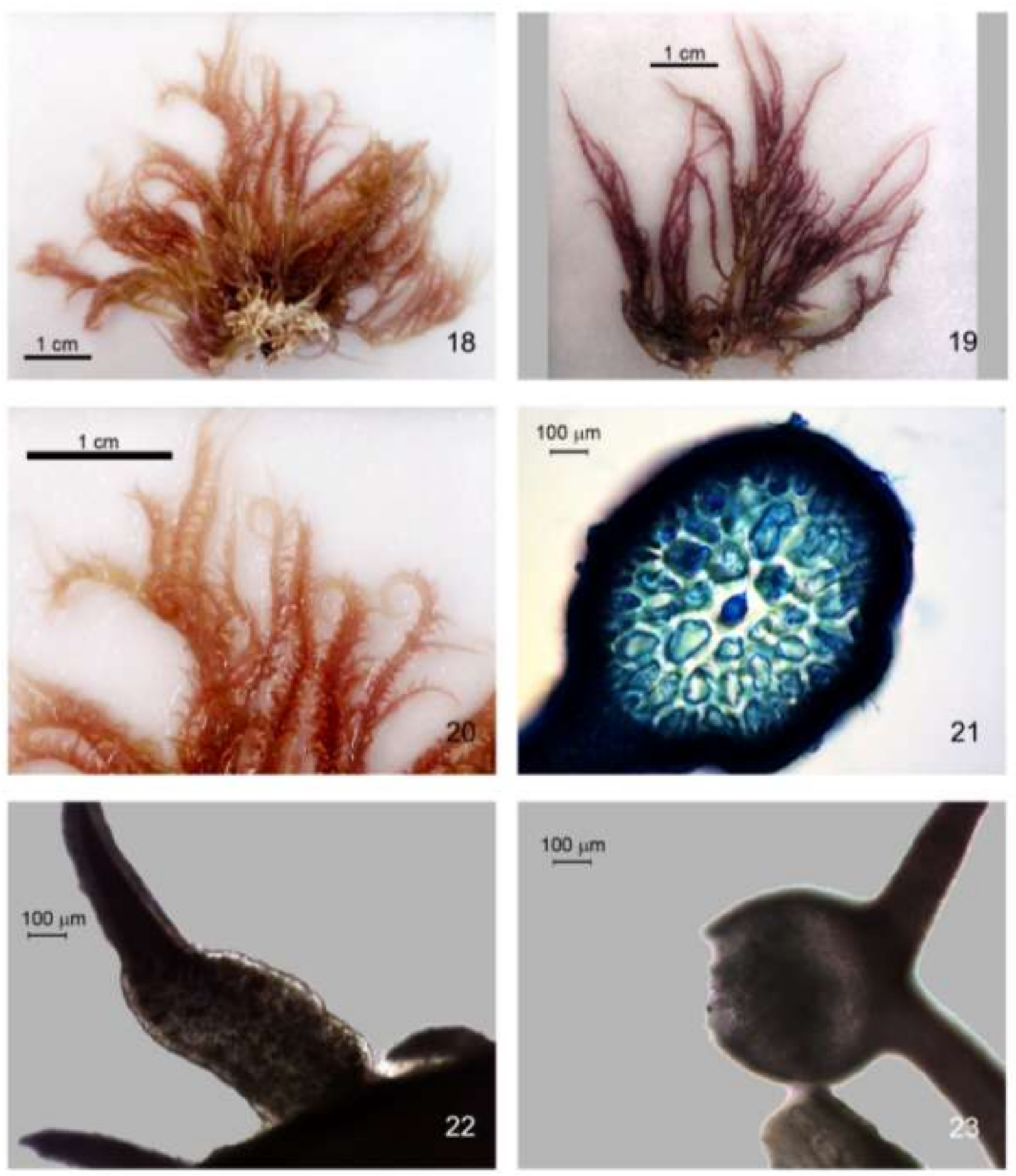

Figuras 18-23. Hypnea.musciformis. Figuras 18 e 19. Aspecto geral do talo. Figura 20. Detalhe das ramificações e ápices com gavinhas. Figura 21. Corte transversal da região subapical do talo. Figura 22. Detalhe do râmulo com tetrasporângios. Figura 23. Detalhe do cistocarpo. 
4- Hypnea spinella (C.Agardh) Kützing. Diagnosen und Bemerkungen zu neuen oder kritischen Algen 5: 1-5, 22-25, 33-38, 52-55, 164-167, 177-180, 193-198, 219-223, 1847

Basiônimo: Sphaerococcus spinellus C. Agardh Spec. Algar. 2: 323; 1822. Localidade tipo: Índia Ocidental

Figs. 24 - 29

Plantas formando tufos densos, relativamente prostrados, com ramos fortemente entrelaçados por anastomoses abundantes, de coloração vermelho-pálida a vermelhoescura, medindo 2 - $4 \mathrm{~cm}$. Eixo principal indistinguível (Figuras 24-25). Talo cilíndrico, de consistência delicada, com padrão de ramificação irregular a alterno, com pequena distância entre os ramos em algumas partes do talo, podendo aparentar padrão oposto de ramificação (Figuras 25-26). Apresentam ápices retos e algumas vezes bifurcados, sem ganchos ou gavinhas. Râmulos espinescentes retos (Figura 26). Em corte transversal, diâmetro da ramificação medindo de 223,7 - 520,8 um na porção subapical do talo (Figura 27). Talo com uma a duas camadas de células corticais arredondadas (ovaladas) com diâmetro de 8,6 13,9 $\mu \mathrm{m}$. Células axiais medindo de 45,8 - 78,7 $\mu \mathrm{m}, 5$ - 6 células periaxiais por célula axial, com diâmetro de 32,2 - 102,5 $\mu \mathrm{m}$ (Figura 28). Espessamentos lenticulares ausentes (Figura 28). Tetrasporângios localizados em volta da base dos râmulos, zonados (Figura 29). Plantas femininas e masculinas não foram observadas.

Hábitat: Plantas crescendo em local de costão exposto ao impacto de ondas ou infralitoral, associadas frequentemente a coralináceas, sendo difícil separar os ramos sem parti-los.

Material examinado: São Paulo - Ubatuba: Praia Vermelha do Sul (13.x.2008) E.C.Oliveira, planta tetraspórica, SPF56879. Domingas Dias (16.iii.2010), S.M.P.B.Guimarães \& M.T. Fujii, planta tetraspórica, SPF57037; São Sebastião: Ilhabela: Saco do Poço, 31.x.2008, M.C.Oliveira, planta tetraspórica, SPF 56884. 

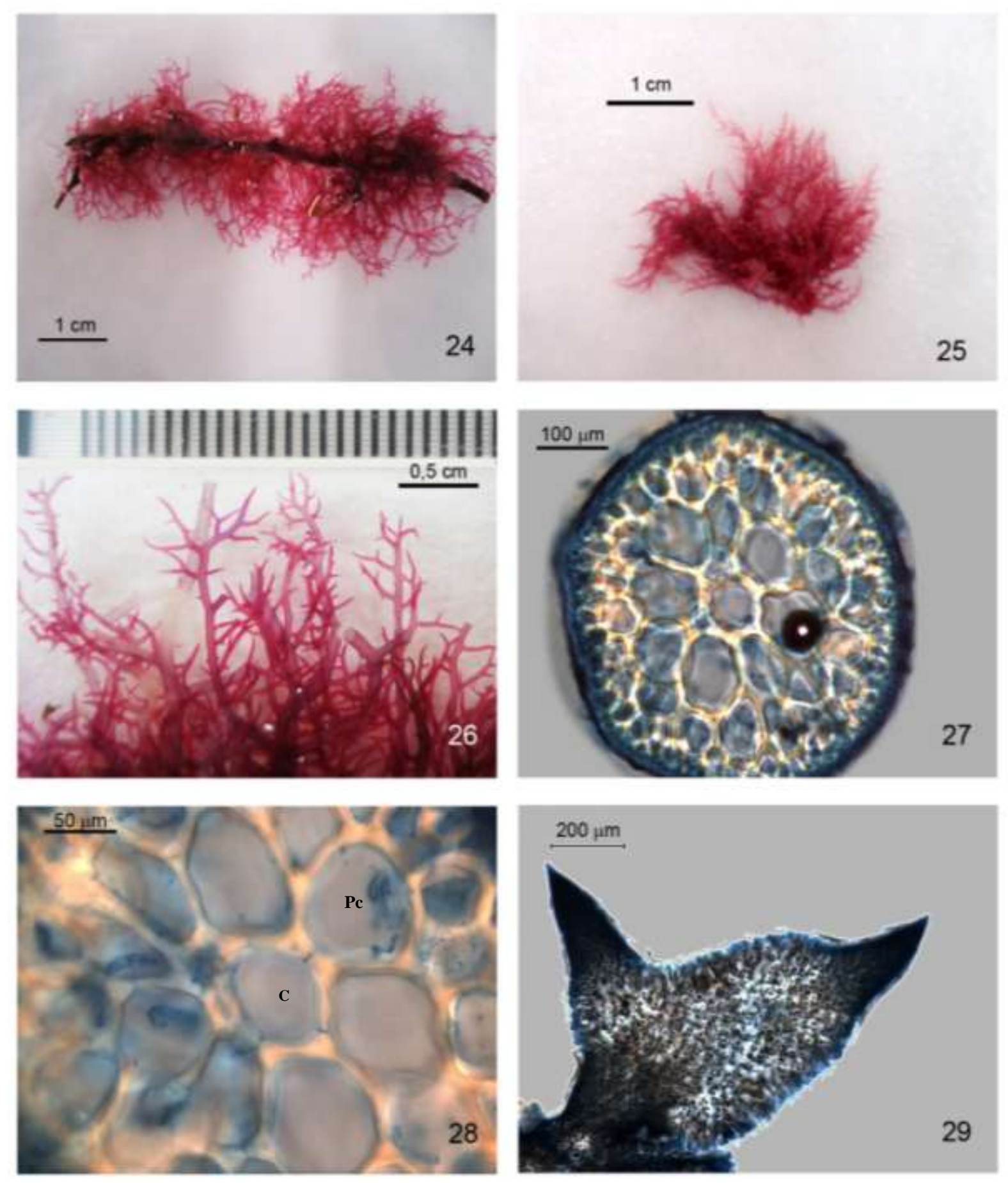

Figuras 24-29. Hypnea spinella. Figuras 24-25. Aspecto geral do talo. Figura 26. Detalhe das ramificações e ápices. Figuras 27. Corte transversal da região subapical do talo. Figura 28. Detalhe das células central $(C)$ e pericentrais $(P c)$ no corte transversa. Figura 29. Detalhe do râmulo com tetrasporângios. 


\section{5- Hypnea sp. 1}

Figs. 30-34

Plantas formando emaranhado ou tapete de ramos de coloração vermelho -rosada (forte), medindo 1,5 - $3 \mathrm{~cm}$ de altura (Figura 30). Os espécimes apresentaram perda de coloração pelo armazenamento em formol, e aparece com coloração diferenciada nas fotos (Figura 30). Eixo principal distinguível, cilíndrico, de consistência delicada, apresentando ápice reto e levemente afinado, sem ganchos ou gavinhas (Figura 30). Ramificação irregular, em ângulo agudo ou reto, mais densa nas partes mais velhas do talo (Figura 31). Ramos de ordem primária com diâmetro pouco menor que o eixo principal. Ramos de ordem secundária com diâmetro visivelmente menor que do eixo principal, curtos e mais finos no ápice (Figura 31). Anastomoses presentes. Em corte transversal da região subapical do talo, diâmetro do eixo principal uniforme, medindo de 181,4 - 252,7 $\mu \mathrm{m}$ (Figuras 32-33). Talo com uma a duas camadas de células corticais de contorno arredondado (ovalado). Células axiais medindo de 26,5 - 33,3 $\mu \mathrm{m}$ (Figura 32). Cada célula axial produz 5-6 células periaxais, com diâmetro de 23,3 - 63,2 $\mu \mathrm{m}$. Espessamentos lenticulares abundantes (Figura 32-33). Tetrasporângios localizados na parte mediana dos râmulos, zonados (Figura 34). Plantas femininas e masculinas não foram observadas.

Hábitat: Plantas crescendo em áreas de costão exposto ao impacto de ondas, epífitas sobre outras algas, e encontrada em poça de maré.

Material examinado: São Paulo - Ubatuba: Pincinguaba, 17.iii.2010, M.C.Oliveira \& M.B.B.Barreto, planta tetraspórica, SPF57044 e Praia Vermelha do Sul, 18.iii.2010, N.R.Guimarães, planta tetraspórica, SPF57045. 

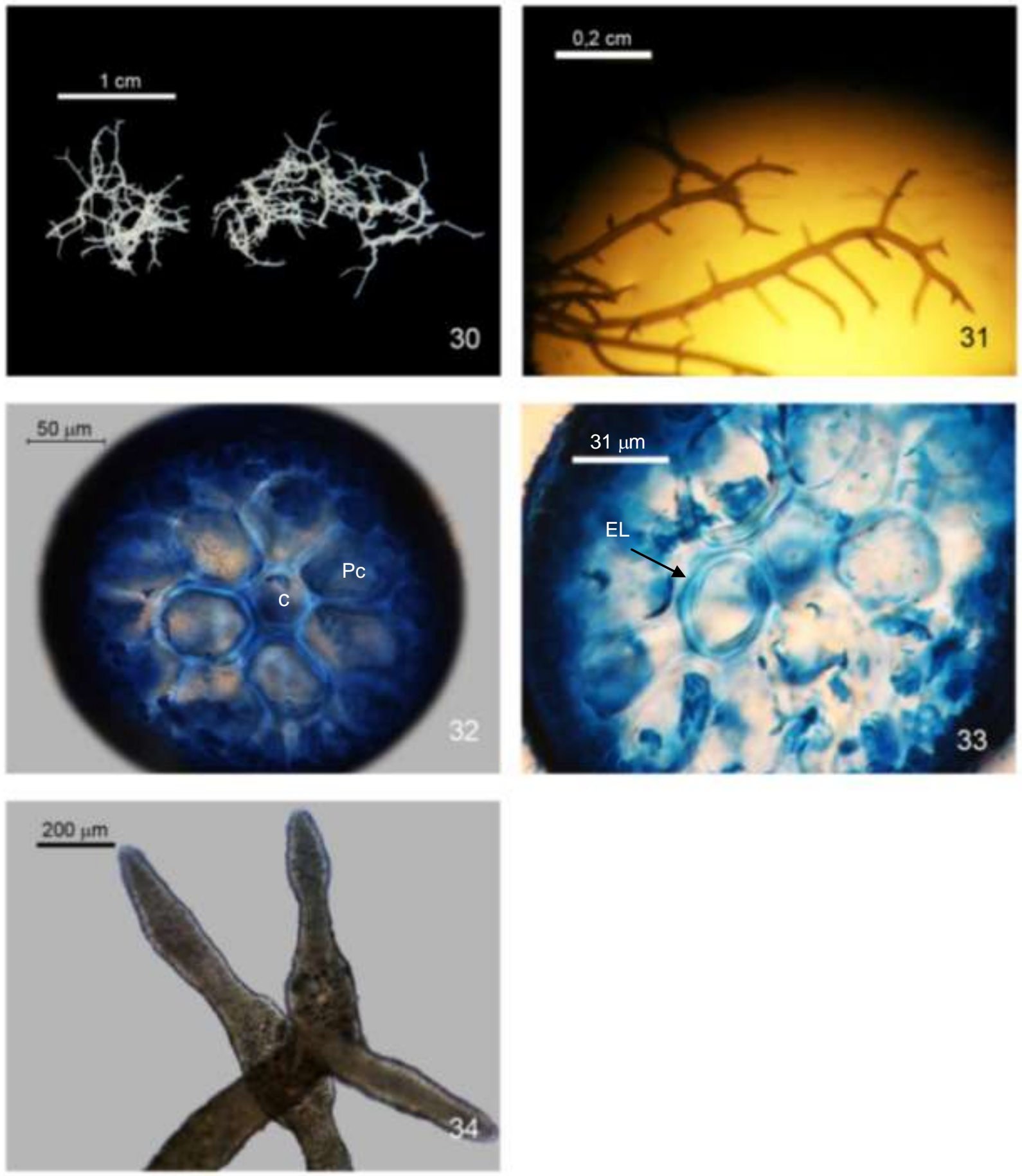

Figuras 30 - 34. Hypnea sp. 1. Figura 30. Aspecto geral do talo. Figura 31. Detalhe das ramificações e ápices. Figuras 32. Corte transversal da região subapical do talo mostrando células central $(C)$ e pericentral $(P c)$. Figura 33. Detalhe do espessamento lenticular (EL) no corte transversal. Figura 34. Detalhe do râmulo com tetrasporângios. 


\section{6- Hypnea sp. 2}

Figs. 35-39

Plantas formando emaranhado de ramos de coloração avermelhada medindo $6 \mathrm{~cm}$ de altura. Eixo principal distinguível, cilíndrico, de consistência carnosa apresentando ápice reto sem ganchos ou gavinhas (Figura 35). Ramificação irregular, com predominância de ramificações opostas em ângulo agudo ou reto, mais densa nas partes mais basais do talo. Ramos de ordem primária com diâmetro visivelmente menor que o eixo principal. Ramos de segunda ordem com diâmetro pouco menor que os de primeira ordem. Râmulos espinescentes presentes (Figura 35). Anastomoses ausentes. Em corte transversal da região subapical, diâmetro do eixo principal medindo, na porção subapical, de 366,1 - 415,7 um (Figura 36). Talo com uma a duas camadas de células corticais de contorno arredondado (ovalado) com diâmetro de 13,5 - 16,1 $\mu \mathrm{m}$ (Figura 36). Células axiais medindo de $(19,7) 33,8-49,9$ um (Figura 37). Cada célula axial 5 - 6 células periaxiais, com diâmetro de $(33,6)$ 50,5 - 116,2 $\mu \mathrm{m}$ (Figura 36-37). Espessamentos lenticulares ausentes. Tetrasporângios localizados na base, envolvendo os râmulos ou em um único lado do râmulo zonados (Figura 38). Plantas femininas e masculinas não foram observadas.

Habitat: As plantas coletadas cresciam em local de costão batido.

Material examinado: São Paulo - São Sebastião: Praia das Cigarras, 27.v.2002, S.M.P.B.Guimarães, planta tetraspórica, SP390803.

\section{Comentários: Descrição da morfologia de espécimes cultivados em laboratório(Figura} 39): Plantas de cor laranja a vermelho-pálido, medindo aproximadamente $3 \mathrm{~cm}$ de altura. Eixo principal distinguível, cilíndrico, com diâmetro maior do que o das ramificações, medindo aproximadamente $300 \mu \mathrm{m}$. Ramificações cilíndricas, inseridas em ângulo agudo ou reto, mais abundantes nas partes mais velhas do talo. Ápices sem ganchos ou gavinhas. Não apresenta anastomoses. Râmulos espinescentes retos ou levemente curvados. 

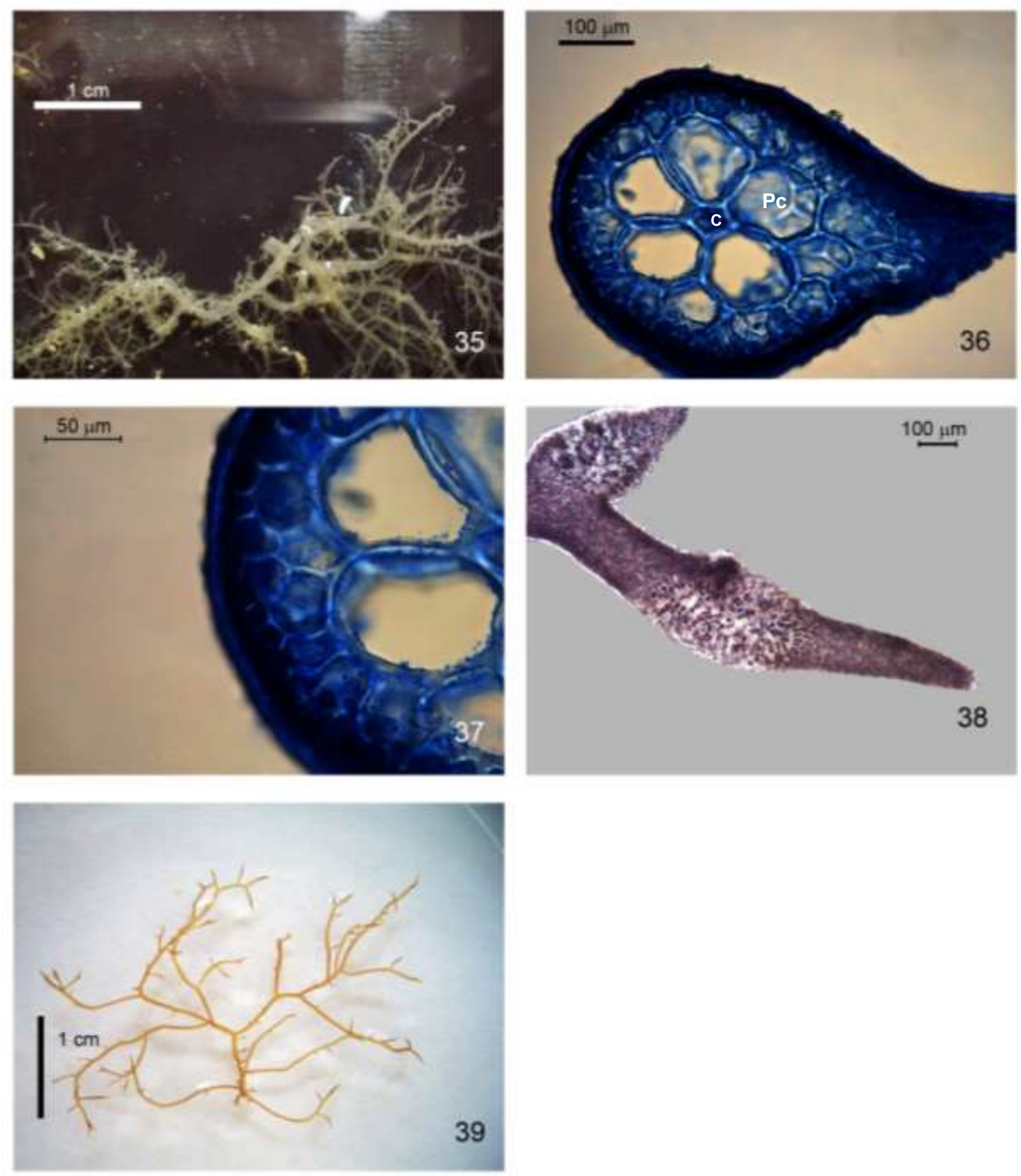

Figuras 35 - 39. Hypnea sp. 2. Figura 35. Aspecto geral do talo. Figura 36. Corte transversal da região subapical do talo com células central $(\mathrm{C})$ e pericentral $(\mathrm{Pc})$. Figura 37. Detalhe das células corticais no corte transversal. Figura 38. Detalhe do râmulo com tetrasporângios. Figura 39. Aspecto geral da planta cultivada em laboratório. 
Tabela 15. Características morfológicas das espécies do gênero Hypnea analisadas neste trabalho.

\begin{tabular}{|c|c|c|c|c|c|c|}
\hline $\begin{array}{l}\text { Característica } \\
\text { morfológica }\end{array}$ & H. cervcornis & H.flexicaulis & H.musciformis & H.spinella & Hypnea sp1 & Hypnea sp2 \\
\hline Tamanho & $1-3 \mathrm{~cm}$ & $5-7 \mathrm{~cm}$ & $3-7 \mathrm{~cm}$ & $2-4 \mathrm{~cm}$ & $1,5-3 \mathrm{~cm}$ & $6 \mathrm{~cm}$ \\
\hline Eixo principal & distinguível & distinguível & distinguível & indistinguível & distinguível & distinguível \\
\hline Cor & $\begin{array}{l}\text { vermelho-rosada a } \\
\text { amarronzada }\end{array}$ & vermelho-enegrecido & $\begin{array}{l}\text { esverdeada /vinho- } \\
\text { enegrecida }\end{array}$ & vermelho-pálida & vermelho- rosado/forte & vermelho \\
\hline Anastomoses & raras & ausentes & ausentes & abundantes & presentes & ausentes \\
\hline Gavinhas & ausentes & raras & presentes & ausentes & ausentes & ausentes \\
\hline Padrão de ramificação & alterno/espiralado & alterno & $\begin{array}{l}\text { irregular- } \\
\text { alterno/espiralado }\end{array}$ & irregular-alterno/oposto & irregular & oposto \\
\hline Ramificações (ângulo) & agudo/reto & agudo & agudo/reto & agudo/reto & agudo/reto & agudo/reto \\
\hline $\begin{array}{l}\text { Diâmetro do eixo } \\
\text { principal/talo }\end{array}$ & $218,9-547,5 \mu \mathrm{m}$ & $(65,4) 457,5-530,4 \mu \mathrm{m}$ & $266,1-622,2 \mu \mathrm{m}$ & $223,7-520,8 \mu \mathrm{m}$ & $181,4-252,7 \mu \mathrm{m}$ & $366,1-415,7 \mu \mathrm{m}$ \\
\hline Célula cortical & $6,2-22,1 \mu \mathrm{m}$ & não oservado & $6,0-14,8 \mu \mathrm{m}$ & $8,6-13,9 \mu \mathrm{m}$ & não observado & $13,5-16,1 \mu \mathrm{m}$ \\
\hline Célula axial & $31,3-49,55 \mu \mathrm{m}$ & $58,2-72,4 \mu \mathrm{m}$ & $42,1-83,3 \mu \mathrm{m}$ & $45,8-78,7 \mu \mathrm{m}$ & $26,5-33,3 \mu \mathrm{m}$ & $(19,7) 33,8-49,9 \mu \mathrm{m}$ \\
\hline № de células periaxiais & $5-6$ & 6 & $5-8$ & 6 & $5-6$ & $5-6$ \\
\hline $\begin{array}{l}\text { Diâmetro células } \\
\text { periaxiais }\end{array}$ & $\begin{array}{c}(33,8) 52,8-72,0(91,1) \\
\mu \mathrm{m}\end{array}$ & $77,4-158,1 \mu \mathrm{m}$ & $20,0-66,9 \mu \mathrm{m}$ & $32,2-102,5 \mu \mathrm{m}$ & $23,3-63,2 \mu \mathrm{m}$ & $(33,6) 50,5-116,2 \mu \mathrm{m}$ \\
\hline $\begin{array}{l}\text { Espessamentos } \\
\text { lenticulares }\end{array}$ & raros & ausentes & ausentes & ausente & abundantes & ausente \\
\hline Tetrasporângio & $307,5-316,7 \mu \mathrm{m}$ & não observados & $580,4-939,8(1166,1) \mu \mathrm{m}$ & $410,7-862,5 \mu \mathrm{m}$ & $196,3-320,3 \mu \mathrm{m}$ & $237,7-655,9 \mu \mathrm{m}$ \\
\hline $\begin{array}{c}\text { Posição do } \\
\text { tetrasporângio }\end{array}$ & $\begin{array}{l}\text { envolvendo a base dos } \\
\text { râmulos }\end{array}$ & não oservado & $\begin{array}{l}\text { envolvendo a base dos } \\
\text { râmulos }\end{array}$ & $\begin{array}{l}\text { envolvendo a base dos } \\
\text { râmulos }\end{array}$ & $\begin{array}{l}\text { parte mediana dos } \\
\text { râmulos }\end{array}$ & $\begin{array}{l}\text { envolvendo a base dos } \\
\text { râmulos }\end{array}$ \\
\hline Cistocarpo & não observados & não observado & $456,0-537,7 \mu \mathrm{m}$ & não observado & não observado & não observado \\
\hline
\end{tabular}


As amostras analisadas formaram seis agrupamentos baseados nos três marcadores moleculares e na análise da morfologia sendo denominadas de: Hypnea cervicornis. J. Agardh, Hypnea flexicaulis, Hypnea musciformis (Wulfen) J.V. Lamour, H. spinella (C. Agardh) Kutz, Hypnea sp.1 e Hypnea sp.2 (Tabela 16).

Tabela 16. Amostras identificadas pelo número de projeto (№Rhodo-SP), indicando local de coleta e número do voucher depositado nos herbários SP ou SPF. ** indicam voucher não localizados.

\begin{tabular}{|c|c|c|c|}
\hline RHODO-SP & Espécie & Local de Coleta & Número de acesso \\
\hline ВОТ0001 & Hypnea musciformis & Espírito Santo & SP365646 \\
\hline ВОT0002 & Hypnea musciformis & Espírito Santo & SP365645 \\
\hline ВОT0003 & Hypnea sp.2 & São Sebastião,SP & SP 390803 \\
\hline ВОТ0004 & Hypnea cervicornis & Ubatuba,SP & SP 390804 \\
\hline ВОТ0005 & Hypnea musciformis & Ubatuba,SP & SP 365557 \\
\hline IBC0028 & Hypnea cervicornis & Ubatuba,SP & SPF56877 \\
\hline IBC0040 & Hypnea musciformis & Ubatuba,SP & SPF56878 \\
\hline IBC0041 & Hypnea spinella & Ubatuba,SP & SPF56879 \\
\hline IBC0051 & Hypnea cervicornis & Ubatuba,SP & SPF56880 \\
\hline IBC0064 & Hypnea cervicornis & Ubatuba,SP & SPF56881 \\
\hline IBC0067 & Hypnea musciformis & Ubatuba,SP & SPF56882 \\
\hline IBC0089 & Hypnea musciformis & Ubatuba, SP & SPF57008 \\
\hline IBC0098 & Hypnea musciformis & São Sebastião, SP & SPF56883 \\
\hline IBC0123 & Hypnea musciformis & São Sebastião, SP & SPF57009 \\
\hline IBC0129 & Hypnea spinella & São Sebastião,SP & SPF56884 \\
\hline IBC0137 & Hypnea musciformis & São Sebastião,SP & SPF56888 \\
\hline IBC0138 & Hypnea musciformis & São Sebastião,SP & SPF56886 \\
\hline IBC0139 & Hypnea cervicornis & Ubatuba,SP & SPF56887 \\
\hline IBC0184 & Hypnea spinella & Ubatuba,SP & SPF57011 \\
\hline IBC0185 & Hypnea musciformis & Ubatuba,SP & SPF57012 \\
\hline IBC0186 & Hypnea cervicornis & Ubatuba,SP & SPF56889 \\
\hline IBC0187 & Hypnea musciformis & Itanhaém,SP & SPF56890 \\
\hline IBC0188 & Hypnea musciformis & Itanhaém,SP & SPF56891 \\
\hline IBC0189 & Hypnea musciformis & Paraty, RJ & SPF56539 \\
\hline IBC0190 & Hypnea flexicaulis & Paraty, RJ & SPF56540 \\
\hline IBC0194 & Hypnea cervicornis & Ubatuba, SP & SPF57029 \\
\hline IBC0195 & Hypnea cervicornis & Ubatuba, SP & SPF57030 \\
\hline IBC0196 & Hypnea musciformis & Ubatuba, SP & SPF57031 \\
\hline IBC0197 & Hypnea cervicornis & Ubatuba, SP & SPF57032 \\
\hline IBC0198 & Hypnea spinella & Ubatuba, SP & ** \\
\hline IBC0199 & Hypnea musciformis & Ubatuba, SP & SPF57033 \\
\hline IBC0200 & Hypnea cervicornis & Ubatuba, SP & SPF57034 \\
\hline IBC0201 & Hypnea cervicornis & Ubatuba, SP & SPF57035 \\
\hline IBC0202 & Hypnea musciformis & Ubatuba, SP & SPF57036 \\
\hline IBC0203 & Hypnea spinella & Ubatuba, SP & SPF57037 \\
\hline
\end{tabular}


Tabela 16. Continuação.

\begin{tabular}{cccc}
\hline RHODO-SP & Espécie & Local de Coleta & Número de acesso \\
\hline IBC0204 & Hypnea cervicornis & Ubatuba, SP & SPF57038 \\
IBC0205 & Hypnea cervicornis & Ubatuba, SP & $* *$ \\
IBC0206 & Hypnea sp. & Ubatuba, SP & SPF57039 \\
IBC0210 & Hypnea cervicornis & Ubatuba, SP & SPF57043 \\
IBC0211 & Hypnea sp.1 & Ubatuba, SP & SPF57044 \\
IBC0212 & Hypnea sp.1 & Ubatuba, SP & SPF57045 \\
IBC0213 & Hypnea cervicornis & Ubatuba, SP & SPF57046 \\
IBC0214 & Hypnea cervicornis & Ubatuba, SP & SPF57047 \\
IBC0216 & Hypnea cervicornis & Ubatuba, SP & SPF57049 \\
IBC0217 & Hypnea cervicornis & Ubatuba, SP & SPF57050 \\
IBC242 & Hypnea cervicornis & Ubatuba, SP & SPF57051 \\
IBC243 & Hypnea musciformis & Itanhaém, SP & SPF57052 \\
IBC244 & Hypnea musciformis & Cananéia, SP & SPF57053 \\
IBC0245 & Hypnea cervicornis & Cananéia, SP & SPF57139 \\
IBC0246 & Hypnea cervicornis & Cananéia, SP & SPF57140 \\
IBC0247 & Hypnea cervicornis & Cananéia, SP & SPF57141 \\
IBC0248 & Hypnea cervicornis & Cananéia, SP & SPF57142 \\
IBC0249 & Hypnea cervicornis & Cananéia, SP & SPF57143 \\
IBC0250 & Hypnea cervicornis & Cananéia, SP & SPF57144 \\
IBC0251 & Hypnea cervicornis & Cananéia, SP & SPF57145 \\
IBC0252 & Hypnea cervicornis & Itanhaém, SP & SPF57146 \\
\hline
\end{tabular}

\section{5- Discussão}

\section{1- Marcadores Moleculares e Filogenia}

Baseando-se nas análises moleculares e morfológicas, indicamos a existência de cinco espécies do gênero Hypnea para o estado de São Paulo: $H$. cervicornis, $H$. musciformis, H. spinella, Hypnea sp.1, Hypnea sp.2. Uma sexta espécie, H. flexicaulis, foi coletada no litoral sul do Rio de Janeiro.

Nas análises realizadas os três marcadores, cox1, UPA e rbcL, confirmaram a separação das seis espécies. Os marcadores cox1 e UPA, respectivamente dos genomas mitocondrial e do cloroplasto, se mostraram eficientes na separação das espécies do gênero Hypnea, corroborando com outros trabalhos que utilizam esses marcadores como "DNA barcodes" (Geraldino et al. 2006, 2009 e 2010; Sherwood et al. 2010). 
A divergência interespecífica do marcador cox1, para as amostras deste estudo, apresentou valores próximos aos encontrados para o gênero em outros locais (Geraldino et al. 2009, 2010). Porém, divergência mínima de 10,1\% foi superior ao valor proposto por Saunders (2005) de 4,5\% (Tabela 17) para as Rhodophyta de forma geral, justificando a separação das seis entidades taxonômicas em espécies diferentes. Os valores observados neste trabalho encontram-se mais próximos dos valores descritos por Geraldino et al. 2009 para espécies de Hypnea da Ásia.

A variação intraespecífica do marcador cox1, para as amostras deste estudo está próximo aos valores observados em estudos com Hypnea para outras regiões. Ainda que seu valor máximo seja menor que o observado nesses estudos, ele está bem próximo aos valores observados nos estudos com Rhodophyta (Tabela 17).

Os resultados indicam que a discriminação a nível específico é possível com a utilização do marcador cox1, corroborando os resultados de Saunders (2005) e dos estudos realizados com o gênero Hypnea (Yamagishi \& Masuda 2000, Yamagshi et al. 2003; Geraldino et al. 2006, 2009 e 2010). As divergências observadas para o marcador cox1 neste estudo, em relação aos outros marcadores utilizados mostrou-se mais alto, o que indica uma maior capacidade de distinção das espécies proximamente relacionadas. A amplificação do cox1 para as amostras de Hypnea nesse estudo foi relativamente fácil utilizando os "primers" e protocolos propostos por Saunders (2005); o mesmo foi observado para o sequenciamento. M.C. Oliveira (comunicação pessoal) afirma que para outros gêneros de Rhodophyta tem sido observada alguma dificuldade na amplificação e sequenciamento do marcador cox1.

A divergência interespecífica observada para o marcador UPA entre as amostras deste estudo possui um valor dentro do observado por Clarkston \& Saunders (2010) (Tabela 17). A divergência intraespecífica do marcador UPA (obtida apenas para as amostras de $H$. cervicornis e $H$. musciformis) entre as amostras do estado de São Paulo também são próximas aos valores apresentados por Clarkston \& Saunders (2010) (Tabela17).

O marcador UPA tem sido testado apenas mais recentemente para o "DNA barcoding" por isso ainda não possui muitas sequencias disponíveis no banco de dados (GenBank). Entretanto, Sherwood et al. (2010) e Clarkston \& Saunders (2010) usaram esse marcador com sucesso para separação de espécies de Rhodophyta do Havaí e do gênero Kallymeniaceae do Canadá, respectivamente. Sendo assim, as sequências do gênero Hypnea de Sherwood et al. (2010), disponíveis no banco de dados, foram utilizadas para a análise de NJ do marcador UPA no presente estudo. Nas árvores apresentadas, percebe-se uma discrepância entre os dados das espécies do Havaí e das amostras de São Paulo. As amostras do estado de São Paulo que 
possuíam mais de uma sequência na análise ficaram agrupadas num mesmo clado, corroborando sua identidade e sua separação taxonômica em relação aos outros grupos. Porém, as amostras do Havaí representantes de uma mesma espécie aparecem distribuídas em diferentes clados (i.e. H. musciformis e $H$. valentiae). Segundo A. Sherwood (comunicação pessoal) a identificação das espécies de Hypnea no Havaí é bastante problemática, e nem todas as amostras que constam do banco de sequências tiveram a sua morfologia detalhada. Ainda, segundo a pesquisadora, os nomes utilizados para as amostras do Havaí são provisórios. No caso das amostras brasileiras, o marcador UPA mostrou eficácia na separação se espécies para o gênero Hypnea, corroborando com os outros marcadores utilizados.

Sherwood et al. (2010) afirmam que o marcador UPA deve ser considerado para futuros levantamentos de biodiversidade de algas pela capacidade observada na resolução de problemas taxonômicos. Clarkston \& Saunders (2010) afirmam que o marcador UPA pode apresentar baixa capacidade na separação de espécies proximamente relacionadas, subestimando a diversidade, sendo assim necessários mais estudos para seu uso como "DNA barcode". Embora o UPA tenha sido aplicado com sucesso na separação das espécies de Hypnea analisadas neste trabalho, acreditamos que mais estudos devem ser realizados com este marcador, a fim de estabelecer sua eficácia para os diferentes gêneros de Rhodophyta, assim como estabelecer seus limites de confiança (variações intra e interespecíficas).

As análises de rbcL neste trabalho, assim como em estudos mais recentes com o gênero (Yamagishi \& Masuda 2000, Yamagishi et al. 2003, Geraldino et al. 2006, Geraldino et al. 2009 e Geraldino et al. 2010), mostraram-se robustas para a abordagem das relações filogenéticas entre as espécies de Hypnea.

A variação interespecífica observada para o marcador $r b c \mathrm{~L}$, comparando as amostras sequenciadas neste estudo tem valor máximo próximo aos resultados apresentados em outros estudos (Tabela 17) sendo mais próximos aos de Yamagishi \& Masuda 2000 e Geraldino et al. 2009, que estudaram respectivamente, amostras de $H$. charoides do Japão e $H$. asiatica da Coréia, Japão e Taiwan. O valor mínimo encontrado entre as amostras brasileiras foi de $3,2 \%$, o que corrobora a existência de pelo menos seis espécies de Hypnea na costa brasileira. Comparando-se as sequências de rbcL das espécies brasileiras com as de outras espécies de Hypnea disponíveis no GenBank o valor mínimo de divergência interespecífica é observado entre as espécies asiáticas $H$. japônica, $H$. boergesenii, $H$. nidulans e $H$. pannosa que é de $0,2 \%$ para esse marcador, o que indica a necessidade de revisão nesses táxons. 
A divergência intraespecífica para o marcador $r b c \mathrm{~L}$, considerando apenas as amostras sequenciadas neste trabalho, apresentou valores dentro do observado em outros estudos com o gênero Hypnea em outras regiões do mundo (Tabela 17).

Tabela 17. Comparação entre divergências inter e intraespecíficas com espécies do gênero Hypnea e para Rhodophyta em geral. Sublinhados os valores obtidos utilizando somente as amostras deste estudo.

\begin{tabular}{|c|c|c|c|c|c|c|c|}
\hline & \multirow[t]{2}{*}{ Referência } & \multicolumn{3}{|c|}{$\begin{array}{c}\text { Divergência } \\
\text { Interespecífica }\end{array}$} & \multicolumn{3}{|c|}{$\begin{array}{c}\text { Divergência } \\
\text { Intraespecífica }\end{array}$} \\
\hline & & $r b c L$ & $\operatorname{cox} 1$ & UPA & $r b c L$ & $\operatorname{cox} 1$ & UPA \\
\hline \multirow{5}{*}{ Hypnea } & $\begin{array}{l}\text { Yamagishi \& } \\
\text { Masuda } 2000\end{array}$ & $\begin{array}{c}71-88 p b \\
(5,3-6,6 \%)\end{array}$ & * & * & * & * & * \\
\hline & $\begin{array}{l}\text { Yamagishi et } \\
\text { al } 2003\end{array}$ & $\begin{array}{c}16-96 \mathrm{pb} \\
(1,2-7,2 \%)\end{array}$ & * & * & $\begin{array}{c}0-3 p b \\
(0-0,2 \%)\end{array}$ & * & * \\
\hline & $\begin{array}{l}\text { Geraldino et al } \\
2006\end{array}$ & * & * & * & $\begin{array}{c}1-5 p b \\
(0,06-0,33 \%)\end{array}$ & $\begin{array}{c}1-34 \mathrm{pb} \\
(7,2-24,47 \%)\end{array}$ & * \\
\hline & $\begin{array}{l}\text { Geraldino et al } \\
2009\end{array}$ & $\begin{array}{c}58-96 b p \\
(4,2-7 \%)\end{array}$ & $\begin{array}{c}157-165 \mathrm{pb} \\
(11,53-12,12 \%)\end{array}$ & * & $5 \mathrm{pb}(0,37 \%)$ & $28 \mathrm{pb}(2,06 \%)$ & * \\
\hline & $\begin{array}{l}\text { Geraldino et al } \\
2010\end{array}$ & $\begin{array}{c}18-93 p b \\
(1,3-6,8 \%)\end{array}$ & $\begin{array}{c}50-162 \mathrm{pb} \\
(4-13 \%)\end{array}$ & * & $\begin{array}{c}2-8 p b \\
(0,1-0,5 \%)\end{array}$ & $\begin{array}{c}8-59 p b \\
(0,6-4,7 \%)\end{array}$ & * \\
\hline Hypnea & Este trabalho & $\begin{array}{c}3-97 \mathrm{pb} \\
(0,2-7,4 \%) \\
\underline{\mathbf{4 2}-\mathbf{8 8} \mathbf{p b}} \\
\underline{(3,2-6,7 \%)}\end{array}$ & $\begin{array}{c}0-74 \mathrm{pb} \\
(0-36,5 \%) \\
\\
\underline{\mathbf{6 2 - 1 0 0} \mathbf{p b}} \\
\mathbf{1 0 , 1 - 1 6 , 3 \% )} \\
\end{array}$ & $\frac{9-16 \mathrm{pb}}{(2,5-4,4 \%)}$ & $\frac{0-6 \mathrm{pb}}{(0-0,5 \%)}$ & $\frac{0-5 \mathrm{pb}}{(0-0,9 \%)}$ & $\frac{0-6,5 \mathrm{pb}}{(0-0,3 \%)}$ \\
\hline \multirow{4}{*}{ Rhodophyta } & $\begin{array}{l}\text { Saunders } \\
(2005)\end{array}$ & * & $\begin{array}{l}>30 p b \\
(>4,5 \%)\end{array}$ & * & * & $\begin{array}{c}0-2 \mathrm{pb} \\
(0-0,3 \%)\end{array}$ & * \\
\hline & $\begin{array}{l}\text { Sherwood et } \\
\text { al.(2010) }\end{array}$ & * & * & * & * & $\begin{array}{c}\sim 3,5 \mathrm{pb} \\
(0-0,5 \%)\end{array}$ & $\begin{array}{l}\sim 2,1 \mathrm{pb} \\
(0-0,3 \%)\end{array}$ \\
\hline & $\begin{array}{c}\text { Clarkston \& } \\
\text { Saunders } \\
(2010)\end{array}$ & & $\begin{array}{c}29,8 \mathrm{pb} \\
(>4.5 \%)\end{array}$ & $\begin{array}{c}2,9-23 \mathrm{pb} \\
(0.8-6.2 \% .)\end{array}$ & * & $\begin{array}{l}0-5,9 \mathrm{pb} \\
(0-0.9 \%)\end{array}$ & $\begin{array}{c}0-1,0 \mathrm{pb} \\
(0-0,27 \%)\end{array}$ \\
\hline & Robba (2006) & * & $\begin{array}{c}28-48 p b \\
(5,2-27,7 \%)\end{array}$ & * & * & $\begin{array}{c}0-4 p b \\
(0-0,7 \%)\end{array}$ & * \\
\hline
\end{tabular}

* indica dados não apresentados nas referências.

As análises filogenéticas para as sequências de $r b c L$ mostram que os espécimes brasileiros estão espalhados nos ramos principais e tem como grupos mais proximamente relacionados espécimes da região Pacífica. Uma análise incluindo outras amostras de Hypnea para a região do Atlântico poderá esclarecer melhor a origem e distribuição das diferentes espécies.

\section{2- Hypnea cervicornis X Hypnea spinella}

Shenckman (1986) citou para o Estado de São Paulo seis espécies (Tabela 3), sendo duas delas $H$. cervicornis e $H$. spinella. A autora fala da dificuldade da separação dessas duas espécies em relação aos caracteres morfológicos e 
apresentou resultados de cultura onde $H$. cervicornis cresce com talo muito semelhante à $H$. spinella, porém com sutis diferenças em relação às ramificações. $A$ autora citou ainda o fato de que a observação dos materiais tipo ( $\mathrm{Hb}$. Ag.) não foi muito esclarecedora, porque os tipos encontravam-se mal herborizados e não traziam informações sobre local de coleta e coletor.

Muitos autores, também citados por Schenkman (1986), apontavam a possibilidade de estas espécies serem morfotipos da mesma espécie, sendo um presente em ambientes mais protegidos ( $H$. cervicornis) e outros em locais de maior ação das ondas ( $H$. spinella); ou ainda uma terceira espécie, podendo ser esta $H$. divaricata ou $H$. cenomyce. No entanto, Schenkman (1986) concluiu que a separação das espécies deveria ser mantida até que todas as possiblidades de sinonímia fossem avaliadas detalhadamente.

Haroun \& Prud'Homme van Reine (1993) sugerem, como já citado, a junção de $H$. cervicornis e $H$. spinella afirmando que espécimes de morfologia intermediária haviam sido observados. A partir deste trabalho muito autores têm adotado essa sinonímia (Yamagishi 2000, Geraldino et al. 2006, Lucio 2009),

As amostras coletadas em diferentes pontos do litoral do estado de São Paulo nomeadas previamente, baseado na morfologia, como $H$. cervicornis ou $H$. spinella formaram, segundo as análises do marcador cox1, dois grupos diferentes. Essas análises do marcador cox1, confirmadas pelos marcadores UPA e $r b c \mathrm{~L}$, mostram que se tratam de duas espécies diferentes e não proximamente relacionadas conforme a análise do $r b c L$.

Após a observação detalhada de suas morfologias, comprando-as com literaturas e descrições originais das espécies, os dois grupos foram nomeados $H$. cervicornis e $H$. spinella, corroborando com Abbot (1999) e Guimarães (2006). Sendo que $H$. spinella apresenta talo em forma de tapete emaranhado, sem um eixo principal distinto, com anastomoses abundantes, enquanto $H$. cervicornis apresenta um eixo principal distinto e ramificações levemente curvadas em relação ao ramo principal e anastomoses raras ou ausentes. Nenhum espécime intermediário foi encontrado e pudemos observar a presença de $H$. cervicornis em ambientes de maior ação de ondas e em locais mais protegidos.

Na comparação com as sequências disponíveis de rbcL no banco de dados, $H$. spinella de São Paulo não correspondeu ao espécime nomeado no banco como $H$. spinella, proveniente do Japão, sendo que a amostra brasileira foi mais proximamente relacionada com Hypnea sp. IzuH1 e Hypnea valentiae (97\% de identidade). O mesmo aconteceu com as sequências de $\operatorname{cox} 1$ e UPA de $H$. spinella, todas da região do Oceano Pacífico. 
A localidade tipo de H. spinella, referida como "India Occidentalis", é vaga e não indica a região específica do local onde foi coletada. O termo é normalmente associado à região do Caribe, logo sugerimos que o nosso espécime designado de $H$. spinella estaria mais próximo da localidade tipo do que as demais amostras do Japão. Além disso, sugerimos que um estudo detalhado dos documentos e espécimes de herbários referentes à localidade tipo deva ser realizado, a fim de estabelecer corretamente esta localidade.

Para $H$. cervicornis não existiam sequências nos bancos de dados para $r b c L$, apenas para cox1 e UPA, ambas para o Havaí, e que não se agruparam com as $H$. cervicornis coletadas no Brasil.A localidade tipo de $H$. cervicornis é desconhecida. Alguns autores citam que a probabilidade de que essa localidade seja llhas Maurício, mas não existem comprovações em relação a isso.

\section{3- Hypnea musciformis X Hypnea nigrescens}

Outra espécie controversa, citada por Schenkman (1986) foi $H$. nigrescens, que no referido trabalho teve sua primeira citação para o Brasil e para o Oceano Atlântico. No Estado de São Paulo, Schenkman (1986) cita espécimes coletados em Peruíbe, Itanhaém, Ilha do Cardoso e Ubatuba. No presente estudo somente em Itanhaém foram encontrados espécimes que correspondiam à morfologia citada por Schenkman como H. nigrescens. Estas amostras (SPF56891), provenientes da Praia dos Sonhos, segundo as análises moleculares de cox1 e rbcL foram identificadas como $H$. musciformis. Apesar de não apresentar a morfologia externa típica dos outros espécimes de $H$. musciformis (cor esverdeada, epífita e com gavinhas abundantes) (Fig.18 e 19), em corte transversal, essas amostras possuem a mesma anatomia de $H$. musciformis. Além disso, em alguns dos espécimes coletados, foram observadas algumas gavinhas que são tipicamente encontradas em $H$. musciformis. Estes espécimes com morfologia do tipo "nigrescens" foram encontrados em um habitat onde existe grande impacto das ondas e da maré, fixo à rocha por apressórios resistentes e expostos à grande radiação solar. Após a análise morfológica e molecular, concluímos que a amostras identificadas como $H$. nigrescens para o estado de São Paulo são uma variação morfológica de H.musciformis. Segundo o Algaebase, $H$. nigrescens ocorre somente na região da Índia.

Em relação a $H$. musciformis, em nossas análises com os três marcadores, os espécimes de $H$. musciformis coletados no Brasil aparecem como grupo irmão de $H$. musciformis de outras regiões, incluindo amostras do Pacífico (Havaí) e do Atlântico 
Norte. A divergência encontrada entre as sequências brasileiras de $H$. musciformis e as sequências de outras regiões $(0,1$ - 1,9 \% para o rbcL do Atlântico Norte; 1,4 1,7\% para o UPA; e 4,3 - 4,6\% para o cox1) pode indicar que essa espécie é na verdade um complexo, que necessita maiores estudos avaliando sua variação intraespecífica.

\section{4- Hypnea flexicaulis}

H.flexicaulis foi descrita como uma espécie nova por Yamagish \& Masuda (2000) em estudo com espécimes de Hypnea do complexo charoides-valentiae no Japão. Yamagishi \& Masuda (2000) afirmam que a alga por eles coletada teria morfologia semelhante à alga que chamavam de H.cervicornis no Japão. Porém, adotando a sinonímia proposta por Haroun \& Prud'homme van Reine (1993) e afirmando que a nova espécie também não se encaixava na descrição original de Hypnea spinella C. Agardh (1822) nem de H.cervicornis J. Agardh (1852), Yamagishi \& Masuda (2000) determinaram, assim, uma nova espécie, Hypnea flexicaulis.

O espécime coletado no município de Paraty (SPF56540), Rio de Janeiro (Brasil) foi separado das demais amostras coletadas para o Estado de São Paulo pelas sequências de cox1 e UPA. O marcador rbcL corroborou este resultado e, na comparação com o banco de dados, este espécime obteve alta identidade (99\%) com três espécies de ocorrência na Ásia: Hypnea boergesenii, Hypnea flexicaulis e Hypnea japonica. Após um estudo mais detalhado de sua morfologia, observamos que o aspecto geral do espécime coletado diferia de $H$. boergesenii (Masuda 1997) pelo aspecto do talo e disposição dos ramos. Ainda, em corte transversal, nossa amostra não apresentou espessamentos lenticulares como $H$. boergesenii. Em relação à $H$. japonica a morfologia externa também diferia pelo fato de nosso espécime possuir eixo central distinguível, contrário à espécie $H$. japonica; em relação ao corte transversal do eixo central, a conformação de suas células diferiam das de $H$. japonica, onde células centrais e pericentrais possuem espessamentos lenticulares e são distribuídas de forma descentralizada, não podendo ser distinguidas. Após a corroboração da semelhança morfoanatômica entre o espécime estudado e $H$. flexicaulis descrita por Yamagish \& Masuda (2000) o nome atribuído a este espécime foi $H$. flexicaulis; sendo assim a primeira citação dessa espécie para a região do Oceano Atlântico, assim como para o Brasil.

$\mathrm{Na}$ filogenia a partir do marcador $r b c \mathrm{~L}, H$. flexicaulis do Japão e Filipinas apresentaram uma divergência de 3 a 12 pb (0,2 - 0,9\%) em relação à $H$. flexicaulis 
de Paraty ( RJ). Essa divergência é relativamente baixa corroborando a identificação específica pela morfologia. Na análise filogenética para o rbcL (Figura 5) o exemplar sequenciado por nós é o único para a região do Atlântico, sendo todos os demais de ocorrência no Pacífico. A ocorrência desta espécie no Brasil precisa ser melhor investigada para uma avaliação da possibilidade de que seja uma alga introduzida no país a partir da Ásia.

\section{5- Hypnea sp.1 e Hypnea sp.2}

Os dois espécimes (SPF57044 e SPF57045) identificados como Hypnea sp.1 foram coletados no litoral norte do estado de São Paulo, ambos em Ubatuba. Suas sequências determinadas pelo marcador cox1, se mostraram diferentes das outras espécies e este resultado foi corroborado pelos marcadores rbcL e UPA. Na comparação com o banco de dados suas sequências não apresentaram uma afinidade próxima com nenhuma das sequências disponíveis. Os estudos morfoanatômicos dos espécimes coletados mostraram uma grande semelhança destes com Hypnea cenomyce J.Agardh (1851). Esta espécie, H. cenomyce, foi citada para o Brasil por Yoneshigue (1985), Nunes (2005) e Guimarães (2006), respectivamente, para os estados do Rio de Janeiro, Bahia e Espírito Santo. Apesar das semelhanças, não podemos afirmar que as amostras de Hypnea sp.1 sejam, de fato, Hypnea cenomyce, devido ao limitado número de amostras e locais de coleta e à falta de confirmação com o as sequências disponíveis no banco de dados.

O espécime Hypnea sp.2 também possui apenas uma amostra (SP390803), mantida em cultura no Instituto de Botânica. Os espécimes coletados na natureza que deram origem à cultura, mantidos em formol, foram avaliados morfologicamente, mas sua identificação não pôde ser confirmada.

Uma vez que, temos disponíveis poucos exemplares destas duas espécies, achamos necessário obter e estudar mais materiais, afim de que estudos morfológicos e moleculares mais completos possam ser realizados e as espécies descritas. 


\section{6- Conclusão}

Schenkman (1986) aponta a presença de seis espécies para o Estado de São Paulo: $H$. cervicornis, $H$. cornuta, $H$. nigrescens, $H$. musciformis, $H$. spinella e $H$. valentiae (Tabela 4). Das espécies citadas por Schenkman (1986) para o estado de São Paulo, não foram coletadas as espécies $H$. valentiae e $H$. cornuta no presente estudo. Estas espécies apresentam morfologias bem definidas e distintas, portanto seriam de fácil identificação dentre as amostras coletadas. No presente estudo, os espécimes identificados como $H$. nigrescens pelas suas características morfológicas apresentaram sequências idênticas a $H$. musciformis, indicando que $H$. nigrescens não ocorre no estado de São Paulo. Estudos detalhados da morfologia e dos dados moleculares de $H$. nigrescens provenientes de outros estados do litoral brasileiro são necessários para confirmar a existência desta entidade taxonômica no Brasil. As espécies de $H$. cervicornis e $H$. spinella não devem ser colocadas em sinonímia uma vez que suas características morfológicas e as diferenças nas sequências obtidas através dos três marcadores utilizados mostram que são duas espécies distintas. Citamos pela primeira vez a ocorrência da espécie Hypnea flexicaulis para o Oceano Atlântico. Por fim nossos dados apontam ainda para a existência de duas outras espécies de Hypnea ainda não identificadas. Os nossos resultados e os de Schenkman (1986) apontam, portanto, para a ocorrência de pelo menos sete espécies de Hypnea para o estado de São Paulo: $H$. cervicornis, $H$. cornuta, $H$. musciformis, $H$. spinella, H. valentiae, Hypnea sp.1 e Hypnea sp.2.

O gênero Hypnea possui uma plasticidade fenotípica muito grande e sua identificação através dos caracteres morfológicos vegetativos é, de fato, bastante problemática. Ainda mais quando somada às dúvidas apresentadas na literatura em relação ao local de coleta e descrição original dos tipos para as espécies. A utilização do cox1 como um marcador para a separação das espécies do gênero ("DNA barcoding") juntamente com as observações morfológicas é uma ferramenta poderosa que deve ser utilizada a fim de ajudar nas resoluções taxonômicas para este complexo grupo. Além do cox1, o UPA também se mostrou adequado para a distinção das espécies brasileiras de Hypnea analisadas e também pode ser utilizado como "DNA barcode".

A utilização do marcador rbcL para inferir a filogenia no gênero Hypnea, também mostrou ser uma ferramenta bastante útil e complementar para confirmação da identidade das amostras analisadas. Além de permitir a detecção de alguns complexos específicos que devem ser analisados com maior cobertura geográfica. 
Sugerimos ainda que, revisões regionais minuciosas unindo a taxonomia molecular e morfológica, a fim de estabelecer corretamente as espécies para o gênero Hypnea, seus caracteres morfológicos, assim como suas variações morfológicas e seus limites geográficos, ajudando, dessa forma, a solucionar os problemas de identificação. Por fim, os resultados desse trabalho corroboram que marcadores cox1 e UPA são adequados para a separação a nível específico e que essa abordagem é indicada para a resolução dos problemas do gênero Hypnea. 


\section{Referências}

Abbott, I.A., 1999. Marine red algae of the Hawaiian Islands. $x v+477$ pp. Honolulu Museum Press, Honolulu, Hawaii.

Agardh, J.G., 1851. Species genera et ordines algarum... Volumen secundum: algas florideas complectens. Lundae [Lund]. XII+ 1291 pp. part 2, fasc.1, pp. 337-504.

Agardh, J. G. 1852. Algas florideas complectens. Part 2. In Species genera et ordines algarum. Vol. 2. Gleerup, Lund, pp. 337-720.

Altschul S.F., Madden, T.L., Schäffer, A.A., Zhang, J., Zhang, Z., Miller, W. \& Lipman D.J. 1997. Gapped BLAST and PSI-BLAST: a new generation of protein database search programs. Nucleic Acids Research 25:3389-3402.

Bhattacharya, D. \& Medlin, L. 1995. The phylogeny of plastids: a review based on comparisons of small-subunit ribosomal RNA coding regions. J. Phycol. 31:489-98.

Bhattacharya, D., Yoon,H. S. \& Hackett, J. D. 2004. Photosynthetic eukaryotes unite: endosymbiosis connects the dots. BioEssays 26:50-60.

Berchez, F. A.S. \& Oliveira, E.C. 1989. Maricultural essays with the carragenophyte Hypnea musciformis in S.Paulo, Brazil Int.Foudation so science "cultivation of seaweed in Latin America", April 2-8, 1989.

Bravin.I.C. \& Yoneshigue-Valentin, Y. 2002. Influência de fatores ambientais sobre 0 crescimento in vitro de Hypnea musciformis (Wulfen) Lamouroux (Rhodophyta) Revista Brasil. Bot., V.25, n.4, p.469-474, dez. 2002.

Cavalier-Smith, T., 1998. A revised six-Kingdom syste of life. Biological Revews 73: 203-266.

Chase M.W., Salamin N., Wilkinson M., Dunwell, J.M., Kesanakurthi, R.P., Haidar N. \& Savolainen V. 2005. Land plants and DNA barcoding: short-term and long-term goals. Phil. Trans. R. Soc. B 360.

Chiovitti A., Kraft, G.T., Bacic, A., Craik, D.J., Munro, S.L.A., \& Liao, M.-L. 1998. Carrageenans from Australian representa tives of the family Cystocloniaceae (Gigartinales, Rhodophyta), with description of Calliblepharis celatospora sp. nov., and transfer of Austroclonium to the family Areschougiaceae. J. Phycol. 34: 515-535.

Clarkston B.E. \& Saunders G.W. 2010. A comparison of two DNA barcode markers for species discrimination in the red algal family Kallymeniaceae (Gigartinales, lorideophyceae), with a description of Euthora timburtonii sp. nov. Botany 88: 119-131 (2010).

Crichley, A.T. \& Ohno, M. 1998. Seaweed resources of the world. Japan International Cooperation Agency, Nagai, 431 pp. Delwiche, C. F., Kuhsel, M. \& Palmer, J. D. 1995. Phylogenetic analysis of tufA sequences indicates a cyanobacterial origin of all plastids. Mol. Phylogenet. Evol. 4:110-28.

Delwiche, C. E, Kuhsel, M, \& PALMER, J.D. 1995. Phylogenetic analysis of tufA sequences indicates a cyanobacterial origin of all plastids. Mol. Phylogenet. Evol. 4: 110-128.

De Salle, R., Egan, M.G. \& Siddall M. 2005. The unholy trinity: taxonomy, species delimitation, and DNA barcoding. Phil. Trans. R. Soc. B. 360(1462): $1905-1916$

Felsenstein, J. 1985. Confidence limits on phylogenies: an approach using the bootstrap. Evolution, 39: 783-791.

Folmer, O., Black, M., Hoeh, W., Lutz, R. \& Vrijenhoek, R. 1994. DNA "primers"for amplification of mitochondrial cytochrome $c$ oxidase subunit I from diverse metazoan invertebrates. Mol. Mar. Biol. Biotechnol. 3, 294-299.

Fredericq, S., \& Hommersand, M.H. 1989. Proposal of the Gracilariales ord. nov. (Rhodophyta) based on an analysis of the reproductive development of Gracilaria verrucosa. J. Phycol. 25: 213-227. 
Fredericq, S., Hommersand, M.H. \& Freshwater, D.W. 1996. The molecular systematics of some agar- and carrageenan-containing marine red algae based on $r b c L$ sequence analysis. Hydrobiologia 326/327: 125-135.

Fredricq,S. \& Hommersand, M.H. 2003. Biogeography of the marine red algae of the South African West Coast: a molecular approach. Procedings of the XVIIth International Seaweed Symposium. Oxford University Press, pg325-340.

Freshwater D.W., Fredericq S., Butler B.S., Hommersand M.H. \& Chase M.W. 1994. A gene phylogeny of the red algae (Rhodophyta) based on plastid $r b c \mathrm{~L}$. Proceedings of the National Academy of Sciences of the United States of America 91: 7281-7285.

Fujii, M.T., Barata, D., Chiracava, S. \& Guimarães, S.M.P.B. 2008. Anais do $99^{\circ}$ Congresso Nacional de Botânica. Mesa-Redonda 29- Biodiversidade, Conservação e Uso Sustentável das Macroalgas p371.

Garbary D. J. \& P. W. Gabrielson 1990. Taxonomy and evolution. In K. M. Cole and R. G. Sheath [eds.], Biology of the red algae, 477-498. Cambridge University Press, Cambridge, UK.

Geraldino,P.J.L.,Yang, E.C. \& Boo, S.M. 2006. Morphology and Molecular Phylogeny of Hypnea flexicaulis (Gigartinales, Rhodophyta) from Korea Algae Volume 21(4): 417-423.

Geraldino, P.J.L., Yang, E.C, Kim, M.S. \& Boo, S.M. 2009. Systematics of Hypnea asiatica sp. nov. (Hypneaceae, Rhodophyta) based on morphology and nrDNA SSU, plastid rbcL, and mitochondrial cox1. TAXON 58(2). 606-616.

Geraldino, P.J.L., Riosmena-Rodriguez, R., Liao, L.M. \& Boo, S.M. 2010. Phylogenetic relationships within the genus Hypnea (Gigartinales, Rhodophya), with a description of H.caespitosa sp. nov. J. Phycol.46,336-345.

Goff L.J., Moon D.A. \& Coleman A.W. 1994. Molecular delineation of species and species relationship in the red algal agarophytes Gracilariopsis and Gracilaria (Gracilariales). Journal of Phycology 30:521-537.

Graham, L.E. \& Wilcox, L.W., 2009. Algae. Prentice-Hall, New Jersey. 640 pp

Greer, C.W., Shomer, I., Goldstein, M.E., \& Yaphe, W. 1984. Analysis of the carrageenan from Hypnea musciformis by using - and -carrageenases and 13C-n.m.r. spectroscopy. Carbohydr. Res. 129: 189-196.

Guimarães. S.M.P.B. 2006. A revised checklist of benthic Rhodophyta from the State of Espírito Santo, Brazil. - Boletim do Instituto de Botânica № 17: 143 - 194

Hagopian, J.C., Reis, M., Kitajima, J.P., Bhattacharya, D. \& Oliveira, M.C. 2004. Comparative analysis of the complete plastid genome sequence of the red alga Gracilaria tenuistipitata var. liui provides insights on the evolution of rhodoplasts and their relationship to other plastids. Journal of Molecular Evolution 59(4): 464-477.

Hajibabaei, M., Singer, G.A.C., Hebert, P.D.N. \& Hickey, D.A. 2007. DNA barcoding: how it complements taxonomy, molecular phylogenetics and population genetics. TRENDS in Genetics Vol.23 No.4.

Hall, T.A. 1999. BioEdit: a user-friendly biological alignment editor and analysis program for Windows 95/98/NT. Nucl. Acids Symp. Ser. 41: 95-98.

Haroun, R.J. e Prud'Homme van Reine, W.F. 1993. A Biogeographycal study of Laurencia and Hypnea species of the Macaronesian Region. Courier Forsch -Inst. Senckenberg 159:119125.

Harper, J. T. \& Saunders, G. W., 2001. Molecular systematics of the Florideophycieae (Rhodophyta) using nuclear large and small subunit rDNA sequence data. Journal of Phycology 37 (6): 1073-1082. 
Herbert P.D.N., Cywinska A., Ball S.L. \& deWaard J.R. 2003. Biological identifications through DNA barcoding. Proceedings of the Royal Society of London, B, 270: 313-322.

Hommersand,M.H, Fredericq,S. \& Freshwater, D.W. 1994. Phylogenetic systematics and biogeography of the Gigartinaceae (Gigartinales, Rhodophyta) based on sequence analysis of rbcL. Botanica Marina 1994, vol. 37, n 3, pp. 193-203.

Hommersand, M.H. \& Fredericq, S. 2003. Biogeographycal of the marine red algae of the South African West Coast: a molecular approach. Seventeenth International Seaweed Symposium: Proceedings of the Seventeenth International Seaweed Symposium pp 325-336.

Horta P.A., Amancio E., Coimbra C.S. \& Oliveira E.C. 2001. Considerações sobre a distribuição e origem da flora de macroalgas marinhas Brasileiras. Hoehnea 28: 243-265

Huelsenbeck, J.P., \& Ronquist, F.R. 2001. MRBAYES: Bayesian inference of phylogenetic trees. Bioinformatics, 17: 754-755.

Hughey, J. R., Silva, P. C. \& Hommersand, M. H. 2001. olving taxonomic and nomenclatural problems in Pacific Gigartinaceae (Rhodophyta) using DNA from type material. J. Phycol. 37, 1091-1109. (doi:10.1046/j.1529 - 8817.2001.01048.x.)

John, D.M., Prud'homme van Reine, W.F., Lawson, G.W., Kostermans, T.B. \& Price, J.H., 2004. A taxonomic and geographical catalogue of the seaweeds of the western coast of Africa and adjacent islands. Beihefte zur Nova Hedwigia 127: 1-339, 1 fig.

Kraft, G.T. \& Robins, P.A., 1985. Is the Order Cryptonemiales (Rhodophyta) defensible? Phycologia 24: 67-77.

Knowlton, N. \& Weigt, L. A. 1998. New dates and new rates for divergence across the Isthmus of Panama. Proc. R. Soc.Lond. B 265, 2257-2263. (DOI 10.1098/rspb.1998.0568.)

Knutsen, S.H., Murano, E., D’Amato, M., Toffanin, R., Rizzo, R. \& Paoletti, S. 1995. Modified procedures for extraction and analysis of carrageenan applied to the red alga Hypnea musciformis. J. Appl. Phycol. 7: 565-576.

Kützing, F.T. 1849. Species Algarum, Lipsidae [Leipzig]. VI + 922 pp.

Kylin, H. 1930. Über die entwicklungsgeschichte der Florideen. Lunds Univ. Årsskr. N.F. Avd. 2, 24: 1-127.

Kylin, H. 1932. Die Florideenordnung Gigartinales. Lunds Univ. Årsskr. N.F. Avd. 2, 28: 1-88, Plates 1-28.

Kylin, H. 1956. Die Gattungen der Rhodophyceen. C. W. K. Gleerups Förlag, Lund.

Lamouroux, J.V. 1813. Essai sur les genres de la famille des thalassiophytes non articulées. Annales du Muséum d'Histoire Naturelle [Paris] 20:21-47, 115-139, 267-293, pls. 7-13.

Le Gall, L., \& Saunders, G.W. 2007. A nuclear phylogeny of the Florideophyceae (Rhodophyta) inferred from combined EF2, small subunit and large subunit ribosomal DNA: establishing the new red algal subclass Corallinophycidae. Mol. Phylogenet. Evol. 43(3): 11181130. doi:10.1016/j.ympev.2006.11.012. PMID:17197199.

Littler, D.S. \& Littler, M.M., 2000. Caribbean reef plants. An identification guide to the reef plants of the Caribbean, Bahamas, Florida and Gulf of Mexico. Offshore Graphics, Washington. $542 \mathrm{pp}$.

Lucio, A.M. 2006. El género Hypnea Lamouroux (Gigartinales, Rhodophyta) em las costas Del Océano Atlántico. Tese Doctoral. Universidad Complutense de Madrid- Faculdad de Ciencias Biológicas Deparatmento de Biologia Vegetal I.

Maggs, C.A., \& Pueschel, C.M. 1989. Morphology and development of Ahnfeltia plicata (Rhodophyta): proposal of Ahnfeltiales ord. nov. J. Phycol. 25: 333-351.

Maggs C.A., Douglas S.E., Fenety J. \& Bird C. J. 1992. A molecular and morphological analysis of the Gymnogongrus devoniensis (Rhodophyta) complex in the North Atlantic. Journal of Phycology 28: 214-232.

Martins, A. P., Necchi O.J, Colepicolo, P. \& Yokoya. N.S. 2011. Effects of nitrate and phosphate availabilities on growth, photosynthesis and pigment and protein contents in colour strains of Hypnea musciformis (Wulfen in Jacqu.) J.V. Lamour. (Gigartinales, Rhodophyta). 
Revista Brasileira de Farmacognosia Brazilian Journal of Pharmacognosy 21(2): 340-348, Mar./Apr. 2011.

Masuda, M., Yamagishi, Y., Chiang, Y.-M., Lewmanomont, K. \& Xia, B. 1997. Overview of Hypnea (Rhodophyta, Hypneaceae). In Abbott, I. A. (Ed.) Taxonomy of Economic Seaweeds, Vol. 6. California Sea Grant College System, La Jolla, pp. 127-33.

McFadden, G. I. 1999. Plastids and protein targeting. J. Eukar. Microbiol. 46:339-46.

Min-Thein, U. \& Womersley, H.B.S. 1976. Studies on the southern Australia taxa of Solieriaceae, Rhabdoniaceae and Rhodophyllidaceae (Rhodophyta). Aust. J. Bot. 24.

Mshigeni, K. E. 1978a. The biology and ecology of benthic marine algae with special reference to Hypnea (Rhodophyta, Gigartinales). A review of the literature. Bibl. Phycol. 37: 1-168.

Mshigeni, K.E., 1978b. Taxonomic studies on the Hawaiian Hypneaceae with special reference to the genus Hypnea Lamouroux (Rhodophyta). Nova Hedwigia 29: 859-894. Mshigeni, K.E. and D.J. Chapman. 1994. Hypnea (Gigartinales, Rhodophyta). In: (I.katsuka, ed.). Biology of Economic Algae. SPB Academic Publishing bv, The Hague. pp. 245-281.

Mshigeni, K.E. \& Chapman, D.J. 1994. Hypnea (Gigartinales, Rhodophyta). In: (I. Katsuka , ed.). Biology of Economic Algae. SPB Academic Publishing bv, The Hague.245 - 281

Norton T.A, Melkonian M. \& Andersen R.A. 1996. Algal biodiversity. Phycologia 35: 308-326. Nylander, J.A.A. 2004. Bayesian phylogenetics and the evolution of gall wasps. Comprehensive Summaries of Uppsala Dissertations from the Faculty of Science and

Technology, 34p.

Papenfuss, G.F., 1968. A history, catalogue, and bibliography of the Red Sea benthic algae. Israel Journal of Botany 17: 1-118.

Presting, G. G. 2006. Identification of conserved regions in the plastid genome-implications for DNA barcoding and biological function. Can. J. Bot. 84:1434-43.

Pueschel, C.M., \& Cole, K.M. 1982. Rhodophycean pit plugs: an ultrastructural survey with taxonomic implications. Am. J. Bot.69: 703-720.

Ragan M.A., Bird C.J., Rice E.L., Gutell R.R., Murphy C.A. \& Singh R.K. 1994. A molecular phylogeny of the marine red algae (Rhodophyta) based on the nuclear small-subunit rRNA gene. Proceedings of the National Academy of Sciences of the United States of America 91: 7276-80.

Ratnasinghan, S. \& Hebert, P.D.N. 2007. BOLD: The Barcode of Life Data System (www.barcoding oflife.org). Molecular Ecology Notes.

Reis, R. P., Caldeira, A.Q., Miranda, A.N.S., Barros-Barreto, M.B. 2006. Mariculture potential of carragenophyta Hypnea musciformis (Wulfen) J.V. Lamour (Gigartinales - Rhodophyta) on Marambaia Island, Baía de Sepetiba, Rio de Janeiro State, Brazil. Acta Bot. Bras., 763-769.

Robba, L., Russel, S.J., Barker, G.L. \& Brodie, J. 2006. Assessing th use of the mitochondrial cox1 marker for use in DNA barcoding of Red Algae (Rhodophyta) American Journal of Botany 93(8):1101-1108.

Rodri'guez-Ezpeleta, N., Brinkmann, H., Burey, S. C., Roure, B., Burger, G., Loffelhardt, W., Bohnert, H. J., Philippe, H. \& Lang, B. F. 2005. Monophyly of primary photosynthetic eukaryotes: green plants, red algae, and glaucophytes. Curr.Biol. 15:1325-30.

Ross, P. J., Donaldson, S. L. \& Saunders, G. W. 2003. A molecular investigation of Mazzaella (Gigartinales Rhodophyta) morphologically intermediate between Mazzaella linearis and $\mathrm{M}$. splendens. Bot. Mar. 46, 202-213. (doi:10.1515/BOT.2003.020.).

Saito, R.S. \& Oliveira, E.C. 1990. Chemical screening of Brazilian marine algae producing carrageenans. Hydrobiologia 2: 204/205 : 585-588, 1990.

Sambrook, J., Fritsch, E.F. \& Maniatis, T. 1989. Molecular Cloning: A Laboratory Manual, 2nd ed., 3 vol. Cold Spring Harbour Laboratories press, New York. 
Saunders, G.W., Chiovitti, A. \& Kraft, G.T. 2004 Small-subunit rDNA sequences from representatives of selected families of the Gigartinales and Rhodymeniales (Rhodophyta). 3. Delineating the Gigartinales sensu stricto. Can. J. Bot. Vol. 82, 2004

Saunders, G.W., \& Kraft, G.T. 1994. Small-subunit rRNA gene sequences from representatives of selected families of the Gigartinales and Rhodymeniales (Rhodophyta). I. Evidence for the Plocamiales ord. nov. Can. J. Bot. 72: 1250-1263.

Saunders, G.W., \& Kraft, G.T. 1996. Small-subunit rRNA gene sequences from representatives of selected families of the Gigartinales and Rhodymeniales (Rhodophyta). II. Recognition of the Halymeniales ord. nov. Can. J. Bot. 74: 694-707.

Saunders, G.W., \& Kraft, G.T. 2002. Two new Australian species of Predaea (Nemastomataceae, Rhodophyta), with taxonomic recommendations for an emended Nemastomatales and expanded Halymeniales. J. Phycol. 38: 1245-1260.

Saunders, G.W., Chiovitti, A. \& Kraft, G.T. 2004. Small-subunit rDNA sequences from representatives of selected families of the Gigartinales and Rhodymeniales (Rhodophyta). 3.Delineating the Gigartinales sensu stricto. Can. J. Bot. 82: 43-74.

Saunders, G.W \& Hommersand, M.H., 2004. Assessing red algal supraordinal diversity and taxonomy in the context of contemporary sistematic data. American Journal of Botany 91 (10): 1494-1507.

Saunders G.W. 2005. Applying DNA barcoding to red macroalgae: a preliminary appraisal holds promise for future applications. Phil. Trans. R. Soc. B (2005) 360, 1879-1888.

Schenkman, R. P. F. 1980. Biomassa, crescimento, reprodução e ficocolóide de Hypnea musciformis (Rhodophyta) no litoral do Estado de São Paulo. Dissertação de Mestrado, Instituto de Biociências, USP, 73 p.

Schenkman, R.P.F. 1986. Cultura de Hypnea (Rhodophyta) in vitro como subsídio para estudos morfológicos, reprodutivos e taxonômicos. Tese de Doutorado. Instituto de Biociências, Universidade de São Paulo. 81 pp.

Schmitz, F. 1892. [6. Klasse Rhodophyceae] 2. Unterklasse Florideae. In Syllabus der Vorlesungen uber specielle und medicinisch-pharmaceutische Botanik...Grosse Ausgabe. Edited by A. Engler. Gebr. Borntraeger, Berlin. pp. 16-23.

Sherwood, A.R., and Presting, G.G. 2007. Universal "primers"amplify a 23S rDNA plastid marker in eukaryotic algae and cyanobacteria. J. Phycol. 43(3): 605-608. doi:10.1111/j.15298817.

Sherwood, A.R, Kurihara, A., Conklin, K.Y., Sauvage, T. \& Presting, G.G. 2010. The Hawaiian Rhodophyta Biodiversity Survey (2006-2010): a summary of principal findings BMC Plant Biology 2010, 10:258.

Silva, P.C. \& Johansen, H.W. 1986. A reappraisal of the order Corallinales (Rhodophyceae). Br. Phycol. J. 21: 245-254.

Stoeckle M. 2003. Taxonomy, DNA, and the bar code of life. BioScience, 53: 796-797 Swofford, D.L. 2002. PAUP: Phylogenetic Analysis Using Parismony, version 4.08a. Computer program distributed by the Illinois Natural History Survey, Champaign, III.

Tai, V., Lindstrom, S.C. \& Saunders, G.W. 2001. Phylogeny of the Dumontiaceae (Gigartinales, Rhodophyta) and associated families based on small-subunit rDNA and internal transcribed spacer sequence data. J. Phycol. 37: 184-196.

Womersley, H.B.S. 1994. The marine benthic flora of southern Australia. Rhodophyta. Part IIIA, Bangiophyceae and Florideophyceae (Acrochaetiales, Nemaliales, Gelidiales, Hildenbrandiales and Gigartinales sensu lato). Australian Biological Resources Study, Canberra.

Wynne, M. J., 2005. A checklist of benthic marine algae of the tropical and subtropical western Atlantic: second revision. Beiheft Nova Hedwigia 129: 1-152. 
Wynne, M.J. 2011. A checklist of benthic marine algae of the tropical and subtropical western Atlantic: third revision. Nova Hedwigia Beihefte 140: [1-6], 7-166.

Yamagishi, Y \& Masuda, M. 2000. A taxonomic revision of a Hypnea charoides-valentiae complex (Rhodophyta, Gigartinales) in Japan, with a description of Hypnea flexicaulis sp. nov. Phycol. Res.48:27-35.

Yamagishi, Y., Masuda, M., Abe, T., Uwai, S., Kogami, K., Kawagushi, S. \& Phang, S.M. 2003. Taxonomic Notes on Marine Algae from Malaysia. XI. Four Species of Rhodophyceae1.

Yoon, H.S, Müller, K.M., Sheat, R.G., Ott, F.D. \& Bhattacharya, D. 2006. Defining the Major Lineages od Red Algae (Rhodophyta). J. Phycol. 42, 482-492.

Zhang, D.X. \& Hewitt, G. M. 1997 Assessment of the universality and utility of a set of conserved mitochondrial "primers"in insects. Insect Mol. Biol. 6, 143-150.

Zuccarello, G.C. \& West, J. A. 1997. Hybridization studies in Bostrychia. 2: Correlation of crossing data and plastid DNA sequence data within B. radicans and B. moritziana (Rhodophyta, Ceramiales). Phycologia 36: 293 - 304.

Zuccarello, G.C., West, J. A. \& and R. J. King 1999. A mitochondrial marker for red algal intraspecific relationships. Molecular Ecology (1999) 8: 1443-1447

Zuccarello, G.C. \& West, J. A. 2002. Phylogeography of the Bostrychia calliptera-B. pinnata complex (Rhodomelacea, Rhodophyta) and divergence rates based on nuclear, mitochondrial and plastid DNA markers. Phycologia 41(1): 49-60. 
ANEXO I - Matriz de sequências de cox1 das espécies de Hypnea sequenciadas neste estudo. As amostras estão identificadas de acordo com a Tabela 5.

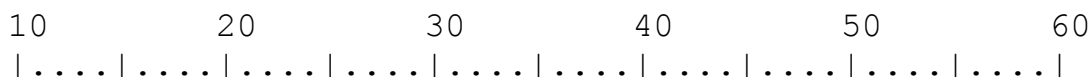
$\ldots \ldots|\ldots| \ldots|\ldots| \ldots|\ldots| \ldots|\ldots| \ldots|\ldots| \ldots|\ldots| \ldots|\ldots| \ldots|\ldots| \ldots \mid$

ВОT0001 ВОТ0002

ВОT 0005 IBC 0040 IBC0067 IBC0089 IBC0098 IBC0123 IBC0137 IBC 0138 IBC 0174 IBC0185 IBC0187 IBC 0188 IBC0189 IBC0196 IBC0199 IBC0202 IBC024 4 IBC0252 ВОT0004 IBC0028 IBC 0051 IBC0064 IBC0139 IBC0186 IBC 0194 IBC0195 IBC0197 IBC0200 IBC0201 IBC020 4 IBC0205 IBC0210 IBC 0213 IBC0214 IBC0216 IBC0217 IBC 0242 IBC0245 IBC024 6 IBC0247 IBC0248 IBC02 49 IBC0250 IBC0251 IBC 0041 IBC0129 IBC0184 IBC0198 IBC0203 ВОТ0003 IBC 0190 IBC0211 IBC 0212 TACACTATATCTTGTTTTTGGAGCTTTTTCAGGTATTTTGGGAGGATGTATGTCGATGCT TACACTATATCTTGTTTTTGGAGCTTTTTCAGGTATTTTGGGAGGATGTATGTCGATGCT TACACTATATCTTGTTTTTGGAGCTTTTTCAGGTATTTTGGGAGGATGTATGTCGATGCT TACACTATATCTTGTTTTTGGAGCTTTTTCAGGTATTTTGGGAGGATGTATGTCGATGCT TACACTATATCTTGTTTTTGGAGCTTTTTCAGGTATTTTGGGAGGATGTATGTCGATGCT TACACTATATCTTGTTTTTGGAGCTTTTTCAGGTATTTTGGGAGGATGTATGTCGATGCT TACACTATATCTTGTTTTTGGAGCTTTTTCAGGTATTTTGGGAGGATGTATGTCGATGCT TACACTATATCTTGTTTTTGGAGCTTTTTCAGGTATTTTGGGAGGATGTATGTCGATGCT TACACTATATCTTGTTTTTGGAGCTTTTTCAGGTATTTTGGGAGGATGTATGTCGATGCT TACACTATATCTTGTTTTTGGAGCTTTTTCAGGTATTTTGGGAGGATGTATGTCGATGCT TACACTATATCTTGTTTTTGGAGCTTTTTCAGGTATTTTGGGAGGATGTATGTCGATGCT TACACTATATCTTGTTTTTGGAGCTTTTTCAGGTATTTTGGGAGGATGTATGTCGATGCT TACACTATATCTTGTTTTTGGAGCTTTTTCAGGTATTTTGGGAGGATGTATGTCGATGCT TACACTATATCTTGTTTTTGGAGCTTTTTCAGGTATTTTGGGAGGATGTATGTCGATGCT TACACTATATCTTGTTTTTGGAGCTTTTTCAGGTATTTTGGGAGGATGTATGTCGATGCT TACACTATATCTTGTTTTTGGAGCTTTTTCAGGTATTTTGGGAGGATGTATGTCGATGCT TACACTATATCTTGTTTTTGGAGCTTTTTCAGGTATTTTGGGAGGATGTATGTCGATGCT TACACTATATCTTGTTTTTGGAGCTTTTTCAGGTATTTTGGGAGGATGTATGTCGATGCT TACACTATATCTTGTTTTTGGAGCTTTTTCAGGTATTTTGGGAGGATGTATGTCGATGCT TACATTATATCTTATTTTTGGTGCTTTTTCAGGTATTCTAGGAGGGTGTATGTCTATGTT TACATTATATCTTATTTTTGGTGCTTTTTCAGGTATTCTAGGAGGGTGTATGTCTATGTT TACATTATATCTTATTTTTGGTGCTTTTTCAGGTATTCTAGGAGGGTGTATGTCTATGTT TACATTATATCTTATTTTTGGTGCTTTTTCAGGTATTCTAGGAGGGTGTATGTCTATGTT TACATTATATCTTATTTTTGGTGCTTTTTCAGGTATTCTAGGAGGGTGTATGTCTATGTT TACATTATATCTTATTTTTGGTGCTTTTTCAGGTATTCTAGGAGGATGTATGTCTATGTT TACATTATATCTTATTTTTGGTGCTTTTTCAGGTATTCTAGGAGGGTGTATGTCTATGTT TACATTATATCTTATTTTTGGTGCTTTTTCAGGTATTCTAGGAGGGTGTATGTCTATGTT TACATTATATCTTATTTTTGGTGCTTTTTCAGGTATTCTAGGAGGGTGTATGTCTATGTT TACATTATATCTTATTTTTGGTGCTTTTTCAGGTATTCTAGGAGGGTGTATGTCTATGTT TACATTATATCTTATTTTTGGTGCTTTTTCAGGTATTCTAGGAGGGTGTATGTCTATGTT TACATTATATCTTATTTTTGGTGCTTTTTCAGGTATTCTAGGAGGGTGTATGTCTATGTT TACATTATATCTTATTTTTGGTGCTTTTTCAGGTATTCTAGGAGGGTGTATGTCTATGTT TACATTATATCTTATTTTTGGTGCTTTTTCAGGTATTCTAGGAGGGTGTATGTCTATGTT TACATTATATCTTATTTTTGGTGCTTTTTCAGGTATTCTAGGAGGGTGTATGTCTATGTT TACATTATATCTTATTTTTGGTGCTTTTTCAGGTATTCTAGGAGGATGTATGTCTATGTT TACATTATATCTTATTTTTGGTGCTTTTTCAGGTATTCTAGGAGGATGTATGTCTATGTT TACATTATATCTTATTTTTGGTGCTTTTTCAGGTATTCTAGGAGGATGTATGTCTATGTT TACATTATATCTTATTTTTGGTGCTTTTTCAGGTATTCTAGGAGGGTGTATGTCTATGTT TACATTATATCTTATTTTTGGTGCTTTTTCAGGTATTCTAGGAGGGTGTATGTCTATGTT TACATTATATCTTATTTTTGGTGCTTTTTCAGGTATTCTAGGAGGGTGTATGTCTATGTT TACATTATATCTTATTTTTGGTGCTTTTTCAGGTATTCTAGGAGGGTGTATGTCTATGTT TACATTATATCTTATTTTTGGTGCTTTTTCAGGTATTCTAGGAGGGTGTATGTCTATGTT TACATTATATCTTATTTTTGGTGCTTTTTCAGGTATTCTAGGAGGGTGTATGTCTATGTT TACATTATATCTTATTTTTGGTGCTTTTTCAGGTATTCTAGGAGGGTGTATGTCTATGTT TACATTATATCTTATTTTTGGTGCTTTTTCAGGTATTCTAGGAGGGTGTATGTCTATGTT TACACTATATCTTATTTTTGGTGCATTTTCTGGTATTTTAGGAGGTTGTATGTCAATGTT TACACTATATCTTATTTTTGGTGCATTTTCTGGTATTTTAGGAGGTTGTATGTCAATGTT TACACTATATCTTATTTTTGGTGCATTTTCTGGTATTTTAGGAGGTTGTATGTCAATGTT TACACTATATCTTATTTTTGGTGCATTTTCTGGTATTTTAGGAGGTTGTATGTCAATGTT TACACTATATCTTATTTTTGGTGCATTTTCTGGTATTTTAGGAGGTTGTATGTCAATGTT TACTCTATATCTTATTTTTGGCGCTTTTTCTGGTATTTTGGGTGGTTGTATGTCTATGTT TACACTATATCTTATTTTTGGAGCTTTTTCAGGTATTTTAGGAGGGTGTATGTCTATGCT TACTTTATATCTTATTTTTGGTGCTTTTTCTGGTATTTTAGGAGGCTGTATGTCAATGTT TACTTTATATCTTATTTTTGGTGCTTTTTCTGGTATTTTAGGAGGCTGTATGTCAATGTT 


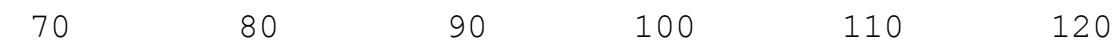

$\ldots|\ldots| \ldots|\ldots| \ldots|\ldots| \ldots|\ldots| \ldots|\ldots| \ldots|\ldots| \ldots|\ldots| \ldots \mid$

Вот0001

ВОТ0002

ВОТ0005

IBC 0040

IBC0067

IBC0089

IBC0098

IBC 0123

IBC 0137

IBC 0138

IBC0174

IBC 0185

IBC 0187

IBC0188

IBC0189

IBC0196

IBC0199

IBC 0202

IBC 0244

IBC0252

ВОТ0004

IBC0028

IBC 0051

IBC0064

IBC0139

IBC 0186

IBC0194

IBC0195

IBC 0197

IBC0200

IBC0201

IBC0204

IBC0205

IBC 0210

IBC 0213

IBC 0214

IBC0216

IBC 0217

IBC0242

IBC 0245

IBC0246

IBC 0247

IBC 0248

IBC0249

IBC 0250

IBC0251

IBC 0041

IBC 0129

IBC 0184

IBC 0198

IBC0203

ВОТ0003

IBC0190

IBC 0211

IBC0212

AATCCGTATGGAATTAGCTCAACCGAGTAATCAATTACTTTTAGGTAATCATCAAGTTTA AATCCGTATGGAATTAGCTCAACCGAGTAATCAATTACTTTTAGGTAATCATCAAGTTTA AATCCGTATGGAATTAGCTCAACCGAGTAATCAATTACTTTTAGGTAATCATCAAGTTTA AATCCGTATGGAATTAGCTCAACCGAGTAATCAATTACTTTTAGGTAATCATCAAGTTTA AATCCGTATGGAATTAGCTCAACCGAGTAATCAATTACTTTTAGGTAATCATCAAGTTTA AATCCGTATGGAATTAGCTCAACCGAGTAATCAATTACTTTTAGGTAATCATCAAGTTTA AATCCGTATGGAATTAGCTCAACCGAGTAATCAATTACTTTTAGGTAATCATCAAGTTTA AATCCGTATGGAATTAGCTCAACCGAGTAATCAATTACTTTTAGGTAATCATCAAGTTTA AATCCGTATGGAATTAGCTCAACCGAGTAATCAATTACTTTTAGGTAATCATCAAGTTTA AATCCGTATGGAATTAGCTCAACCGAGTAATCAATTACTTTTAGGTAATCATCAAGTTTA AATCCGTATGGAATTAGCTCAACCGAGTAATCAATTACTTTTAGGTAATCATCAAGTTTA AATCCGTATGGAATTAGCTCAACCGAGTAATCAATTACTTTTAGGTAATCATCAAGTTTA AATTCGTATGGAATTAGCTCAACCGAGTAATCAATTACTTTTAGGTAATCATCAAGTTTA AATTCGTATGGAATTAGCTCAACCGAGTAATCAATTACTTTTAGGTAATCATCAAGTTTA AATCCGTATGGAATTAGCTCAACCGAGTAATCAATTACTTTTAGGTAATCATCAAGTTTA AATCCGTATGGAATTAGCTCAACCGAGTAATCAATTACTTTTAGGTAATCATCAAGTTTA AATCCGTATGGAATTAGCTCAACCGAGTAATCAATTACTTTTAGGTAATCATCAAGTTTA AATCCGTATGGAATTAGCTCAACCGAGTAATCAATTACTTTTAGGTAATCATCAAGTTTA AATTCGTATGGAATTAGCTCAACCGAGTAATCAATTACTTTTAGGTAATCATCAAGTTTA AATCCGTATGGAATTAGCTCAACCGAGTAATCAATTACTTTTAGGTAATCATCAAGTTTA AATTCGTATGGAACTGGCACAGCCTAGTAACCAATTATTATTAGGTAATCACCAAGTATA AATTCGTATGGAACTGGCACAGCCTAGTAACCAATTATTATTAGGTAATCACCAAGTATA AATTCGTATGGAACTGGCACAGCCTAGTAACCAATTATTATTAGGTAATCACCAAGTATA AATTCGTATGGAACTGGCACAGCCTAGTAACCAATTATTATTAGGTAATCACCAAGTATA AATTCGTATGGAACTGGCACAGCCTAGTAACCAATTATTATTAGGTAATCACCAAGTATA AATTCGTATGGAACTGGCACAGCCTAGTAACCAATTATTATTAGGTAATCACCAAGTATA AATTCGTATGGAACTGGCTCAGCCTAGTAACCAATTATTATTAGGTAATCACCAAGTATA AATTCGTATGGAACTGGCACAGCCTAGTAACCAATTATTATTAGGTAATCACCAAGTATA AATTCGTATGGAACTGGCACAGCCTAGTAACCAATTATTATTAGGTAATCACCAAGTATA AATTCGTATGGAACTGGCACAGCCTAGTAACCAATTATTATTAGGTAATCACCAAGTATA AATTCGTATGGAACTGGCACAGCCTAGTAACCAATTATTATTAGGTAATCACCAAGTATA AATTCGTATGGAACTGGCACAGCCTAGTAACCAATTATTATTAGGTAATCACCAAGTATA AATTCGTATGGAACTGGCACAGCCTAGTAACCAATTATTATTAGGTAATCACCAAGTATA AATTCGTATGGAACTGGCACAGCCTAGTAACCAATTATTATTAGGTAATCACCAAGTATA AATTCGTATGGAACTGGCACAGCCTAGTAACCAATTATTATTAGGTAATCACCAAGTATA AATTCGTATGGAACTGGCACAGCCTAGTAACCAATTATTATTAGGTAATCACCAAGTATA AATTCGTATGGAACTGGCACAGCCTAGTAACCAATTATTATTAGGTAATCACCAAGTATA AATTCGTATGGAACTGGCACAGCCTAGTAACCAATTATTATTAGGTAATCACCAAGTATA AATTCGTATGGAACTGGCACAGCCTAGTAACCAATTATTATTAGGTAATCACCAAGTATA AATTCGTATGGAACTGGCACAGCCTAGTAACCAATTATTATTAGGTAATCACCAAGTATA AATTCGTATGGAACTGGCACAGCCTAGTAACCAATTATTATTAGGTAATCACCAAGTATA AATTCGTATGGAACTGGCACAGCCTAGTAACCAATTATTATTAGGTAATCACCAAGTATA AATTCGTATGGAACTGGCACAGCCTAGTAACCAATTATTATTAGGTAATCACCAAGTATA AATTCGTATGGAACTGGCACAGCCTAGTAACCAATTATTATTAGGTAATCACCAAGTATA AATTCGTATGGAACTGGCACAGCCTAGTAACCAATTATTATTAGGTAATCACCAAGTATA AATTCGTATGGAACTGGCACAGCCTAGTAACCAATTATTATTAGGTAATCACCAAGTATA AATTCGTATGGAATTAGCTCAACCAAGTAATCAATTATTGTTAGGTAATCATCAAGTATA AATTCGTATGGAATTAGCTCAACCAAGTAATCAATTATTGTTAGGTAATCATCAAGTATA AATTCGTATGGAATTAGCTCAACCAAGTAATCAATTATTGTTAGGTAATCATCAAGTATA AATTCGTATGGAATTAGCTCAACCAAGTAATCAATTATTGTTAGGTAATCATCAAGTATA AATTCGTATGGAATTAGCTCAACCAAGTAATCAATTATTGTTAGGTAATCATCAAGTATA AATTCGTATGGAATTAGCACAACCTAGTAATCAATTATTATTAGGTAACCATCAAGTATA AATCCGTATGGAATTAGCTCAACCAAGTAATCAATTATTATTAGGCAATCATCAAGTTTA AATTCGTATGGAATAGCTCAGCCTAGTAATCAACTATTATTAGGTAATCATCAAGTATA AATTCGTATGGAATTAGCTCAGCCTAGTAATCAACTATTATTAGGTAATCATCAAGTATA 


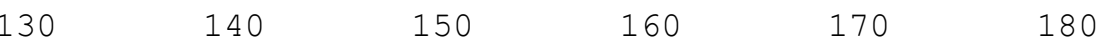
$\ldots|\ldots| \ldots|\ldots| \ldots|\ldots| \ldots|\ldots| \ldots|\ldots| \ldots|\ldots| \ldots|\ldots| \ldots|\ldots|$

ВОT0001 ВОТ0002 ВОт0005 IBC 0040 IBC0067 IBC0089 IBC 0098 IBC 0123 IBC 0137 IBC 0138 IBC 0174 IBC 0185 IBC 0187 IBC 0188 IBC0189 IBC0196 IBC 0199 IBC 0202 IBC0244 IBC0252 ВОТ0004 IBC 0028 IBC 0051 IBC0064 IBC0139 IBC0186 IBC0194 IBC0195 IBC 0197 IBC0200 IBC0201 IBC0204 IBC0205 IBC 0210 IBC 0213 IBC 0214 IBC0216 IBC 0217 IBC 0242 IBC 0245 IBC0246 IBC 0247 IBC 0248 IBC0249 IBC 0250 IBC0251 IBC 0041 IBC 0129 IBC 0184 IBC0198 IBC0203 ВОТ0003 IBC 0190 IBC 0211 IBC 0212 TAATGTATTAATAACGGCACACGCATTTTTGATGATTTTTTTTATGGTAATGCCAGTCAT TAATGTATTAATAACGGCACACGCATTTTTGATGATTTTTTTTATGGTAATGCCAGTCAT TAATGTATTAATAACGGCACACGCATTTTTGATGATTTTTTTTATGGTAATGCCAGTCAT TAATGTATTAATAACGGCACACGCATTTTTGATGATTTTTTTTATGGTAATGCCAGTCAT TAATGTATTAATAACGGCACACGCATTTTTGATGATTTTTTTTATGGTAATGCCAGTCAT TAATGTATTAATAACGGCACACGCATTTTTGATGATTTTTTTTATGGTAATGCCAGTCAT TAATGTATTAATAACGGCACACGCATTTTTGATGATTTTTTTTATGGTAATGCCAGTCAT TAATGTATTAATAACGGCACACGCATTTTTGATGATTTTTTTTATGGTAATGCCAGTCAT TAATGTATTAATAACGGCACACGCATTTTTGATGATTTTTTTTATGGTAATGCCAGTCAT TAATGTATTAATAACGGCACACGCATTTTTGATGATTTTTTTTATGGTAATGCCAGTCAT TAATGTATTAATAACGGCACACGCATTTTTGATGATTTTTTTTATGGTAATGCCAGTCAT TAATGTATTAATAACGGCACACGCATTTTTGATGATTTTTTTTATGGTAATGCCAGTCAT TAATGTATTAATAACGGCACACGCATTTTTGATGATTTTTTTTATGGTAATGCCAGTCAT TAATGTATTAATAACGGCACACGCATTTTTGATGATTTTTTTTATGGTAATGCCAGTCAT TAATGTATTAATAACGGCACACGCATTTTTGATGATTTTTTTTATGGTAATGCCAGTCAT TAATGTATTAATAACGGCACACGCATTTTTGATGATTTTTTTTATGGTAATGCCAGTCAT TAATGTATTAATAACGGCACACGCATTTTTGATGATTTTTTTTATGGTAATGCCAGTCAT TAATGTATTAATAACGGCACACGCATTTTTGATGATTTTTTTATGGTAATGCCAGTCAT TAATGTATTAATAACGGCACACGCATTTTTGATGATTTTTTTTATGGTAATGCCAGTCAT TAATGTATTAATAACGGCACACGCATTTTTGATGATTTTTTTTATGGTAATGCCAGTCAT CAATGTTCTTATAACAGCACACGCGTTTTTAATGATATTTTTTATGGTAATGCCTGTTAT CAATGTTCTTATAACAGCACACGCGTTTTTAATGATATTTTTTATGGTAATGCCTGTTAT CAATGTTCTTATAACAGCACACGCGTTTTTAATGATATTTTTTATGGTAATGCCTGTTAT CAATGTTCTTATAACAGCACACGCGTTTTTAATGATATTTTTTATGGTAATGCCTGTTAT CAATGTTCTTATAACAGCACACGCGTTTTTAATGATATTTTTTATGGTAATGCCTGTTAT CAATGTTCTTATAACAGCACACGCGTTTTTAATGATATTTTTTATGGTAATGCCTGTTAT CAATGTTCTTATAACAGCACACGCGTTTTTAATGATATTTTTTATGGTAATGCCTGTTAT CAATGTTCTTATAACAGCACACGCGTTTTTAATGATATTTTTTATGGTAATGCCTGTTAT CAATGTTCTTATAACAGCACACGCGTTTTTAATGATATTTTTTATGGTAATGCCTGTTAT CAATGTTCTTATAACAGCACACGCGTTTTTAATGATATTTTTTATGGTAATGCCTGTTAT CAATGTTCTTATAACAGCACACGCGTTTTTAATGATATTTTTTATGGTAATGCCTGTTAT САATGTTCTTATAACAGCACACGCGTTTTTAATGATATTTTTTATGGTAATGCCTGTTAT CAATGTTCTTATAACAGCACACGCGTTTTTAATGATATTTTTTATGGTAATGCCTGTTAT CAATGTTCTTATAACAGCACACGCGTTTTTAATGATATTTTTTATGGTAATGCCTGTTAT CAATGTTCTTATAACAGCACACGCGTTTTTAATGATATTTTTTATGGTAATGCCTGTTAT CAATGTTCTTATAACAGCACACGCGTTTTTAATGATATTTTTTATGGTAATGCCTGTTAT CAATGTTCTTATAACAGCACACGCGTTTTTAATGATATTTTTTATGGTAATGCCTGTTAT CAATGTTCTTATAACAGCACACGCGTTTTTAATGATATTTTTTATGGTAATGCCTGTTAT CAATGTTCTTATAACAGCACACGCGTTTTTAATGATATTTTTTATGGTAATGCCTGTTAT CAATGTTCTTATAACAGCACACGCGTTTTTAATGATATTTTTTATGGTAATGCCTGTTAT CAATGTTCTTATAACAGCACACGCGTTTTTAATGATATTTTTTATGGTAATGCCTGTTAT CAATGTTCTTATAACAGCACACGCGTTTTTAATGATATTTTTTATGGTAATGCCTGTTAT CAATGTTCTTATAACAGCACACGCGTTTTTAATGATATTTTTTATGGTAATGCCTGTTAT CAATGTTCTTATAACAGCACACGCGTTTTTAATGATATTTTTTATGGTAATGCCTGTTAT CAATGTTCTTATAACAGCACACGCGTTTTTAATGATATTTTTTATGGTAATGCCTGTTAT CAATGTTCTTATAACAGCACACGCGTTTTTAATGATATTTTTTATGGTAATGCCTGTTAT TAATGTCCTTATAACAGCACATGCATTTTTGATGATCTTTTTTATGGTAATGCCTGTTAT TAATGTCCTTATAACAGCACATGCATTTTTGATGATCTTTTTTATGGTAATGCCTGTTAT TAATGTCCTTATAACAGCACATGCATTTTTGATGATCTTTTTTATGGTAATGCCTGTTAT TAATGTCCTTATAACAGCACATGCATTTTTGATGATCTTTTTTATGGTAATGCCTGTTAT TAATGTCCTTATAACAGCACATGCATTTTTGATGATCTTTTTTATGGTAATGCCTGTTAT TAATGTTCTTATAACAGCACATGCATTTTTAATGATTTTTTTTATGGTAATGCCAGTAAT TAACGTACTTATAACAGCACATGCTTTCTTGATGATTTTCTTTATGGTAATGCCTGTTAT TAATGTCCTTATAACAGCACACGCTTTTTTGATGATTTTTTTATGGTAATGCCTGTTAT TAATGTCCTTATAACAGCACACGCTTTTTTGATGATTTTTTTTATGGTAATGCCTGTTAT 
$190 \quad 200 \quad 210 \quad 220 \quad 230 \quad 240$ $\ldots|\ldots| \ldots|\ldots| \ldots|\ldots| \ldots|\ldots| \ldots|\ldots| \ldots|\ldots| \ldots|\ldots| \ldots|\ldots|$

ВОT0001 ВОТ0002 ВОТ0005 IBC 0040 IBC0067 IBC0089 IBC 0098 IBC 0123 IBC0137 IBC 0138 IBC 0174 IBC0185 IBC 0187 IBC 0188 IBC0189 IBC0196 IBC 0199 IBC 0202 IBC0244 IBC0252 ВОТ0004 IBC 0028 IBC 0051 IBC0064 IBC0139 IBC0186 IBC0194 IBC0195 IBC 0197 IBC0200 IBC0201 IBC0204 IBC0205 IBC 0210 IBC 0213 IBC 0214 IBC 0216 IBC 0217 IBC 0242 IBC 0245 IBC0246 IBC 0247 IBC 0248 IBC0249 IBC 0250 IBC0251 IBC 0041 IBC 0129 IBC 0184 IBC 0198 IBC0203 ВОТ0003 IBC 0190 IBC 0211 IBC 0212 GATAGGAGGATTTGGTAATTGGCTGGTTCCTATAATGATAGGTAGTCCTGATATGGCATT GATAGGAGGATTTGGTAATTGGCTGGTTCCTATAATGATAGGTAGTCСTGATATGGCATT GATAGGAGGATTTGGTAATTGGCTGGTTCCTATAATGATAGGTAGTCСTGATATGGCATT GATAGGAGGATTTGGTAATTGGCTGGTTCCTATAATGATAGGTAGTCCTGATATGGCATT GATAGGAGGATTTGGTAATTGGCTGGTTCCTATAATGATAGGTAGTCCTGATATGGCATT GATAGGAGGATTTGGTAATTGGCTGGTTCCTATAATGATAGGTAGTCCTGATATGGCATT GATAGGAGGATTTGGTAATTGGCTGGTTCCTATAATGATAGGTAGTCCTGATATGGCATT GATAGGAGGATTTGGTAATTGGCTGGTTCCTATAATGATAGGTAGTCСTGATATGGCATT GATAGGAGGATTTGGTAATTGGCTGGTTCCTATAATGATAGGTAGTCCTGATATGGCATT GATAGGAGGATTTGGTAATTGGCTGGTTCCTATAATGATAGGTAGTCCTGATATGGCTTT GATAGGAGGATTTGGTAATTGGCTGGTTCCTATAATGATAGGTAGTCСTGATATGGCATT GATAGGAGGATTTGGTAATTGGCTGGTTCCTATAATGATAGGTAGTCCTGATATGGCATT GATAGGAGGATTTGGTAATTGGCTGGTTCCTATAATGATAGGTAGTCCTGATATGGCATT GATAGGAGGATTTGGTAATTGGCTGGTTCCTATAATGATAGGTAGTCСTGATATGGCATT GATAGGAGGATTTGGTAATTGGCTGGTTCCTATAATGATAGGTAGTCCTGATATGGCATT GATAGGAGGATTTGGTAATTGGCTGGTTCCTATAATGATAGGTAGTCСTGATATGGCATT GATAGGAGGATTTGGTAATTGGCTGGTTCCTATAATGATAGGTAGTCСTGATATGGCATT GATAGGAGGATTTGGTAATTGGCTGGTTCCTATAATGATAGGTAGTCCTGATATGGCATT GATAGGAGGATTTGGTAATTGGCTGGTTCCTATAATGATAGGTAGTCCTGATATGGCATT GATAGGAGGATTTGGTAATTGGCTGGTTCCTATAATGATAGGTAGTCCTGATATGGCATT GATAGGGGGTTTTGGTAATTGATTAGTTCCTATCATGATAGGAAGTCCAGATATGGCATT GATAGGGGGTTTTGGTAATTGATTAGTTCCTATCATGATAGGAAGTCCAGATATGGCATT GATAGGGGGTTTTGGTAATTGATTAGTTCCTATCATGATAGGAAGTCCAGATATGGCATT GATAGGGGGTTTTGGTAATTGATTAGTTCCTATCATGATAGGAAGTCCAGATATGGCATT GATAGGGGGTTTTGGTAATTGATTAGTTCCTATCATGATAGGAAGTCCAGATATGGCATT GATAGGGGGTTTTGGTAATTGATTAGTTCCTATCATGATAGGAAGTCCAGATATGGCATT GATAGGGGGTTTTGGTAATTGATTAGTTCCTATCATGATAGGAAGTCCAGATATGGCATT GATAGGGGGTTTTGGTAATTGATTAGTTCCTATCATGATAGGAAGTCCAGATATGGCATT GATAGGGGGTTTTGGTAATTGATTAGTTCCTATCATGATAGGAAGTCCAGATATGGCATT GATAGGGGGTTTTGGTAATTGATTAGTTCCTATCATGATAGGAAGTCCAGATATGGCATT GATAGGGGGTTTTGGTAATTGATTAGTTCCTATCATGATAGGAAGTCCAGATATGGCATT GATAGGGGGTTTTGGTAATTGATTAGTTCCTATCATGATAGGAAGTCCAGATATGGCATT GATAGGGGGTTTTGGTAATTGATTAGTTCCTATCATGATAGGAAGTCCAGATATGGCATT GATAGGGGGTTTTGGTAATTGATTAGTTCCTATCATGATAGGAAGTCCAGATATGGCATT GATAGGGGGTTTTGGTAATTGATTAGTTCCTATCATGATAGGAAGTCCAGATATGGCATT GATAGGGGGTTTTGGTAATTGATTAGTTCCTATCATGATAGGAAGTCCAGATATGGCATT GATAGGGGGTTTTGGTAATTGATTAGTTCCTATCATGATAGGAAGTCCAGATATGGCATT GATAGGGGGTTTTGGTAATTGATTAGTTCCTATCATGATAGGAAGTCCAGATATGGCATT GATAGGGGGTTTTGGTAATTGATTAGTTCCTATCATGATAGGAAGTCCAGATATGGCATT GATAGGGGGTTTTGGTAATTGATTAGTTCCTATCATGATAGGAAGTCCAGATATGGCATT GATAGGGGGTTTTGGTAATTGATTAGTTCCTATCATGATAGGAAGTCCAGATATGGCATT GATAGGGGGTTTTGGTAATTGATTAGTTCCTATCATGATAGGAAGTCCAGATATGGCATT GATAGGGGGTTTTGGTAATTGATTAGTTCCTATCATGATAGGAAGTCCAGATATGGCATT GATAGGGGGTTTTGGTAATTGATTAGTTCCTATCATGATAGGAAGTCCAGATATGGCATT GATAGGGGGTTTTGGTAATTGATTAGTTCCTATCATGATAGGAAGTCCAGATATGGCATT GATAGGGGGTTTTGGTAATTGATTAGTTCCTATCATGATAGGAAGTCCAGATATGGCATT GATAGGTGGTTTTGGTAATTGATTAGTACCTATAATGATTGGGAGCCСTGATATGGCATT GATAGGTGGTTTTGGTAATTGATTAGTACCTATAATGATTGGGAGCCСTGATATGGCATT GATAGGTGGTTTTGGTAATTGATTAGTACCTATAATGATTGGGAGCCСTGATATGGCATT GATAGGTGGTTTTGGTAATTGATTAGTACCTATAATGATTGGGAGCССTGATATGGCATT GATAGGTGGTTTTGGTAATTGATTAGTACCTATAATGATTGGGAGCССTGATATGGCATT GATAGGGGGTTTTGGTAATTGATTAGTTCCTATAATGATAGGGAGCCCAGATATGGCATT GATAGGGGGATTTGGTAATTGGTTAGTCCCTATAATGATTGGTAGTCCGGATATGGCATT GATAGGTGGTTTTGGTAACTGATTGGTTCCTATAATGATAGGGAGTCCAGATATGGCATT GATAGGTGGTTTTGGTAACTGATTGGTTCCTATAATGATAGGGAGTCCAGATATGGCATT 


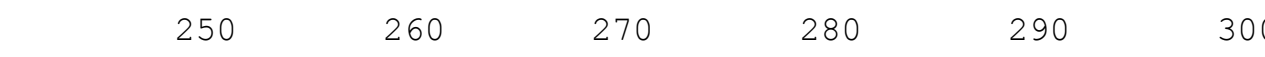
$\ldots|\ldots| \ldots|\ldots| \ldots|\ldots| \ldots|\ldots| \ldots|\ldots| \ldots|\ldots| \ldots|\ldots| \ldots \mid$

ВОТ0001 ВОТ0002 ВОт0005 IBC 0040 IBC0067 IBC0089 IBC0098 IBC 0123 IBC 0137 IBC 0138 IBC 0174 IBC 0185 IBC 0187 IBC 0188 IBC0189 IBC0196 IBC 0199 IBC 0202 IBC 0244 IBC0252 ВОТ0004 IBC 0028 IBC 0051 IBC0064 IBC0139 IBC0186 IBC0194 IBC0195 IBC 0197 IBC0200 IBC 0201 IBC 0204 IBC0205 IBC 0210 IBC 0213 IBC0214 IBC0216 IBC 0217 IBC 0242 IBC 0245 IBC0246 IBC 0247 IBC0248 IBC0249 IBC 0250 IBC0251 IBC 0041 IBC0129 IBC 0184 IBC 0198 IBC0203 ВОТ0003 IBC 0190 IBC 0211 IBC 0212 TCCTCGTTTAAATAATATTTCTTTTTGATTATTACCGCCCTCATTATGTTTATTATTATT TCСTCGTTTAAATAATATTTCTTTTTGATTATTACCGCССTCATTATGTTTATTATTATT TCСTCGTTTAAATAATATTTCTTTTTGATTATTACCGCССTСАTTATGTTTATTATTATT TCCTCGTTTAAATAATATTCTTTTTGATTATTACCGCCCTCATTATGTTTATTATTATT TCCTCGTTTAAATAATATTTCTTTTTGATTATTACCGCССTCATTATGTTTATTATTATT TCCTCGTTTAAATAATATTTCTTTTTGATTATTACCGCССТСАTTATGTTTATTATTATT TCCTCGTTTAAATAATATTTCTTTTTGATTATTACCGCCСTCATTATGTTTATTATTATT TCCTCGTTTAAATAATATTTCTTTTTGATTATTACCGCССTCATTATGTTTATTATTATT TCCTCGTTTAAATAATATTTCTTTTTGATTATTACCGCССTCATTATGTTTATTATTATT TCСTCGTTTAAАTAАTATTTCTTTTTGATTATTACCGCССТСАTTATGTTTATTATTATT TCCTCGTTTAAATAATATTTCTTTTTGATTATTACCGCCСTCATTATGTTTATTATTATT TCCTCGTTTAAATAATATTTCTTTTTGATTATTACCGCССTCATTATGTTTATTATTATT TCCTCGTTTAAATAATATTTCTTTTTGATTATTACCGCCCTCATTATGTTTATTATTATT TCСTCGTTTAAATAАTATTTCTTTTTGATTATTACCGCССТСАTTATGTTTATTATTATT TCCTCGTTTAAATAATATTTCTTTTTGATTATTACCGCССTCATTATGTTTATTATTATT TCCTCGTTTAAATAATATTTCTTTTTGATTATTACCGCCCTCATTATGTTTATTATTATT TCCTCGTTTAAATAATATTTCTTTTTGATTATTACCGCCСTCATTATGTTTATTATTATT TCCTCGTTTAAATAATATTTCTTTTTGATTATTACCGCССTCATTATGTTTATTATTATT TCСTCGTTTAAATAATATTTCTTTTTGATTATTACCGCССТСАTTATGTTTATTATTATT TCCTCGTTTAAATAATATTTCTTTTTGATTATTACCGCCСTCATTATGTTTATTATTATT TCCTAGATTAAATAACATATCTTTTTGATTATTACCGCСTTCGTTATGCTTATTGTTATT TCCTAGATTAAATAACATATCTTTTTGATTATTACCGCСTTCGTTATGCTTGTTGTTATT TCCTAGATTAAATAACATATCTTTTTGATTATTACCGCСTTCGTTATGCTTGTTGTTATT TCCTAGATTAAATAACATATCTTTTTGATTATTACCGCСTTCGTTATGCTTGTTGTTATT TCCTAGATTAAATAACATATCTTTTTGATTATTACCGCCTTCGTTATGCTTGTTGTTATT TCCTAGATTAAATAATATATCTTTTTGATTATTACCGCCTTCGTTATGCTTATTGTTATT TCCTAGATTAAATAACATATCTTTTTGATTATTACCGCСTTCGTTATGCTTGTTGTTATT TCCTAGATTAAATAACATATCTTTTTGATTATTACCGCСTTCGTTATGCTTGTTGTTATT TCCTAGATTAAATAACATATCTTTTTGATTATTACCGCCTTCGTTATGCTTGTTGTTATT TCCTAGATTAAATAACATATCTTTTTGATTATTACCGCCTTCGTTATGCTTGTTGTTATT TCCTAGATTAAATAACATATCTTTTTGATTATTACCGCCTTCGTTATGCTTGTTGTTATT TCCTAGATTAAATAACATATCTTTTTGATTATTACCGCСTTCGTTATGCTTGTTGTTATT TCCTAGATTAAATAACATATCTTTTTGATTATTACCGCCTTCGTTATGCTTGTTGTTATT TCCTAGATTAAATAACATATCTTTTTGATTATTACCGCCTTCGTTATGCTTGTTGTTATT TCCTAGATTAAATAACATATCTTTTTGATTATTACCGCСTTCGTTATGCTTGTTGTTATT TCCTAGATTAAATAATATATCTTTTTGATTATTACCGCСTTCGTTATGCTTATTGTTATT TCCTAGATTAAATAATATATCTTTTTGATTATTACCGCСTTCGTTATGCTTATTGTTATT TCCTAGATTAAATAATATATCTTTTTGATTATTACCGCCTTCGTTATGCTTATTGTTATT TCCTAGATTAAATAACATATCTTTTTGATTATTACCGCCTTCGTTATGCTTGTTGTTATT TCCTAGATTAAATAACATATCTTTTTGATTATTACCGCCTTCGTTATGCTTGTTGTTATT TCCTAGATTAAATAACATATCTTTTTGATTATTACCGCСTTCGTTATGCTTGTTGTTATT TCCTAGATTAAATAACATATCTTTTTGATTATTACCGCCTTCGTTATGCTTGTTGTTATT TCCTAGATTAAATAACATATCTTTTTGATTATTACCGCCTTCGTTATGCTTGTTGTTATT TCCTAGATTAAATAACATATCTTTTTGATTATTACCGCCTTCGTTATGCTTGTTGTTATT TCCTAGATTAAATAACATATCTTTTTGATTATTACCGCCTTCGTTATGCTTGTTGTTATT TCCTAGATTAAATAACATATCTTTTTGATTATTACCGCСTTCGTTATGCTTGTTGTTATT TCCTCGTTTAAATAATATTTCTTTTTGATTGCTTCCGCCGTCATTATGTTTATTATTGTT TCCTCGTTTAAATAATATTTCTTTTTGATTGCTTCCGCCGTCATTATGTTTATTATTGTT TCCTCGTTTAAATAATATTTCTTTTTGATTGCTTCCGCCGTCATTATGTTTATTATTGTT TCСTCGTTTAAATAATATTTCTTTTTGATTGCTTCCGCCGTCATTATGTTTATTATTGTT TCCTCGTTTAAATAATATTTCTTTTTGATTGCTTCCGCCGTCATTATGTTTATTATTGTT CССTCGTTTAAATAATATATCTTTTTGGTTATTACCCCCATCATTATGTCTATTATTATT TCCTCGATTAAATAATATTTCTTTTTGACTACTACCACСTTCTCTATGTTTATTACTTCT CССTCGATTAAATAATATTTCTTTTGGTTGTTGCCTCCTTCATTATGTTTATTATTATT СССTCGATTAAATAATATTTCTTTTTGGTTGTTGCСTCСTTCATTATGTTTATTATTATT 
$\begin{array}{lllll}310 & 320 & 330 & 340 & 350\end{array}$ $\ldots|\ldots| \ldots|\ldots| \ldots|\ldots| \ldots|\ldots| \ldots|\ldots| \ldots|\ldots| \ldots|\ldots| \ldots|\ldots|$

Вот0001 ВОT0002 ВОТ0005 IBC 0040 IBC0067 IBC0089 IBC0098 IBC 0123 IBC0137 IBC 0138 IBC 0174 IBC 0185 IBC 0187 IBC 0188 IBC0189 IBC0196 IBC0199 IBC0202 IBC0244 IBC0252 ВОТ0004 IBC0028 IBC 0051 IBC0064 IBC0139 IBC0186 IBC0194 IBC0195 IBC0197 IBC0200 IBC0201 IBC0204 IBC0205 IBC0210 IBC 0213 IBC 0214 IBC0216 IBC 0217 IBC0242 IBC 0245 IBC0246 IBC0247 IBC0248 IBC0249 IBC 0250 IBC0251 IBC 0041 IBC0129 IBC0184 IBC0198 IBC0203 ВОТ0003 IBC0190 IBC0211 IBC0212 ATCAGCTCTAGTAGAGGTAGGAGTAGGTACAGGTTGAACGGTTTATCCACCTTTAAGCTC ATCAGCTCTAGTAGAGGTAGGAGTAGGTACAGGTTGAACGGTTTATCCACCTTTAAGCTC ATCAGCTCTAGTAGAGGTAGGAGTAGGTACAGGTTGAACGGTTTATCCACCTTTAAGCTC ATCAGCTCTAGTAGAGGTAGGAGTAGGTACAGGTTGAACGGTTTATCCACCTTTAAGCTC ATCAGCTCTAGTAGAGGTAGGAGTAGGTACAGGTTGAACGGTTTATCCACCTTTAAGCTC ATCAGCTCTAGTAGAGGTAGGAGTAGGTACAGGTTGAACGGTTTATCCACCTTTAAGCTC ATCAGCTCTAGTAGAGGTAGGAGTAGGTACAGGTTGAACGGTTTATCCACCTTTAAGCTC ATCAGCTCTAGTAGAGGTAGGAGTAGGTACAGGTTGAACGGTTTATCCACCTTTAAGCTC ATCAGCTCTAGTAGAGGTAGGAGTAGGTACAGGTTGAACGGTTTATCCACCTTTAAGCTC ATCAGCTCTAGTAGAGGTAGGAGTAGGTACAGGTTGAACGGTTTATCCACCTTTAAGCTC ATCAGCTCTAGTAGAGGTAGGAGTAGGTACAGGTTGAACGGTTTATCCACCTTTAAGCTC ATCAGCTCTAGTAGAGGTAGGAGTAGGTACAGGTTGAACGGTTTATCCACCTTTAAGCTC ATCAGCTCTAGTAGAGGTAGGAGTAGGTACAGGTTGAACGGTTTATCCACCTTTAAGCTC ATCAGCTCTAGTAGAGGTAGGAGTAGGTACAGGTTGAACGGTTTATCCACCTTTAAGCTC ATCAGCTCTAGTAGAGGTAGGAGTAGGTACAGGTTGAACGGTTTATCCACCTTTAAGCTC ATCAGCTCTAGTAGAGGTAGGAGTAGGTACAGGTTGAACGGTTTATCCACCTTTAAGCTC ATCAGCTCTAGTAGAGGTAGGAGTAGGTACAGGTTGAACGGTTTATCCACCTTTAAGCTC ATCAGCTCTAGTAGAGGTAGGAGTAGGTACAGGTTGAACGGTTTATCCACCTTTAAGCTC ATCAGCTCTAGTAGAGGTAGGAGTAGGTACAGGTTGAACGGTTTATCCACCTTTAAGCTC ATCAGCTCTAGTAGAGGTAGGAGTAGGTACAGGTTGAACGGTTTATCCACCTTTAAGCTC ATCTGCTTTAGTTGAAGTGGGTGTAGGTACAGGATGAACCGTATATCCTCCTTTAAGTTC ATCTGCTTTAGTTGAAGTGGGTGTAGGTACAGGATGAACCGTATATCCTCCTTTAAGTTC ATCTGCTTTAGTTGAAGTGGGTGTAGGTACAGGATGAACCGTATATCCTCCTTTAAGTTC ATCTGCTTTAGTTGAAGTGGGTGTAGGTACAGGATGAACCGTATATCCTCCTTTAAGTTC ATCTGCTTTAGTTGAAGTGGGTGTAGGTACAGGATGAACCGTATATCCTCCTTTAAGTTC ATCTGCTTTAGTTGAAGTGGGTGTAGGTACAGGATGAACCGTATATCCTCCTTTAAGTTC ATCTGCTTTAGTTGAAGTGGGTGTAGGTACAGGATGAACCGTATATCCTCCTTTAAGTTC ATCTGCTTTAGTTGAAGTGGGTGTAGGTACAGGATGAACCGTATATCCTCCTTTAAGTTC ATCTGCTTTAGTTGAAGTGGGTGTAGGTACAGGATGAACCGTATATCCTCCTTTAAGTTC ATCTGCTTTAGTTGAAGTGGGTGTAGGTACAGGATGAACCGTATATCCTCCTTTAAGTTC ATCTGCTTTAGTTGAAGTGGGTGTAGGTACAGGATGAACCGTATATCCTCCTTTAAGTTC ATCTGCTTTAGTTGAAGTGGGTGTAGGTACAGGATGAACCGTATATCCTCCTTTAAGTTC ATCTGCTTTAGTTGAAGTGGGTGTAGGTACAGGATGAACCGTATATCCTCCTTTAAGTTC ATCTGCTTTAGTTGAAGTGGGTGTAGGTACAGGATGAACCGTATATCCTCCTTTAAGTTC ATCTGCTTTAGTTGAAGTGGGTGTAGGTACAGGATGAACCGTATATCCTCCTTTAAGTTC ATCTGCTTTAGTTGAAGTGGGTGTAGGTACAGGATGAACCGTATATCCTCCTTTAAGTTC ATCTGCTTTAGTTGAAGTGGGTGTAGGTACAGGATGAACCGTATATCCTCCTTTAAGTTC ATCTGCTTTAGTTGAAGTGGGTGTAGGTACAGGATGAACCGTATATCCTCCTTTAAGTTC ATCTGCTTTAGTTGAAGTGGGTGTAGGTACAGGATGAACCGTATATCCTCCTTTAAGTTC ATCTGCTTTAGTTGAAGTGGGTGTAGGTACAGGATGAACCGTATATCCTCCTTTAAGTTC ATCTGCTTTAGTTGAAGTGGGTGTAGGTACAGGATGAACCGTATATCCTCCTTTAAGTTC ATCTGCTTTAGTTGAAGTGGGTGTAGGTACAGGATGAACCGTATATCCTCCTTTAAGTTC ATCTGCTTTAGTTGAAGTGGGTGTAGGTACAGGATGAACCGTATATCCTCCTTTAAGTTC ATCTGCTTTAGTTGAAGTGGGTGTAGGTACAGGATGAACCGTATATCCTCCTTTAAGTTC ATCTGCTTTAGTTGAAGTGGGTGTAGGTACAGGATGAACCGTATATCCTCCTTTAAGTTC ATCTGCTTTAGTTGAAGTGGGTGTAGGTACAGGATGAACCGTATATCCTCCTTTAAGTTC ATCTGCTTTAGTAGAAGTTGGTGTAGGTACTGGATGAACAGTATATCCTCCTTTAAGTTC ATCTGCTTTAGTAGAAGTTGGTGTAGGTACTGGATGAACAGTATATCCTCCTTTAAGTTC ATCTGCTTTAGTAGAAGTTGGTGTAGGTACTGGATGAACAGTATATCCTCCTTTAAGTTC ATCTGCTTTAGTAGAAGTTGGTGTAGGTACTGGATGAACAGTATATCCTCCTTTAAGTTC ATCTGCTTTAGTAGAAGTTGGTGTAGGTACTGGATGAACAGTATATCCTCCTTTAAGTTC ATCTGCTTTGGTCGAAGTAGGTGTTGGTACAGGGTGAACAGTATATCCTCCTTTAAGTTC ATCTGCTTTAGTAGAAGTAGGAGTTGGTACAGGATGGACGGTTTATCCCCCTTTAAGTTC ATCAGCGCTAGTAGAAGTGGGTGTGGGTACAGGGTGAACTGTTTACCCCCCTTTAAGTTC ATCAGCGCTAGTAGAAGTGGGTGTGGGTACAGGGTGAACTGTTTACCCCCCTTTAAGTTC 
$\begin{array}{lllll}370 & 380 & 390 & 400 & 410\end{array}$ $\ldots|\ldots| \ldots|\ldots| \ldots|\ldots| \ldots|\ldots| \ldots|\ldots| \ldots|\ldots| \ldots|\ldots| \ldots|\ldots|$

ВОт0001 ВОТ0002 ВОт0005 IBC 0040 IBC0067 IBC0089 IBC 0098 IBC 0123 IBC 0137 IBC 0138 IBC 0174 IBC0185 IBC 0187 IBC 0188 IBC0189 IBC0196 IBC 0199 IBC 0202 IBC0244 IBC0252 ВОТ0004 IBC 0028 IBC 0051 IBC0064 IBC0139 IBC 0186 IBC0194 IBC0195 IBC 0197 IBC 0200 IBC0201 IBC0204 IBC0205 IBC 0210 IBC 0213 IBC 0214 IBC0216 IBC 0217 IBC 0242 IBC 0245 IBC0246 IBC 0247 IBC0248 IBC0249 IBC 0250 IBC0251 IBC 0041 IBC 0129 IBC 0184 IBC 0198 IBC0203 ВОТ0003 IBC 0190 IBC 0211 IBC 0212 CATACAAAGTCATTCTGGCGGGGCTGTAGATCTAGCGATTTTCAGTTTGCATGTGTCAGG САTACAAAGTCATTCTGGCGGGGCTGTAGATCTAGCGATTTTCAGTTTGCATGTGTCAGG САTACAAAGTCATTCTGGCGGGGCTGTAGATCTAGCGATTTTCAGTTTGCATGTGTCAGG CATACAAAGTCATTCTGGCGGGGCTGTAGATCTAGCGATTTTCAGTTTGCATGTGTCAGG САTACAAAGTCATTCTGGCGGGGCTGTAGATCTAGCGATTTTCAGTTTGCATGTGTCAGG CATACAAAGTCATTCTGGCGGGGCTGTAGATCTAGCGATTTTCAGTTTGCATGTGTCAGG CATACAAAGTCATTCTGGCGGGGCTGTAGATCTAGCGATTTTCAGTTTGCATGTGTCAGG САTACAAAGTCATTCTGGCGGGGCTGTAGATCTAGCGATTTTCAGTTTGCATGTGTCAGG CATACAAAGTCATTCTGGCGGGGCTGTAGATCTAGCGATTTTCAGTTTGCATGTGTCAGG CATACAAAGTCATTCTGGCGGGGCTGTAGATCTAGCGATTTTCAGTTTGCATGTGTCAGG САTACAAAGTCATTCTGGCGGGGCTGTAGATCTAGCGATTTTCAGTTTGCATGTGTCAGG САTACAAAGTCATTCTGGCGGGGCTGTAGATCTAGCGATTTTCAGTTTGCATGTGTCAGG CATACAAAGTCATTCTGGGGGGGCTGTAGATCTAGCGATTTTCAGTTTGCATGTGTCAGG САTACAAAGTCATTCTGGGGGGGCTGTAGATCTAGCGATTTTCAGTTTGCATGTGTCAGG CATACAAAGTCATTCTGGCGGGGCTGTAGATCTAGCGATTTTCAGTTTGCATGTGTCAGG CATACAAAGTCATTCTGGCGGGGCTGTAGATCTAGCGATTTTCAGTTTGCATGTGTCAGG CATACAAAGTCATTCTGGCGGGGCTGTAGATCTAGCGATTTTCAGTTTGCATGTGTCAGG CATACAAAGTCATTCTGGCGGGGCTGTAGATCTAGCGATTTTCAGTTTGCATGTGTCAGG CATACAAAGTCATTCTGGGGGGGCTGTAGATCTAGCGATTTTCAGTTTGCATGTGTCAGG CATACAAAGTCATTCTGGCGGGGCTGTAGATCTAGCGATTTTCAGTTTGCATGTGTCAGG TATACAAAGTCATTCTGGAGGGGCTGTAGATCTGGCTATATTTAGTTTGCATGTTTCTGG TATACAAAGTCATTCTGGAGGGGCTGTAGATCTGGCTATATTTAGTTTGCATGTTTCTGG TATACAAAGTCATTCTGGAGGGGCTGTAGATCTGGCTATATTTAGTTTGCATGTTTCTGG TATACAAAGTCATTCTGGAGGGGCTGTAGATCTGGCTATATTTAGTTTGCATGTTTCTGG TATACAAAGTCATTCTGGAGGGGCTGTAGATCTGGCTATATTTAGTTTGCATGTTTCTGG TATACAAAGTCATTCTGGAGGGGCTGTAGATCTGGCTATATTTAGTTTGCATGTTTCTGG TATACAAAGTCATTCTGGAGGGGCTGTAGATCTGGCTATATTTAGTTTGCATGTTTCTGG TATACAAAGTCATTCTGGAGGGGCTGTAGATCTGGCTATATTTAGTTTGCATGTTTCTGG TATACAAAGTCATTCTGGAGGGGCTGTAGATCTGGCTATATTTAGTTTGCATGTTTCTGG TATACAAAGTCATTCTGGAGGGGCTGAAAATCTGGCTATATTTAGTTTGCATGTTTCTGG TATACAAAGTCATTCTGGAGGGGCTGTAGATCTGGCTATATTTAGTTTGCATGTTTCTGG TATACAAAGTCATTCTGGAGGGGCTGTAGATCTGGCTATATTTAGTTTGCATGTTTCTGG TATACAAAGTCATTCTGGAGGGGCTGTAGATCTGGCTATATTTAGTTTGCATGTTTCTGG TATACAAAGTCATTCTGGAGGGGCTGTAGATCTGGCTATATTTAGTTTGCATGTTTCTGG TATACAAAGTCATTCTGGAGGGGCTGTAGATCTGGCTATATTTAGTTTGCATGTTTCTGG TATACAAAGTCATTCTGGAGGGGCTGTAGATCTGGCTATATTTAGTTTGCATGTTTCTGG TATACAAAGTCATTCTGGAGGGGCTGTAGATCTGGCTATATTTAGTTTGCATGTTTCTGG TATACAAAGTCATTCTGGAGGGGCTGTAGATCTGGCTATATTTAGTTTGCATGTTTCTGG TATACAAAGTCATTCTGGAGGGGCTGTAGATCTGGCTATATTTAGTTTGCATGTTTCTGG TATACAAAGTCATTCTGGAGGGGCTGTAGATCTGGCTATATTTAGTTTGCATGTTTCTGG TATACAAAGTCATTCTGGAGGGGCTGTAGATCTGGCTATATTTAGTTTGCATGTTTCTGG TATACAAAGTCATTCTGGAGGGGCTGTAGATCTGGCTATATTTAGTTTGCATGTTTCTGG TATACAAAGTCATTCTGGAGGGGCTGTAGATCTGGCTATATTTAGTTTGCATGTTTCTGG TATACAAAGTCATTCTGGAGGGGCTGTAGATCTGGCTATATTTAGTTTGCATGTTTCTGG TATACAAAGTCATTCTGGAGGGGCTGTAGATCTGGCTATATTTAGTTTGCATGTTTCTGG TATACAAAGTCATTCTGGAGGGGCTGTAGATCTGGCTATATTTAGTTTGCATGTTTCTGG TATCCAAAGTCATTCTGGAGGTGCTGTAGACTTAGCAATATTTAGTTTACATGTGTCAGG TATCCAAAGTCATTCTGGAGGTGCTGTAGACTTAGCAATATTTAGTTTACATGTGTCAGG TATCCAAAGTCATTCTGGAGGTGCTGTAGACTTAGCAATATTTAGTTTACATGTGTCAGG TATCCAAAGTCATTCTGGAGGTGCTGTAGACTTAGCAATATTTAGTTTACATGTGTCAGG TATCCAAAGTCATTCTGGAGGTGCTGTAGACTTAGCAATATTTAGTTTACATGTGTCAGG TATTCAAAGTCATTCTGGTGGGGCTGTAGATTTGGCTATATTTAGTTTACACGTTTCAGG TATACAAAGTCATTCTGGGGGGGCTGTAGATTTGGCGATATTTAGTCTACATGTATCAGG TATACAAAGTCATTCTGGAGGGGCTGTAGATTTAGCAATATTTAGTTTACATGTATCAGG TATACAAAGTCATTCTGGAGGGGCTGTAGATTTAGCAATATTTAGTTTACATGTATCAGG 


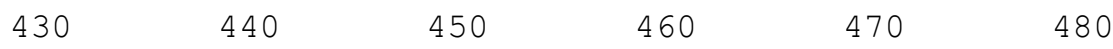
$\ldots|\ldots| \ldots|\ldots| \ldots|\ldots| \ldots|\ldots| \ldots|\ldots| \ldots|\ldots| \ldots|\ldots| \ldots \mid$

ВОT0001 ВОТ0002 ВОт0005 IBC 0040 IBC0067 IBC0089 IBC0098 IBC 0123 IBC 0137 IBC 0138 IBC 0174 IBC 0185 IBC 0187 IBC 0188 IBC0189 IBC0196 IBC 0199 IBC 0202 IBC 0244 IBC0252 ВОТ0004 IBC 0028 IBC 0051 IBC0064 IBC 0139 IBC 0186 IBC0194 IBC0195 IBC 0197 IBC0200 IBC 0201 IBC0204 IBC0205 IBC 0210 IBC 0213 IBC0214 IBC0216 IBC 0217 IBC 0242 IBC 0245 IBC0246 IBC 0247 IBC0248 IBC0249 IBC 0250 IBC 0251 IBC 0041 IBC0129 IBC 0184 IBC 0198 IBC0203 ВОТ0003 IBC 0190 IBC 0211 IBC 0212 TGCTTCATCAATTTTAGGAGCTGTAAATTTTATTTCAACTATTTTAAATATGAGAAGCCC TGCTTCATCAATTTAGGAGCTGTAAATTTATTTCAACTATTTTAAATATGAGAAGCCC TGCTTCATCAATTTTAGGAGCTGTAAATTTTATTTCAACTATTTTAAATATGAGAAGCCC TGCTTCATCAATTTTAGGAGCTGTAAATTTTATTTCAACTATTTTAAATATGAAAAGCCC TGCTTCATCAATTTTAGGAGCTGTAAATTTTATTTCAACTATTTTAAATATGAGAAGCCC TGCTTCATCAATTTTAGGAGCTGTAAATTTTATTTCAACTATTTTAAATATGAGAAGCCC TGCTTCATCAATTTTAGGAGCTGTAAATTTTATTTCAACTATTTTAAATATGAGAAGCCC TGCTTCATCAATTTTAGGAGCTGTAAATTTTATTTCAACTATTTTAAATATGAGAAGCCC TGCTTCATCAATTTTAGGAGCTGTAAATTTTATTTCAACTATTTTAAATATGAGAAGCCC TGCTTCATCAATTTTAGGAGCTGTAAATTTTATTTCAАСTATTTTAAATATGAGAAGCCC TGCTTCATCAATTTTAGGAGCTGTAAATTTTATTTCAACTATTTTAAATATGAGAAGCCC TGCTTCATCAATTTTAGGAGCTGTAAATTTTATTTCAACTATTTTAAATATGAAAAGCCC TGCTTCATCAATTTTAGGAGCTGTAAATTTTATTTCAACTATTTTAAATATGAGAAGCCC TGCTTCATCAATTTTAGGAGCTGTAAATTTTATTTCAACTATTTTAAATATGAGAAGCCC TGCTTCATCAATTTTAGGAGCTGTAAATTTTATTTCAACTATTTTAAATATGAGAAGCCC TGCTTCATCAATTTTAGGAGCTGTAAATTTTATTTCAACTATTTTAAATATGAGAAGCCC TGCTTCATCAATTTTAGGAGCTGTAAATTTTATTTCAACTATTTTAAATATGAGAAGCCC TGCTTCATCAATTTTAGGAGCTGTAAATTTTATTTCAACTATTTTAAATATGAGAAGCCC TGCTTCATCAATTTTAGGAGCTGTAAATTTTATTTCAACTATTTTAAATATGAGAAGCCC TGCTTCATCAATTTTAGGAGCTGTAAATTTTATTTCAACTATTTTAAATATGAGAAGCCC AGCTTCTTCTATCTTAGGTGCAGTAAATTTTATATCGACTATTCTAAATATGCGAAGTCC AGCTTCTTCTATCTTAGGTGCAGTAAATTTTATATCGACTATTCTAAATATGCGAAGTCC AGCTTCTTCTATCTTAGGTGCAGTAAATTTTATATCGACTATTCTAAATATGCGAAGTCC AGCTTCTTCTATCTTAGGTGCAGTAAATTTTATATCGACTATTCTAAATATGCGAAGTCC AGCTTCTTCTATCTTAGGTGCAGTAAATTTTATATCGACTATTCTAAATATGCGAAGTCC AGCTTCTTCTATCTTAGGTGCAGTAAATTTTATATCGACTATTCTAAATATGCGAAGTCC AGCTTCTTCTATCTTAGGAGCAGTAAATTTTATATCGACTATTCTAAATATGCGAAGTCC AGCTTCTTCTATCTTAGGTGCAGTAAATTTTATATCGACTATTCTAAATATGCGAAGTCC AGCTTCTTCTATCTTAGGTGCAGTAAATTTTATATCGACTATTCTAAATATGCGAAGTCC AGCTTCTTCTATCTTAGGTGCAGTAAATTTTATATCGACTATTCTAAATATGCGAAGTCC AGCTTCTTCTATCTTAGGTGCAGTAAATTTTATATCGACTATTCTAAATATGCGAAGTCC AGCTTCTTCTATCTTAGGTGCAGTAAATTTTATATCGACTATTCTAAATATGCGAAGTCC AGCTTCTTCTATCTTAGGTGCAGTAAATTTTATATCGACTATTCTAAATATGCGAAGTCC AGCTTCTTCTATCTTAGGTGCAGTAAATTTTATATCGACTATTCTAAATATGCGAAGTCC AGCTTCTTCTATCTTAGGTGCAGTAAATTTTATATCGACTATTCTAAATATGCGAAGTCC AGCTTCTTCTATCTTAGGTGCAGTAAATTTTATATCGACTATTCTAAATATGCGAAGTCC AGCTTCTTCTATCTTAGGTGCAGTAAATTTTATATCGACTATTCTAAATATGCGAAGTCC AGCTTCTTCTATCTTAGGTGCAGTAAATTTTATATCGACTATTCTAAATATGCGAAGTCC AGCTTCTTCTATCTTAGGTGCAGTAAATTTTATATCGACTATTCTAAATATGCGAAGTCC AGCTTCTTCTATCTTAGGTGCAGTAAATTTTATATCGACTATTCTAAATATGCGAAGTCC AGCTTCTTCTATCTTAGGTGCAGTAAATTTTATATCGACTATTCTAAATATGCGAAGTCC AGCTTCTTCTATCTTAGGTGCAGTAAATTTTATATCGACTATTCTAAATATGCGAAGTCC AGCTTCTTCTATCTTAGGTGCAGTAAATTTTATATCGACTATTCTAAATATGCGAAGTCC AGCTTCTTCTATCTTAGGTGCAGTAAATTTTATATCGACTATTCTAAATATGCGAAGTCC AGCTTCTTCTATCTTAGGTGCAGTAAATTTTATATCGACTATTCTAAATATGCGAAGTCC AGCTTCTTCTATCTTAGGTGCAGTAAATTTTATATCGACTATTCTAAATATGCGAAGTCC AGCTTCTTCAATTTTAGGAGCAGTAAATTTTATATCTACTATATTAAATATGAGAAGTCC AGCTTCTTCAATTTTAGGAGCAGTAAATTTTATATCTACTATATTAAATATGAGAAGTCC AGCTTCTTCAATTTTAGGAGCAGTAAATTTTATATCTACTATATTAAATATGAGAAGTCC AGCTTCTTCAATTTTAGGAGCAGTAAATTTTATATCTACTATATTAAATATGAGAAGTCC AGCTTCTTCAATTTTAGGAGCAGTAAATTTTATATCTACTATATTAAATATGAGAAGTCC AGCTTCTTCAATTTTAGGTGCGGTTAATTTTATATCTACTATATTAAACATGCGGAGTCC AGCTTCTTCAATTTTAGGAGCTGTAAACTTTATATCAACTATCTTAAATATGAGGAGTCC AGCGTCTTCAATTTAGGAGCGGTAAATTTTATATCGACTATATTAAATATGAGAAGTCC AGCGTCTTCAATTTTAGGAGCGGTAAATTTTATATCGACTATATTAAATATGAGAAGTCC 
$490 \quad 500 \quad 510 \quad 520 \quad 530 \quad 540$ $\ldots|\ldots| \ldots|\ldots| \ldots|\ldots| \ldots|\ldots| \ldots|\ldots| \ldots|\ldots| \ldots|\ldots| \ldots \mid$

ВОT0001 ВОТ0002 ВОт0005 IBC 0040 IBC0067 IBC0089 IBC0098 IBC 0123 IBC 0137 IBC 0138 IBC 0174 IBC 0185 IBC 0187 IBC 0188 IBC0189 IBC0196 IBC 0199 IBC 0202 IBC 0244 IBC0252 ВОТ0004 IBC 0028 IBC 0051 IBC0064 IBC0139 IBC 0186 IBC0194 IBC0195 IBC 0197 IBC0200 IBC 0201 IBC0204 IBC0205 IBC 0210 IBC 0213 IBC0214 IBC0216 IBC 0217 IBC 0242 IBC 0245 IBC0246 IBC 0247 IBC0248 IBC0249 IBC 0250 IBC 0251 IBC 0041 IBC 0129 IBC 0184 IBC 0198 IBC0203 ВОТ0003 IBC 0190 IBC 0211 IBC 0212 TGGACAAAGTATGTATAGAATACCTTTATTCGTGTGATCGATTTTCGTAACAGCATTTTT TGGACAAAGTATGTATAGAATACCTTTATTCGTGTGATCGATTTTCGTAACAGCATTTTT TGGACAAAGTATGTATAGAATACCTTTATTCGTGTGATCGATTTTCGTAACAGCATTTTT TGGACAAAGTATGTATAGAATACCTTTATTCGTGTGATCGATTTTCGTAACAGCATTTTT TGGACAAAGTATGTATAGAATACCTTTATTCGTGTGATCGATTTTCGTAACAGCATTTTT TGGACAAAGTATGTATAGAATACCTTTATTCGTGTGATCGATTTTCGTAACAGCATTTTT TGGACAAAGTATGTATAGAATACCTTTATTCGTGTGATCGATTTTCGTAACAGCATTTTT TGGACAAAGTATGTATAGAATACCTTTATTCGTGTGATCGATTTTCGTAACAGCATTTTT TGGACAAAGTATGTATAGAATACCTTTATTCGTGTGATCGATTTTCGTAACAGCATTTTT TGGACAAAGTATGTATAGAATACCTTTATTCGTGTGATCGATTTTCGTAACAGCATTTTT TGGACAAAGTATGTATAGAATACCTTTATTCGTGTGATCGATTTTCGTAACAGCATTTTT TGGACAAAGTATGTATAGAATACCTTTATTCGTGTGATCGATTTTCGTAACAGCATTTTT TGGGCAAAGTATGTATAGAATACCTTTATTCGTGTGATCGATTTTCGTAACAGCATTTTT TGGGCAAAGTATGTATAGAATACCTTTATTCGTGTGATCGATTTTCGTAACAGCATTTTT TGGACAAAGTATGTATAGAATACCTTTATTCGTGTGATCGATTTTCGTAACAGCATTTTT TGGACAAAGTATGTATAGAATACCTTTATTCGTGTGATCGATTTTCGTAACAGCATTTTT TGGACAAAGTATGTATAGAATACCTTTATTCGTGTGATCGATTTTCGTAACAGCATTTTT TGGACAAAGTATGTATAGAATACCTTTATTCGTGTGATCGATTTTCGTAACAGCATTTTT TGGGCAAAGTATGTATAGAATACCTTTATTCGTGTGATCGATTTTCGTAACAGCATTTTT TGGACAAAGTATGTATAGAATACCTTTATTCGTGTGATCGATTTTCGTAACAGCATTTTT AGGGCAAAATATGTATAGAATACCTTTATTTGTTTGGTCTATATTTGTAACTGCTTTATT AGGGCAAAATATGTATAGAATACCTTTATTTGTTTGGTCTATATTTGTAACTGCTTTATT AGGGCAAAATATGTATAGAATACCTTTATTTGTTTGGTCTATATTTGTAACTGCTTTATT AGGGCAAAATATGTATAGAATACCTTTATTTGTTTGGTCTATATTTGTAACTGCTTTATT AGGGCAAAATATGTATAGAATACCTTTATTTGTTTGGTCTATATTTGTAACTGCTTTATT AGGGCAAAATATGTATAGAATACCTTTATTTGTTTGGTCTATATTTGTAACTGCTTTATT AGGGCAAAATATGTATAGAATACCTTTATTTGTTTGGTCTATATTTGTAACTGCTTTATT AGGGCAAAATATGTATAGAATACCTTTATTTGTTTGGTCTATATTTGTAACTGCTTTATT AGGGCAAAATATGTATAGAATACCTTTATTTGTTTGGTCTATATTTGTAACTGCTTTATT AGGGCAAAATATGTATAGAATACCTTTATTTGTTTGGTCTATATTTGTAACTGCTTTATT AGGGCAAAATATGTATAGAATACCTTTATTTGTTTGGTCTATATTTGTAACTGCTTTATT AGGGCAAAATATGTATAGAATACCTTTATTTGTTTGGTCTATATTTGTAACTGCTTTATT AGGGCAAAATATGTATAGAATACCTTTATTTGTTTGGTCTATATTTGTAACTGCTTTATT AGGGCAAAATATGTATAGAATACCTTTATTTGTTTGGTCTATATTTGTAACTGCTTTATT AGGGCAAAATATGTATAGAATACCTTTATTTGTTTGGTCTATATTTGTAACTGCTTTATT AGGGCAAAATATGTATAGAATACCTTTATTTGTTTGGTCTATATTTGTAACTGCTTTATT AGGGCAAAATATGTATAGAATACCTTTATTTGTTTGGTCTATATTTGTAACTGCTTTATT AGGGCAAAATATGTATAGAATACCTTTATTTGTTTGGTCTATATTTGTAACTGCTTTATT AGGGCAAAATATGTATAGAATACCTTTATTTGTTTGGTCTATATTTGTAACTGCTTTATT AGGGCAAAATATGTATAGAATACCTTTATTTGTTTGGTCTATATTTGTAACTGCTTTATT AGGGCAAAATATGTATAGAATACCTTTATTTGTTTGGTCTATATTTGTAACTGCTTTATT AGGGCAAAATATGTATAGAATACCTTTATTTGTTTGGTCTATATTTGTAACTGCTTTATT AGGGCAAAATATGTATAGAATACCTTTATTTGTTTGGTCTATATTTGTAACTGCTTTATT AGGGCAAAATATGTATAGAATACCTTTATTTGTTTGGTCTATATTTGTAACTGCTTTATT AGGGCAAAATATGTATAGAATACCTTTATTTGTTTGGTCTATATTTGTAACTGCTTTATT AGGGCAAAATATGTATAGAATACCTTTATTTGTTTGGTCTATATTTGTAACTGCTTTATT TGGGCAAAGTATGTACAGAATACCTTTGTTTGTATGATCTATTTTTGTAACGGCATTTTT TGGGCAAAGTATGTACAGAATACCTTTGTTTGTATGATCTATTTTTGTAACGGCATTTTT TGGGCAAAGTATGTACAGAATACCTTTGTTTGTATGATCTATTTTTGTAACGGCATTTTT TGGGCAAAGTATGTACAGAATACCTTTGTTTGTATGATCTATTTTTGTAACGGCATTTTT TGGGCAAAGTATGTACAGAATACCTTTGTTTGTATGATCTATTTTTGTAACGGCATTTTT AGGACAAAGTATGTACAGACTACCTTTGTTCGTATGGTCTATTTTTGTAACGGCGTTTTT AGGGCAAAGTATGTATAGAATACCTCTATTTGTGTGATCTATTTTTGTAACAGCTTTTTT AGGACAAAGCATGTATAGAATTCCTTTATTCGTATGATCCATTTTTGTAACTGCTTTTTT AGGACAAAGCATGTATAGAATTCCTTTATTCGTATGATCCATTTTTGTAACTGCTTTTTT 
$550 \quad 560 \quad 570 \quad 580 \quad 590 \quad 600$ $\ldots|\ldots| \ldots|\ldots| \ldots|\ldots| \ldots|\ldots| \ldots|\ldots| \ldots|\ldots| \ldots|\ldots| \ldots \mid$

ВОT0001 ВОТ0002 ВОт0005 IBC 0040 IBC0067 IBC0089 IBC 0098 IBC 0123 IBC 0137 IBC 0138 IBC 0174 IBC 0185 IBC 0187 IBC 0188 IBC0189 IBC0196 IBC 0199 IBC 0202 IBC0244 IBC0252 ВОТ0004 IBC 0028 IBC 0051 IBC0064 IBC0139 IBC0186 IBC0194 IBC0195 IBC 0197 IBC 0200 IBC 0201 IBC0204 IBC0205 IBC 0210 IBC 0213 IBC0214 IBC0216 IBC 0217 IBC 0242 IBC 0245 IBC0246 IBC 0247 IBC0248 IBC0249 IBC 0250 IBC 0251 IBC 0041 IBC0129 IBC 0184 IBC 0198 IBC0203 ВОТ0003 IBC 0190 IBC 0211 IBC 0212 ATTATTATTAGCCGTACCTGTTTTAGCAGGTGCAATTACAATGCTTTTAACAGACCGTAA ATTATTATTAGCCGTACCTGTTTTAGCAGGTGCAATTACAATGCTTTTAACAGACCGTAA АTTATTATTAGCCGTACCTGTTTTAGCAGGTGCAATTACAATGCTTTTAACAGACCGTAA ATTATTATTAGCCGTACCTGTTTTAGCAGGTGCAATTACAATGCTTTTAACAGACCGTAA АTTATTATTAGCCGTACCTGTTTTAGCAGGTGCAATTACAATGCTTTTAACAGACCGTAA ATTATTATTAGCCGTACCTGTTTTAGCAGGTGCAATTACAATGCTTTTAACAGACCGTAA ATTATTATTAGCCGTACCTGTTTTAGCAGGTGCAATTACAATGCTTTTAACAGACCGTAA ATTATTATTAGCCGTACCTGTTTTAGCAGGTGCAATTACAATGCTTTTAACAGACCGTAA ATTATTATTAGCCGTACCTGTTTTAGCAGGTGCAATTACAATGCTTTTAACAGACCGTAA АTTATTATTAGCCGTACCTGTTTTAGCAGGTGCAATTACAATGCTTTTAACAGACCGTAA АTTATTATTAGCCGTACCTGTTTTAGCAGGTGCAATTACAATGCTTTTAACAGACCGTAA ATTATTATTAGCCGTACCTGTTTTAGCAGGTGCAATTACAATGCTTTTAACAGACCGTAA ATTATTATTAGCCGTACCTGTTTTAGCAGGTGCAATTACAATGCTTTTAACAGACCGTAA АTTATTATTAGCCGTACCTGTTTTAGCAGGTGCAATTACAATGCTTTTAACAGACCGTAA ATTATTATTAGCCGTACCTGTTTTAGCAGGTGCAATTACAATGCTTTTAACAGACCGTAA ATTATTATTAGCCGTACCTGTTTTAGCAGGTGCAATTACAATGCTTTTAACAGACCGTAA ATTATTATTAGCCGTACCTGTTTTAGCAGGTGCAATTACAATGCTTTTAACAGACCGTAA ATTATTATTAGCCGTACCTGTTTTAGCAGGTGCAATTACAATGCTTTTAACAGACCGTAA ATTATTATTAGCCGTACCTGTTTTAGCAGGTGCAATTACAATGCTTTTAACAGACCGTAA ATTATTATTAGCCGTACCTGTTTTAGCAGGTGCAATTACAATGCTTTTAACAGACCGTAA ATTATTATTAGCAGTACCTGTTTTGGCAGGAGCTATTACTATGCTTTTAACTGACAGGAA АTTATTATTAGCAGTACCTGTTTTGGCAGGAGCTATTACTATGCTTTTAACTGACAGGAA ATTATTATTAGCAGTACCTGTTTTGGCAGGAGCTATTACTATGCTTTTAACTGACAGGAA ATTATTATTAGCAGTACCTGTTTTGGCAGGAGCTATTACTATGCTTTTAACTGACAGGAA АTTATTATTAGCAGTACCTGTTTTGGCAGGAGCTATTACTATGCTTTTAACTGACAGGAA ATTATTATTAGCAGTACCTGTTTTGGCAGGAGCTATTACTATGCTTTTAACTGACAGGAA ATTATTATTAGCAGTACCTGTTTTGGCAGGAGCTATTACTATGCTTTTAACTGACAGGAA АTTATTATTAGCAGTACCTGTTTTGGCAGGAGCTATTACTATGCTTTTAACTGACAGGAA АTTATTATTAGCAGTACCTGTTTTGGCAGGAGCTATTACTATGCTTTTAACTGACAGGAA АTTATTATTAGCAGTACCTGTTTTGGCAGGAGCTATTACTATGCTTTTAACTGACAGGAA ATTATTATTAGCAGTACCTGTTTTGGCAGGAGCTATTACTATGCTTTTAACTGACAGGAA АTTATTATTAGCAGTACCTGTTTTGGCAGGAGCTATTACTATGCTTTTAACTGACAGGAA АTTATTATTAGCAGTACCTGTTTTGGCAGGAGCTATTACTATGCTTTTAACTGACAGGAA ATTATTATTAGCAGTACCTGTTTTGGCAGGAGCTATTACTATGCTTTTAACTGACAGGAA ATTATTATTAGCAGTACCTGTTTTGGCAGGAGCTATTACTATGCTTTTAACTGACAGGAA ATTATTATTAGCAGTACCTGTTTTGGCAGGAGCTATTACTATGCTTTTAACTGACAGGAA ATTATTATTAGCAGTACCTGTTTTGGCAGGAGCTATTACTATGCTTTTAACTGACAGGAA ATTATTATTAGCAGTACCTGTTTTGGCAGGAGCTATTACTATGCTTTTAACTGACAGGAA ATTATTATTAGCAGTACCTGTTTTGGCAGGAGCTATTACTATGCTTTTAACTGACAGGAA ATTATTATTAGCAGTACCTGTTTTGGCAGGAGCTATTACTATGCTTTTAACTGACAGGAA АTTATTATTAGCAGTACCTGTTTTGGCAGGAGCTATTACTATGCTTTTAACTGACAGGAA ATTATTATTAGCAGTACCTGTTTTGGCAGGAGCTATTACTATGCTTTTAACTGACAGGAA АTTATTATTAGCAGTACCTGTTTTGGCAGGAGCTATTACTATGCTTTTAACTGACAGGAA АTTATTATTAGCAGTACCTGTTTTGGCAGGAGCTATTACTATGCTTTTAACTGACAGGAA ATTATTATTAGCAGTACCTGTTTTGGCAGGAGCTATTACTATGCTTTTAACTGACAGGAA АTTATTATTAGCAGTACCTGTTTTGGCAGGAGCTATTACTATGCTTTTAACTGACAGGAA ATTATTATTAGCAGTACCTGTTTTAGCTGGTGCTATTACGATGCTTTTAACTGATCGAAA ATTATTATTAGCAGTACCTGTTTTAGCTGGTGCTATTACGATGCTTTTAACTGATCGAAA ATTATTATTAGCAGTACCTGTTTTAGCTGGTGCTATTACGATGCTTTTAACTGATCGAAA ATTATTATTAGCAGTACCTGTTTTAGCTGGTGCTATTACGATGCTTTTAACTGATCGAAA ATTATTATTAGCAGTACCTGTTTTAGCTGGTGCTATTACGATGCTTTTAACTGATCGAAA ATTGTTATTAGCAGTACCTGTTTTAGCAGGGGCTATTACCATGCTTCTAACAGATAGGAA GTTATTATTAGCAGTACCTGTTCTTGCAGGAGCCATTACAATGCTTTTAACAGATCGTAA ACTATTATTAGCTGTACCTGTTTTAGCGGGGGCCATTACTATGCTTTTAACTGATAGGAA АСTATTATTAGCTGTACСTGTTTTAGCGGGGGCСTTACTATGCTTTTAACTGATAGGAA 
610

$\ldots|\ldots| \ldots \mid \ldots$

ВОT0001 TTTTAACACATCTTTTT

ВОT0002 TTTTAАСАСАТСТTTTT

ВОT0005 TTTTAАСАСАТСТTTTT

IBC0040 TTTTAACACATCTTTTT

IBC0067 TTTTAACACATCTTTTT

IBC0089 TTTTAACACATCTTTTT

IBC0098 TTTTAACACATCTTTTT

IBC0123 TTTTAACACATCTTTTT

IBC0137 TTTTAACACATCTTTTT

IBC0138 TTTTAACACATCTTTTT

IBC0174 TTTTAACACATCTTTTT

IBC0185 TTTTAACACATCTTTTT

IBC0187 TTTTAACACATCTTTTT

IBC0188 TTTTAACACATCTTTTT

IBC0189 TTTTAACACATCTTTTT

IBC0196 TTTTAACACATCTTTTT

IBC0199 TTTTAACACATCTTTTT

IBC0202 TTTTAACACATCTTTTT

IBC0244 TTTTAACACATCTTTTT

IBC0252 TTTTAACACATCTTTTT

ВОT0004 ТTTТААСАСТTСТTТTT

IBC0028 TTTTAАСАСТTСТTTTT

IBC0051 TTTTAACACTTCTTTTT

IBC0064 TTTTAACACTTCTTTTT

IBC0139 TTTTAACACTTCTTTTT

IBC0186 TTTTAACACTTCTTTTT

IBC0194 TTTTAACACTTCTTTTT

IBC0195 TTTTAACACTTCTTTTT

IBC0197 TTTTAACACTTСТTTTT

IBC0200 TTTTAACACTTCTTTTT

IBC0201 TTTTAACACTTСTTTTT

IBC0204 TTTTAACACTTCTTTTT

IBC0205 TTTTAACACTTCTTTTT

IBC0210 TTTTAACACTTCTTTTT

IBC0213 TTTTAACACTTCTTTTT

IBC0214 TTTTAАСАСТTСТTTTT

IBC0216 TTTTAACACTTCTTTTT

IBC0217 TTTTAACACTTCTTTTT

IBC0242 TTTTAACACTTCTTTTT

IBC0245 TTTTAACACTTCTTTTT

IBC0246 TTTTAACACTTСTTTTT

IBC0247 TTTTAACACTTCTTTTT

IBC0248 TTTTAАСАСТTСТTTTT

IBC0249 TTTTAACACTTCTTTTT

IBC0250 TTTTAACACTTCTTTTT

IBC0251 TTTTAACACTTCTTTTT

IBC0041 TTTTAATACTTCATTTT

IBC0129 TTTTAATACTTCATTTT

IBC0184 TTTTAATACTTCATTTT

IBC0198 TTTTAATACTTCATTTT

IBC0203 TTTTAATACTTCATTTT

ВОT0003 ТTTTAАТАСТTСТTТСТ

IBC0190 TTTTAATACTTCATTTT

IBC0211 TTTTAATACTTCATTCT

IBC0212 TTTTAАTACTTCATTCT 
ANEXO II - Matriz de sequências de UPA das espécies de Hypnea sequenciadas neste estudo. As amostras estão identificadas de acordo com a Tabela 5.

$\begin{array}{lllll}10 & 20 & 30 & 40 & 50\end{array}$

$\ldots|\ldots| \ldots|\ldots| \ldots|\ldots| \ldots|\ldots| \ldots|\ldots| \ldots|\ldots| \ldots|\ldots| \ldots \mid$

IBC28

IBC 64

IBC247

IBC 40

IBC 98

IBC 185

IBC129

IBC 190

ВОT003

IBC212

IBC28

IBC 64

IBC247

IBC 40

IBC 98

IBC 185

IBC 129

IBC 190

ВОT003

IBC 212

IBC28

IBC 64

IBC2 47

IBC 40

IBC 98

IBC 185

IBC 129

IBC 190

ВОТ003

IBC212

IBC28

IBC 64

IBC 247

IBC 40

IBC 98

IBC 185

IBC 129

IBC 190

ВОТ003

IBC 212
СTTTACTGTAGCTTGGAATTGAATTTGGGTATACTTTGCGCAGTATAGGTGGGAGGCAAA CTTTACTGTAGCTTGGAATTGAATTTGGGTATACTTTGCGCAGTATAGGTGGGAGGCAAA СTTTACTGTAGCTTGGAATTGAATTTGGGTATACTTTGCGCAGTATAGGTGGGAGGCAAA CTTTACTGTAGCTTGGAATTGGATTTGGGTATGCTTTGCGCAGTATAGGTGGGAGGCAAA СTTTACTGTAGCTTGGAATTGGATTTGGGTATGCTTTGCGCAGTATAGGTGGGAGGCAAA CTTTACTGTAGCTTGGAATTGGATTTGGGTATGCTTTGCGCAGTATAGGTGGGAGGCAAA СTTTACTGTAGCTTGGAATTGAATTTGGGTATACTTTGCGCAGTATAGGTGGGAGGCAAA СTTTACTGTAGTTTGGAATTGAATTTGGGTATGCTTTGCGCAGTATAGGTGGGAGGCAAA СTTTACTGTAGCTTGGAATTGAATTTGGGTATACTTTGCGCAGTATAGGTGGGAGGCAAA СTTTACTGTAGCTTGGAATTGAATTGGGTATATTTTGTGCAGTATAGGTGGGAGGCAAA

$$
\ldots|\ldots| \ldots|\ldots| \ldots|\ldots| \ldots|\ldots| \ldots|\ldots| \ldots|\ldots| \ldots|\ldots| \ldots|\ldots| \ldots \mid
$$
AАTAATATATTTGCGGATATATAGTAGCCAATAGTGAGATACCACTCTAAATATACTAGA АATAATATATTTGCGGATATATAGTAGCCAATAGTGAGATACCACTCTAAATATACTAGA AATAATATATTTGCGGATATATAGTAGCCAATAGTGAGATACCACTCTAAATATACTAGA GATAATATATTTGCGGATATATATTAGCCAACAGTGAGATACCACTCTAAGTATACTAGA GATAATATATTTGCGGATATATATTAGCCAACAGTGAGATACCACTCTAAGTATACTAGA GATAATATATTTGCGGATATATATTAGCCAACAGTGAGATACCACTCTAAGTATACTAGA GATTATATATTTGTGGATATATAGGAGCCAACAGTGAGATACCACTCTAATTATACTAGG GATAATATATTTGCGGATATATGGGAGCCAACAGTGAGATACCACTCTAAGTATACTAGG GATAATATATTTGTGGATATATAGGAGCCAGCAGTGAGATACCACTCTAAGTATACTAGA GATCATATATTTGCGGATATATAGGAGCCAACAGTGAGATACCACTCTAAATATGCTAGG

$$
\ldots|\ldots| \ldots|\ldots| \ldots|\ldots| \ldots|\ldots| \ldots|\ldots| \ldots|\ldots| \ldots|\ldots| \ldots|\ldots|
$$
ATTCTAACTTTGAAAGCCGTTAACCGGCCAAAGAACAGTTTCAGGTGGGCAGTTTGACTG ATTCTAACTTTGAAAGCCGTTAACCGGCCAAAGAACAGTTTCAGGTGGGCAGTTTGACTG АTTCTAACTTTGAAAGCCGTTAACCGGCCAAAGAACAGTTTCAGGTGGGCAGTTTGACTG АСTCTAACTTTGAAAGCCGTTAACAGGCCAAAGAACAGTTTCAGGTGGGCAGTTTGACTG ACTСTAACTTTGAAAGCCGTTAACAGGCCAAAGAACAGTTTCAGGTGGGCAGTTTGACTG ACTCTAACTTTGAAAGCCGTTAACAGACCAAAGAACAGTTTCAGGTGGGCAGTTTGACTG АTTCTAACTTTGAATGCCGTTAACCGGCCAAAGAACAGTTTCAGGTGGGCAGTTTGACTG ATTCTAACTTTGAAAGTCGTTAACCGGCCAAAGAACAGTTTCAGGTGGGCAGTTTGACTG ATTCTAACTTTGATAGCCGTTAACCGGCCAAAGAACAGTTTCAGGTGGGCAGTTTGACTG АTTCTAACTTTGAAAGCCGTTAGCCGGCCAAAGAACAGTTTCAGGTGGGCAGTTTGACTG

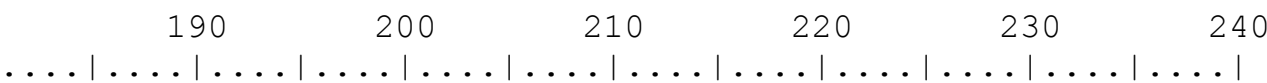
GGGCGGTCGCСTCCTAAAAAGTAACGGAGGCGTACAAAGGTTTCTTCAGACTGGTCGGAA GGGCGGTCGCСTCCTAAAAAGTAACGGAGGCGTACAAAGGTTTCTTCAGACTGGTCGGAA GGGCGGTCGCСTCCTAAAAAGTAACGGAGGCGTACAAAGGTTTCTTCAGACTGGTCGGAA GGGCGGTCGCСTCCTAAAAAGTAACGGAGGCGTACAAAGGTTTCTTCAGACTGGTCGGAA GGGCGGTCGCCTCCTAAAAAGTAACGGAGGCGTACAAAGGTTTCTTCAGACTGGTCGGAA GGGCGGTCGCСTCCTAAAAAGTAACGGAGGCGTACAAAGGTTTCTTCAGACTGGTCGGAA GGGCGGTCGCСTCCTAAAAAGTAACGGAGGCGTACAAAGGTTTCTTCAGACTGGTCGGAA GGGCGGTCGCСTCCTAAAAAGTAACGGAGGCGTACAAAGGTTTCTTCAGACTGGTCGGAA GGGCGGTCGCСTCСTAAAAAGTAACGGAGGCGTACAAAGGTTTCTTCAGACTGGTTGGAA GGGCGGTCGCCTCCTAAAAAGTAACGGAGGCGTACAAAGGTTTCTTCAGACTGGTCGGAA 
$250 \quad 260 \quad 270 \quad 280 \quad 290 \quad 300$ $\ldots|\ldots| \ldots|\ldots| \ldots|\ldots| \ldots|\ldots| \ldots|\ldots| \ldots|\ldots| \ldots|\ldots| \ldots \mid$

IBC28 ATCAGTCTTAGAGTATAAAGGCAAAAAGAAGCTTGACTGCAAGACCTACAAGTCGAGCAG
IBC64 ATCAGTCTTAGAGTATAAAGGCAAAAAGAAGCTTGACTGCAAGACCTACAAGTCGAGCAG

IBC247 ATCAGTCTTAGAGTATAAAGGCAAAAAGAAGCTTGACTGCAAGACCTACAAGTCGAGCAG IBC40 ATCAGTCTCAGAGTATAAAGGCATAAAGAAGCTTGACTGCAAGACCTACAAGTCGAGCAG IBC98 ATCAGTCTCAGAGTATAAAGGCATAAAGAAGCTTGACTGCAAGACCTACAAGTCGAGCAG IBC185 ATCAGTCTCAGAGTATAAAGGCATAAAGAAGCTTGACTGCAAGACCTACAAGTCGAGCAG IBC129 ATCAGTCATAGAGTATAAAGGCATAAAGAAGCTTGACTGCAAGACCTACAAGTCGAGCAG IBC190 ATCAGTCTTAGAGTATAAAGGCATAAAGAAGCTTGACTGCAAGACCTACAAGTCGAGCAG ВОT003 ATCAGTCTTAGAGTATAAAGGCATAAAGAAGCTTGACTGCAAGACCTACAAGTCGAGCAG IBC212 ATCAGTCTTAGAGTATAAAGGCATAAAGAAGCTTGACTGCAAGACTTACAAGTCGAGCAG

$$
\ldots|\ldots| \ldots|\ldots| \ldots|\ldots| \ldots|\ldots| \ldots|\ldots| \ldots|\ldots| \ldots|\ldots| \ldots|\ldots| \ldots \mid
$$

IBC28 AGACGAAAGTCGGTCTTAGTGATCCGACAGTTCTGAGTGGAAAGGCTGTCGCTCAACGGA IBC64 AGACGAAAGTCGGTCTTAGTGATCCGACAGTTCTGAGTGGAAAGGCTGTCGCTCAACGGA IBC247 AGACGAAAGTCGGTCTTAGTGATCCGACAGTTCTGAGTGGAAAGGCTGTCGCTCAACGGA IBC40 AGACGAAAGTCGGTCTTAGTGATCCGACAGTTCTGAGTGGAAAGGCTGTCGCTCAACGGA IBC98 AGACGAAAGTCGGTCTTAGTGATCCGACAGTTCTGAGTGGAAAGGCTGTCGCTCAACGGA IBC185 AGACGAAAGTCGGTCTTAGTGATCCGACAGTTCTGAGTGGAAAGGCTGTCGCTCAACGGA IBC129 AGACGAAAGTCGGTCTTAGTGATCCGACAGTGCTGAGTGGAAAGGCTGTCGCTCAACGGA IBC190 AGACGAAAGTCGGTCTTAGTGATCCGACAGTCCTGAGTGGAAAGGCTGTCGCTCAACGGA BOT003 AGACGAAAGTCGGTCTTAGTGATCCGACAGTTCTGAGTGGAAAGGCTGTCGCTCAACGGA IBC212 AGACGAAAGTCGGTCTTAGTGATCCGACAGTTCTGAGTGGAAAGGCTGTCGCTCAACGGA

$\begin{array}{ll}\text { IBC28 } & \text { TAAAAGTTA } \\ \text { IBC64 } & \text { TAAAAGTTA } \\ \text { IBC247 } & \text { TAAAAGTTA } \\ \text { IBC40 } & \text { TAAAAGTTA } \\ \text { IBC98 } & \text { TAAAAGTTA } \\ \text { IBC185 } & \text { TAAAAGTTA } \\ \text { IBC129 } & \text { TAAAAGTTA } \\ \text { IBC190 } & \text { TAAAAGTTA } \\ \text { BOT003 } & \text { TAAAAGTTA } \\ \text { IBC212 } & \text { TAAAAGTTA }\end{array}$


ANEXO III - Matriz de sequências de rbcL das espécies de Hypnea sequenciadas neste estudo. As amostras estão identificadas de acordo com a Tabela 5.

IBC0028

IBC0064

IBC0245

IBC 0040

IBC0098

IBC0185

IBC0129

BОT0003

IBC0212

IBC0190

IBC0028

IBC0064

IBC0245

IBC 0040

IBC0098

IBC0185

IBC 0129

ВОТ 0003

IBC0212

IBC 0190

IBC 0028

IBC0064

IBC0245

IBC 0040

IBC0098

IBC0185

IBC 0129

ВОТ0003

IBC0212

IBC0190

IBC0028

IBC0064

IBC0245

IBC 0040

IBC0098

IBC 0185

IBC 0129

ВОТ0003

IBC0212

IBC 0190

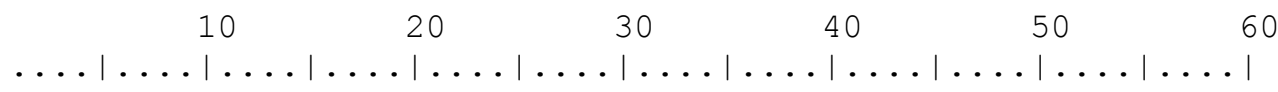
GCCTTATTTCGTGTGACTCCACAACCAGGAGTAGATCCCGTAGAAGCTTCTGCTGCTGTT GCCTTATTTCGTGTGACTCCACAACCAGGAGTAGATCCCGTAGAAGCTTCTGCTGCTGTT GCCTTATTTCGTGTGACTCCACAACCAGGAGTAGATCCCGTAGAAGCTTCTGCTGCTGTT GCTTTATTTCGTGTAACTCCACAACCAGGAGTAGATCCCGTTGAAGCTTCAGCTGCTGTT GCTTTATTTCGTGTAACTCCACAACCAGGAGTAGATCCCATTGAAGCTTCAGCTGCTGTT GCTTTATTTCGTGTAACTCCACAACCAGGAGTAGATCCCGTTGAAGCTTCAGCTGCTGTT GCTTTATTTCGTGTAACTCCACAACCAGGAGTTGATCCCGTTGAAGCTTCTGCTGCCGTT GCTTTATTTCGTGTAACTCCACAACCAGGAGTTGATCCCGTTGAAGCTTCTGCTGCTGTT GCTTTATTTCGTGTAACTCCACAACCAGGAGTTGATCCCGTTGAAGCTTCTGCTGCTGTT GCTTTATTTCGTGTAACTCCACAACCAGGAGTTGATCCCATTGAAGCTTCTGCTGCTGTT

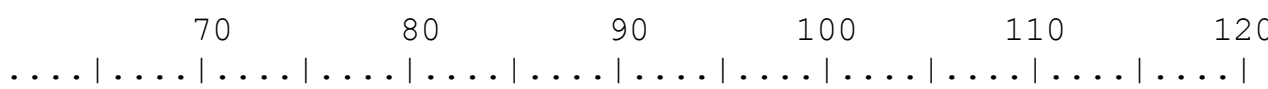
GCTGGTGAATCATCTACTGCAACTTGGACAGTTGTTTGGACAGATCTTTTAACTGCTTGT GCTGGTGAATCATCTACTGCAACTTGGACAGTTGTTTGGACAGATCTTTTAACTGCTTGT GCTGGTGAATCATCTACTGCAACTTGGACAGTTGTTTGGACAGATCTTTTAACTGCTTGT GCTGGTGAATCATCTACTGCAACTTGGACAGTTGTTTGGACAGATCTTTTAACTGCTTGC GCTGGTGAATCATCTACTGCAACTTGGACAGTTGTTTGGACAGATCTTTTAACTGCTTGC GCTGGTGAATCATCTACTGCAACTTGGACAGTTGTTTGGACAGATCTTTTAACTGCTTGC GCTGGTGAATCATCTACTGCAACTTGGACAGTTGTTTGGACAGATCTTTTAACTGCTTGT GCTGGTGAATCATCTACTGCAACTTGGACAGTTGTCTGGACAGATCTTTTAACTGCTTGT GCTGGTGAATCATCTACTGCAACTTGGACAGTTGTTTGGACAGATCTTTTAACTGCTTGT GCTGGTGAATCATCTACTGCAACTTGGACAGTTGTTTGGACAGATCTTTTAACTGCTTGT

$$
\begin{aligned}
& \begin{array}{llllll}
130 & 140 & 150 & 160 & 170 & 180
\end{array} \\
& \ldots . \ldots|\ldots| \ldots|\ldots| \ldots|\ldots| \ldots|\ldots| \ldots|\ldots| \ldots|\ldots| \ldots|\ldots|
\end{aligned}
$$

GACTTATATAGAGCTAAAGCATATAAAGTAGATGCTGTTCCTAATACATCAGATCAATAT GACTTATATAGAGCTAAAGCATATAAAGTAGATGCTGTTCCTAATACATCAGATCAATAT GACTTATATAGAGCTAAAGCATATAAAGTAGATGCTGTTCCTAATACATCAGATCAATAT GACTTATATAGAGCAAAAGCATACAAAGTAGATGCTGTGCCTAATACATCAGACCAGTAT GACTTATATAGAGCAAAAGCATACAAAGTAGATGCTGTGCCTAATACATCAGACCAGTAT GACTTATATAGAGCAAAAGCATACAAAGTAGATGCTGTGCCTAATACATCAGACCAGTAT GACTTATATAGAGCTAAAGCATATAAAGTAGATGCTGTTCCTAATACATCAGACCAATAT GACTTATACAGAGCTAAAGCATATAAAGTAGATGCTGTTCCTAATACATCGGACCAATAT GATTTATACAGAGCTAAAGCATATAAAGTAGATGCTGTTCCTAATACATCAGACCAATAT GACTTATATAGAGCAAAAGCATATAAAGTAGATGCTGTTCCAAATACATCAGACCAATAT

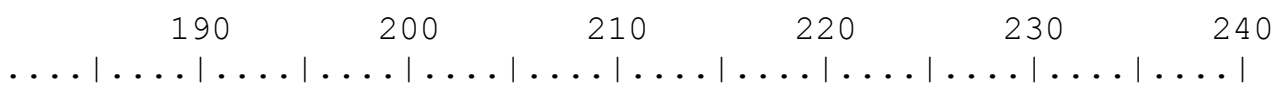
TTTGCTTTTATTGCATATGATATTGATCTTTTTGAAGAAGGATCTATTGCAAATTTAACA TTTGCTTTTATTGCATATGATATTGATCTTTTTGAAGAAGGATCTATTGCAAATTTAACA TTTGCTTTTATTGCATATGATATTGATCTTTTTGAAGAAGGATCTATTGCAAATTTAACA TTTGCTTTCATTGCATACGATATTGATCTTTTTGAAGAAGGATCTATTGCAAATTTAACA TTTGCTTTCATTGCATACGATATTGATCTTTTTGAAGAAGGATCTATTGCAAATTTAACA TTTGCTTTCATTGCATACGATATTGATCTTTTTGAAGAAGGATCTATTGCAAATTTAACA TTTGCTTTTATTGCATATGATATTGATCTTTTTGAAGAAGGATCTATTGCGAATTTAACA TTTGCTTTTATTGCATATGATATTGATCTTTTCGAAGAAGGATCTATTGCAAATTTAACA TTTGCTTTTATTGCATATGATATTGATCTTTTCGAGGAAGGATCTATTGCTAATTTAACA TTTGCTTTTATTGCATATGATATTGATCTTTTCGAAGAAGGATCTATTGCAAATTTAACA 
IBC 0028

IBC0064

IBC 0245

IBC 0040

IBC0098

IBC0185

IBC 0129

ВОТ0003

IBC0212

IBC 0190

IBC 0028

IBC 0064

IBC0245

IBC 0040

IBC0098

IBC0185

IBC0129

ВОT0003

IBC0212

IBC0190

IBC 0028

IBC0064

IBC0245

IBC 0040

IBC0098

IBC0185

IBC 0129

ВОT0003

IBC0212

IBC 0190

IBC0028

IBC0064

IBC0245

IBC 0040

IBC0098

IBC0185

IBC 0129

ВОТ0003

IBC 0212

IBC0190

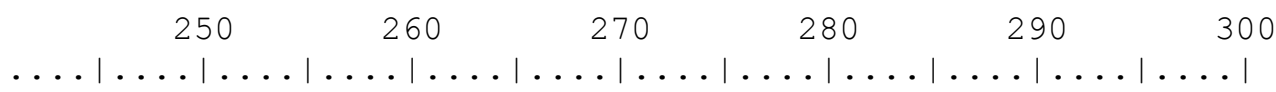

GCTTCAATTATTGGTAATGTTTTTGGTTTTAAAGCTGTAAAAGCTTTACGTTTAGAAGAT GCTTCAATTATTGGTAATGTTTTTGGTTTTAAAGCTGTAAAAGCTTTACGTTTAGAAGAT GCTTCAATTATTGGTAATGTTTTTGGTTTTAAAGCTGTAAAAGCTTTACGTTTAGAAGAT GCTTCAATTATTGGTAATGTTTTTGGTTTTAAAGCTGTTAAAGCTTTACGTTTAGAAGAT GCTTCAATTATTGGTAATGTTTTTGGTTTTAAAGCTGTTAAAGCTTTACGTTTAGAAGAT GCTTCAATTATTGGTAATGTTTTTGGTTTTAAAGCTGTTAAAGCTTTACGTTTAGAAGAT GCTTCAATTATTGGTAATGTTTTTGGTTTTAAAGCTGTAAAAGCTTTACGTTTAGAAGAT GCTTCAATTATTGGTAATGTTTTTGGTTTTAAAGCTGTAAAAGCTTTACGTTTAGAAGAT GCGTCAATTATTGGTAATGTTTTCGGTTTTAAAGCTGTAAAAGCTTTACGTTTAGAAGAT GCTTCAATTATCGGTAATGTTTTTGGTTTTAAGGCTGTCAAAGCTCTACGTTTAGAAGAT
310
320
330
340
350
360

$\ldots|\ldots| \ldots|\ldots| \ldots|\ldots| \ldots|\ldots| \ldots|\ldots| \ldots|\ldots| \ldots|\ldots|$ ATGCGTATACCAGTTGCTTATTTAAAAACTTTCCAAGGACCAGCAACAGGTATTGTTTCT ATGCGTATACCAGTTGCTTATTTAAAAACTTTCCAAGGACCAGCAACAGGTATTGTTTCT ATGCGTATACCAGTTGCTTATTTAAAAACTTTCCAAGGACCAGCAACAGGTATTGTTTCT ATGCGTATACCAGTTGCTTATTTAAAAACTTTCCAAGGACCAGCAACAGGGATTGTTTCT ATGCGTATACCAGTTGCTTATTTAAAAACTTTCCAAGGACCAGCAACAGGGATTGTTTCT ATGCGTATACCAGTTGCTTATTTAAAAACTTTCCAAGGACCAGCAACAGGGATTGTTTCT ATGCGTATACCAGTTGCTTACTTGAAAACTTTCCAAGGGCCAGCAACAGGTATTGTCTCT ATGCGTATACCAGTTGCTTATTTAAAAACTTTCCAAGGACCAGCAACAGGTATTGTTTCT ATGCGTATACCAGTTGCTTATTTAAAAACTTTCCAAGGACCAGCAACAGGTATCGTATCT ATGCGTATACCAGTTGCTTATTTAAAGACTTTCCAGGGACCAGCAACAGGTATTATTTCT

$$
370 \quad 380 \quad 390 \quad 400 \quad 410 \quad 420
$$
$\ldots|\ldots| \ldots|\ldots| \ldots|\ldots| \ldots|\ldots| \ldots|\ldots| \ldots|\ldots| \ldots|\ldots|$ GAACGTGAACGTATGGACAAATTTGGACGTCCATTCCTTGGAGCAACTGTAAAACCTAAA GAACGTGAACGTATGGACAAATTTGGACGTCCATTCCTTGGAGCAACTGTAAAACCTAAA GAACGTGAACGTATGGACAAATTTGGACGTCCATTCCTTGGAGCAACTGTAAAACCTAAA GAACGTGAACGTATGGATAAATTTGGTCGTCCATTCCTTGGTGCAACTGTAAAACCTAAA GAACGTGAACGTATGGATAAATTTGGTCGTCCATTCCTTGGTGCAACTGTAAAACCTAAA GAACGTGAACGTATGGATAAATTTGGTCGTCCATTCCTTGGTGCAACTGTAAAACCTAAA GAACGTGAACGTATGGATAAATTTGGACGACCATTCCTTGGAGCAACTGTAAAACCTAAA GAGCGTGAACGTATGGATAAATTTGGACGTCCATTCCTTGGAGCAACTGTAAAACCTAAA GAGCGTGAACGTATGGATAAATTTGGACGTCCATTCCTTGGAGCAACTGTAAAACCTAAA GAGCGTGAGCGTATGGATAAATTTGGACGTCCATTCCTTGGAGCAACTGTAAAACCTAAA

$$
\ldots|\ldots| \ldots|\ldots| \ldots|\ldots| \ldots|\ldots| \ldots|\ldots| \ldots|\ldots| \ldots|\ldots| \ldots|\ldots| \ldots|\ldots|
$$

TTAGGTTTATCTGGTAAAAACTATGGTCGTGTAGTTTATGAAGGTCTTAAAGGTGGTCTA TTAGGTTTATCTGGTAAAAACTATGGTCGTGTAGTTTATGAAGGTCTTAAAGGTGGTCTA TTAGGTTTATCTGGTAAAAACTATGGTCGTGTAGTTTATGAAGGTCTTAAAGGTGGTCTA TTAGGTTTATCTGGAAAAAACTATGGTCGTGTAGTTTATGAAGGTCTTAAAGGTGGACTA TTAGGTTTATCTGGAAAAAACTATGGTCGTGTAGTTTATGAAGGTCTTAAAGGTGGACTA TTAGGTTTATCTGGAAAAAACTATGGTCGTGTAGTTTATGAAGGTCTTAAAGGTGGACTA CTAGGTCTATCTGGTAAAAACTATGGTCGTGTAGTTTATGAAGGTCTTAAAGGTGGTCTA CTAGGTTTATCTGGTAAAAACTATGGTCGTGTAGTCTATGAAGGTCTTAAAGGTGGTCTA СTGGGTTTATCTGGTAAAAACTATGGTCGTGTAGTTTACGAAGGTCTTAAGGGTGGTCTA TTAGGTTTATCAGGAAAAAATTACGGTCGTGTAGTTTATGAAGGTCTTAAAGGTGGTTTA 
$490 \quad 500 \quad 510 \quad 520 \quad 530 \quad 540$

$\ldots|\ldots| \ldots|\ldots| \ldots|\ldots| \ldots|\ldots| \ldots|\ldots| \ldots|\ldots| \ldots|\ldots| \ldots \mid$

IBC 0028

IBC 0064

IBC0245

IBC 0040

IBC 0098

IBC0185

IBC0129

ВОТ0003

IBC0212

IBC0190

IBC 0028 IBC0064

IBC 0245

IBC 0040

IBC0098

IBC0185

IBC 0129

ВОТ 0003

IBC0212

IBC0190

IBC 0028

IBC0064

IBC 0245

IBC 0040

IBC0098

IBC 0185

IBC0129

ВОТ0003

IBC0212

IBC0190

IBC 0028

IBC0064

IBC0245

IBC 0040

IBC0098

IBC 0185

IBC0129

ВОТ0003

IBC 0212

IBC 0190

GATTTCTTAAAAGATGATGAAAATATTAACTCTCAACCTTTTATGCGTTGGAAAGAGAGA GATTTCTTAAAAGATGATGAAAАTATTAАСTCTCAАССTTTTATGCGTTGGAAAGAGAGA GATTTCTTAAAAGATGATGAAAATATTAACTCTCAACCTTTTATGCGTTGGAAAGAGAGA GATTTCTTAAAGGATGATGAGAATATCAATTCTCAACCATTCATGCGTTGGAAAGAAAGA GATTTCTTAAAGGATGATGAGAATATCAATTCTCAACCATTCATGCGTTGGAAAGAAAGA GATTTCTTAAAGGATGATGAGAATATCAATTCTCAACCATTCATGCGTTGGAAAGAAAGA GATTTCCTAAAAGATGATGAAAATATTAACTCTCAACCTTTTATGCGTTGGAAAGAAAGA GATTTCCTAAAAGATGATGAAAATATTAATTCTCAACCTTTTATGCGTTGGAAAGAAAGA GATTTCCTAAAAGATGATGAAAATATTAATTCTCAACCTTTTATGCGTTGGAAAGAAAGA GACTTTTTAAAAGATGATGAAAATATCAATCTCAACCTTTCATGCGTTGGAAAGAAAGA

$$
550 \quad 560 \quad 570 \quad 580 \quad 590 \quad 600
$$

$\ldots|\ldots| \ldots|\ldots| \ldots|\ldots| \ldots|\ldots| \ldots|\ldots| \ldots|\ldots| \ldots|\ldots| \ldots \mid$ TTTTTATACGCAATGGAAGGGGTAAATAGATCTGTTGCAGCAACAGGTGAAGTTAAAGGA TTTTTATACGCAATGGAAGGGGTAAATAGATCTGTTGCAGCAACAGGTGAAGTTAAAGGA TTTTTATACGCAATGGAAGGGGTAAATAGATCTGTTGCAGCAACAGGTGAAGTTAAAGGA TTCCTATATTCTATGGAAGGTGTAAATAGATCTGTTGCTGCAACAGGTGAAGTTAAAGGA TTCCTATATTCTATGGAAGGTGTAAATAGATCTGTTGCTGCAACAGGTGAAGTTAAAGGA TTCСTATATTCTATGGAAGGTGTAAATAGATCTGTTGCTGCAACAGGTGAAGTTAAAGGA TTTTTATACGCAATGGAAGGCGTAAATAGATCTGTTGCAGCAACAGGTGAAGTTAAAGGA TTTTTATACGCAATGGAAGGCGTCAATAGGTCTGTTGCAGCGACAGGTGAAGTTAAAGGA TTTTTATATTCAATGGAAGGCGTAAATAGATCTGTTGCAGCGACAGGTGAAGTTAAAGGC TTTCTGTATTCAATGGAGGGAGTAAATAGATCTGTTGCAGCAACAGGTGAAGTTAAAGGA

$$
\begin{aligned}
& 610 \quad 620 \quad 630 \quad 640 \quad 650 \quad 660 \\
& \ldots|\ldots| \ldots|\ldots| \ldots|\ldots| \ldots|\ldots| \ldots|\ldots| \ldots|\ldots| \ldots|\ldots| \ldots|\ldots|
\end{aligned}
$$

CATTATCTGAATGTAACAGCAGCTACAATGGAAGATATGTACGAAAGAGCTGAATTTGCA САTTATCTGAATGTAACAGCAGCTACAATGGAAGATATGTACGAAAGAGCTGAATTTGCA CATTATCTGAATGTAACAGCAGCTACAATGGAAGATATGTACGAAAGAGCTGAATTTGCA САTTATTTAAATGTAACTGCTGCTACAATGGAAAATATGTATGAAAGAGCTGAATTTGCT CATTATTTAAATGTAACTGCTGCTACAATGGAAAATATGTATGAAAGAGCTGAATTTGCT САTTATTTAAATGTAACTGCTGCTACAATGGAAAATATGTATGAAAGAGCTGAATTTGCT САTTATTTGAATGTGACAGCAGCTACAATGGAAGATATGTATGAAAGAGCTGAATTTGCA CATTATTTGAATGTAACAGCAGCTACAATGGAAGATATGTATGAAAGAGCTGAATTTGCA CATTATTTGAATGTAACAGCAGCTACAATGGAAGATATGTACGAAAGAGCTGAATTTGCA САTTACTTAAATGTAACAGCTGCTACAATGGAAGATATGTATGAAAGAGCTGAATTTGA

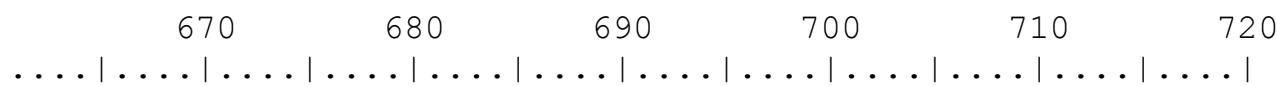
AAACAGCTTGGAAGTATTATTATTATGATTGACCTTGTAATTGGTTATACTGCTATTCAA AAACAGCTTGGAAGTATTATTATTATGATTGACCTTGTAATTGGTTATACTGCTATTCAA AAACAGCTTGGAAGTATTATTATTATGATTGACCTTGTAATTGGTTATACTGCTATTCAA AAACAGCTTGGAAGTATTATTATTATGATTGACCTTGTAATTGGTTATACTGCTATTCAA AAACAGCTTGGAAGTATTATTATTATGATTGACCTTGTAATTGGTTATACTGCTATTCAA AAACAGCTTGGAAGTATTATTATTATGATTGACCTTGTAATTGGTTATACTGCTATTCAA AAACAGCTTGGAAGTATTATTATCATGATTGACCTTGTAATTGGTTATACTGCTATTCAA AAACAGCTTGGAAGTATTATTATTATGATTGACCTTGTAATTGGCTATACTGCTATTCAA AAACAGCTTGGAAGTATTATTATTATGATTGACCTTGTAATTGGTTATACAGCTATCCAA AAACAGCTTGGAAGTATTATTATCATGATTGACCTTGTAATTGGTTACACTGCTATTCAA 
730

740

750

760

770

780

IBC 0028

IBC0064

IBC0245

IBC 0040

IBC 0098

IBC 0185

IBC0129

ВОТ0003

IBC0212

IBC 0190

IBC0028

IBC0064

IBC 0245

IBC 0040

IBC 0098

IBC 0185

IBC0129

ВОТ0003

IBC0212

IBC0190

IBC 0028

IBC0064

IBC0245

IBC 0040

IBC0098

IBC 0185

IBC0129

ВОТ0003

IBC0212

IBC0190

IBC0028

IBC 0064

IBC0245

IBC 0040

IBC 0098

IBC 0185

IBC0129

ВОТ0003

IBC 0212

IBC 0190 $\ldots|\ldots| \ldots|\ldots| \ldots|\ldots| \ldots|\ldots| \ldots|\ldots| \ldots|\ldots| \ldots|\ldots| \ldots|\ldots|$ ACTATGGGAATCTGGGCACGTAAAAATGATATGATTTTACATTTACACCGTGCAGGTAAT ACTATGGGAATCTGGGCACGTAAAAATGATATGATTTTACATTTACACCGTGCAGGTAAT ACTATGGGAATCTGGGCACGTAAAAATGATATGATTTTACATTTACACCGTGCAGGTAAT ACTATGGCAATCTGGGCACGTAAAAATGATATGATTTTACATTTACACCGTGCTGGTAAT ACTATGGCAATCTGGGCACGTAAAAATGATATGATTTTACATTTACACCGTGCTGGTAAT АСTATGGCAATCTGGGCACGTAAAAATGATATGATTTTACATTTACACCGTGCTGGTAAT ACTATGGGAATTTGGGCACGTAAAAATGATATGATTTTACATTTACACCGTGCAGGTAAT ACTATGGGAATTTGGGCACGTAAAAATGATATGATTTTACATTTACATCGTGCAGGTAAT ACTATGGGAATTTGGGCACGTAAAAATGATATGATCTTACATTTACACCGTGCAGGTAAC ACTATGGCAATTTGGCACGTAAAAATGATATGATTTTACATTTACACCGTGCTGGTAAT

$$
\ldots|\ldots| \ldots|\ldots| \ldots|\ldots| \ldots|\ldots| \ldots|\ldots| \ldots|\ldots| \ldots|\ldots| \ldots|\ldots| \ldots \mid
$$
TCTACATACTCTCGTCAAAAAATTCATGGTATGAATTTCCGTGTTATCTGTAAGTGGATG TCTACATACTCTCGTCAAAAAATTCATGGTATGAATTTCCGTGTTATCTGTAAGTGGATG TCTACATACTCTCGTCAAAAAATTCATGGTATGAATTTCCGTGTTATCTGTAAGTGGATG TCTACATATTCTCGTCAAAAAATTCATGGTATGAATTTCCGAGTAATTTGTAAGTGGATG TCTACATATTCTCGTCAAAAAATTCATGGTATGAATTTCCGAGTAATTTGTAAGTGGATG TCTACATATTCTCGTCAAAAAATTCATGGTATGAATTTCCGAGTAATTTGTAAGTGGATG TCTACATATTCTCGTCAAAAAATTCATGGCATGAACTTCCGTGTTATCTGTAAGTGGATG TCTACATATTCTCGTCAAAAAATTCATGGTATGAACTTCCGTGTTATCTGTAAATGGATG TCTACATATTCTCGTCAAAAAATTCATGGTATGAACTTCCGTGTTATTTGTAAATGGATG TCTACATATTCTCGTCAGAAAATTCATGGTATGAATTTCCGTGTAATTTGTAAGTGGATG

$$
\ldots|\ldots| \ldots|\ldots| \ldots|\ldots| \ldots|\ldots| \ldots|\ldots| \ldots|\ldots| \ldots|\ldots| \ldots|\ldots|
$$
CGTATGGCTGGCGTAGATCATATTCATGCTGGTACTGTAGTAGGTAAACTAGAAGGTGAT CGTATGGCTGGCGTAGATCATATTCATGCTGGTACTGTAGTAGGTAAACTAGAAGGTGAT CGTATGGCTGGCGTAGATCATATTCATGCTGGTACTGTAGTAGGTAAACTAGAAGGTGAT CGTATGTCTGGTGTAGATCATATTCATGCAGGTACTGTAGTAGGTAAATTAGAAGGAGAT CGTATGTCTGGTGTAGATCATATTCATGCAGGTACTGTAGTAGGTAAATTAGAAGGAGAT CGTATGTCTGGTGTAGATCATATTCATGCAGGTACTGTAGTAGGTAAATTAGAAGGAGAT CGTATGGCTGGTGTAGACCATATTCATGCAGGTACTGTAGTAGGTAAATTGGAAGGTGAT CGTATGGCTGGTGTAGACCATATTCATGCAGGTACTGTAGTAGGTAAATTAGAAGGTGAT CGTATGGCTGGTGTAGACCATATTCATGCAGGTACTGTAGTAGGTAAATTAGAAGGTGAT CGTATGTCTGGTGTAGATCATATTCATGCAGGTACTGTAGTAGGTAAATTAGAAGGTGAC

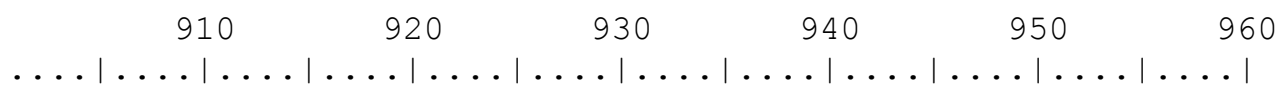
ССTTTAATGATTAGAGGATTTTACAACACTTTATTACTACCATATTTAGAAGTTAATCTA ССТTTAATGATTAGAGGATTTTACAACACTTTATTACTACCATATTTAGAAGTTAATCTA ССTTTAATGATTAGAGGATTTTACAACACTTTATTACTACCATATTTAGAAGTTAATCTA ССTTTAATGATTAAAGGTTTCTATAATACTTTATTATTACCATATCTAGAAATTAATTTA ССТTTAATGATTAAAGGTTTCTATAATACTTTATTATTACCATATCTAGAAATTAATTTA ССTTTAATGATTAAAGGTTTCTATAATACTTTATTATTACCATATCTAGAAATTAATTTA ССTTTAATGATTAGAGGATTTTATAATACTTTATTACTACCATATTTAGAAGTTAATTTA ССТTTAATGATTAAAGGATTCTATAATACTTTATTGCTACCATATTTAGAAGTTAACСTA ССТСTAATGATTAGAGGATTCTATAACACTTTATTACTACCATATTTAGAGATTAATCTA ССТTTAATGATTAAAGGTTTTTACAATACTTTATTATTACCGTATTTAGAAAAGAATCTA 
IBC 0028

IBC0064

IBC0245

IBC 0040

IBC0098

IBC0185

IBC 0129

ВОТ0003

IBC0212

IBC0190

IBC 0028

IBC 0064

IBC0245

IBC 0040

IBC0098

IBC0185

IBC0129

ВОТ0003

IBC0212

IBC 0190

IBC 0028

IBC0064

IBC0245

IBC 0040

IBC0098

IBC0185

IBC0129

ВОТ0003

IBC0212

IBC 0190

IBC 0028

IBC0064

IBC0245

IBC 0040

IBC0098

IBC0185

IBC 0129

ВОТ0003

IBC 0212

IBC0190
$970 \quad 980 \quad 990 \quad 1000 \quad 1010 \quad 1020$ $\ldots|\ldots| \ldots|\ldots| \ldots|\ldots| \ldots|\ldots| \ldots|\ldots| \ldots|\ldots| \ldots|\ldots|$ ССTCAAGGTATTTTCTTTGAACAAGATTGGGCATCTTTACGTAAAGTTACTCCAGTTGCA CCTCAAGGTATTTTCTTTGAACAAGATTGGGCATCTTTACGTAAAGTTACTCCAGTTGCA CСTCAAGGTATTTTCTTGAACAAGAATTGGGCATCTTTACGTAAAGTTACTCCAGTTGCA CСTCAAGGAATTTTCTTTGAACAAGATTGGGCATCTTTACGTAAAGTTACTCCAGTTGCT ССTCAAGGAATTTTCTTTGAACAAGATTGGGCATCTTTACGTAAAGTTACTCCAGTTGCT CСTCAAGGAATTTTCTTTGAACAAGATTGGGCATCTTTACGTAAAGTTACTCCAGTTGCT ССTCAAGGTATCTTCTTTGAACAAGATTGGGCATCTTTACGTAAAGTTACTCCAGTTGCA CCGCAAGGTATTTTCTTTGAACAAGATTGGGCATCTTTACGTAAAGTTACTCCAGTTGCT ССTCAAGGTATTTTCTTTGAACAAGACTGGGCATCTTTACGTAAGGTTACTCCAGTTGCT ССTCAAGGTATTTTCTTCGAACAAGATTGGGCATCTTTACGTAAAGTTACTCCAGTTGCT
1030
1040
1050
1060
1070
1080

$\ldots \ldots|\ldots| \ldots|\ldots| \ldots|\ldots| \ldots|\ldots| \ldots|\ldots| \ldots|\ldots| \ldots|\ldots| \ldots \mid$ TCTGGTGGTATTCACTGTGGTCAAATGCACCAACTACTTGATTATCTAGGTAATGATGTT TCTGGTGGTATTCACTGTGGTCAAATGCACCAACTACTTGATTATCTAGGTAATGATGTT TCTGGTGGTATTCACTGTGGTCAAATGCACCAACTACTTGATTATCTAGGTAATGATGTT TCTGGTGGTATCCACTGTGGTCAAATGCACCAACTTCTTGATTATTTAGGCAATGATGTT TCTGGTGGTATCCACTGTGGTCAAATGCACCAACTTCTTGATTATTTAGGCAATGATGTT TCTGGTGGTATCCACTGTGGTCAAATGCACCAACTTCTTGATTATTTAGGCAATGATGTT TCTGGTGGTATTCACTGTGGTCAAATGCATCAACTTCTTGATTATTTGGGTAATGACGTT TCTGGTGGTATTCATTGTGGTCAAATGCATCAACTTCTTGATTACCTAGGTAATGACGTT TCTGGTGGTATTCATTGTGGTCAAATGCATCAACTTCTTGATTACTTAGGTAATGACGTT TCTGGTGGTATTCATTGTGGTCAAATGCACCAACTTCTTGATTATTTAGGCAATGATGTT

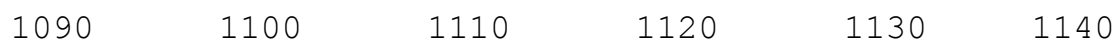
$\ldots|\ldots| \ldots|\ldots| \ldots|\ldots| \ldots|\ldots| \ldots|\ldots| \ldots|\ldots| \ldots|\ldots| \ldots|\ldots|$ GTACTTCAATTTGGAGGTGGTACTATTGGGCATCCTGATGGTATTCAAGCTGGTGCAACA GTACTTCAATTTGGAGGTGGTACTATTGGGCATCCTGATGGTATTCAAGCTGGTGCAACA GTACTTCAATTTGGAGGTGGTACTATTGGGCATCCTGATGGTATTCAAGCTGGTGCAACA GTACTTCAGTTTGGAGGTGGTACTATTGGACATCCTGATGGTATTCAAGCTGGTGCAACA GTACTTCAGTTTGGAGGTGGTACTATTGGACATCCTGATGGTATTCAAGCTGGTGCAACA GTACTTCAGTTTGGAGGTGGTACTATTGGACATCCTGATGGTATTCAAGCTGGTGCAACA GTACTTCAATTTGGTGGTGGTACTATTGGACATCCTGATGGTATTCAAGCTGGTGCAACA GTACTTCAATTTGGAGGTGGTACTATTGGACATCCTGATGGTATTCAAGCTGGTGCAACG GTACTTCAGTTTGGAGGTGGTACTATTGGACATCCTGATGGTATTCAAGCTGGTGCAACA GTACTTCAATTTGGAGGTGGTACTATTGGACATCCTGATGGTATCCAAGCTGGTGCAACA

$$
\begin{gathered}
1150 \\
\ldots .|\ldots| \ldots|\ldots| \ldots|\ldots| \ldots|\ldots| \ldots|\ldots| \ldots|\ldots| \ldots|\ldots| \ldots|\ldots|
\end{gathered}
$$

GCTAATAGAGTAGCTCTAGAATCAATGGTTATGGCTCGTAATGAAGGCCGTGATTATGTT GCTAATAGAGTAGCTCTAGAATCAATGGTTATGGCTCGTAATGAAGGCCGTGATTATGTT GCTAATAGAGTAGCTCTAGAATCAATGGTTATGGCTCGTAATGAAGGCCGTGATTATGTT GCTAATAGGGTAGCTTTAGAATCAATGGTTATGGCTCGTAATGAAGGGCGTGACTATGTT GCTAATAGGGTAGCTTTAGAATCAATGGTTATGGCTCGTAATGAAGGGCGTGACTATGTT GCTAATAGGGTAGCTTTAGAATCAATGGTTATGGCTCGTAATGAAGGGCGTGACTATGTT GCTAATAGAGTAGCTCTAGAGTCAATGGTTATGGCTCGTAATGAAGGTCGTGATTATGTT GCTAATAGAGTAGCTCTAGAGTCAATGGTTATGGCTCGTAATGAAGGTCGTGATTATGTT GCTAACAGAGTAGCTCTAGAATCAATGGTTATGGCTCGTAATGAAGGTCGTGATTATGTT GCTAATAGGGTTGCTTTAGAATCTATGGTTATGGCTCGTAATGAAGGTCGTGATTATGTT 
IBC 0028 IBC0064 IBC0245 IBC 0040 IBC0098 IBC0185 IBC0129 ВОТ0003 IBC0212 IBC0190

IBC 0028 IBC 0064 IBC 0245 IBC 0040 IBC0098 IBC0185 IBC0129 ВОT0003 IBC0212 IBC0190

\section{0}

1220

1230

1240

1250

1260 $\ldots . \ldots .|\ldots| \ldots|\ldots| \ldots|\ldots| \ldots|\ldots \ldots| \ldots|\ldots.| \ldots|\ldots \ldots|$ GCTGAAGGACCACAAATTTTACAAGATGCAGCAAAAACATGTGGTCCTCTACAAACAGCA GCTGAAGGACCACAAATTTTACAAGATGCAGCAAAAACATGTGGTCCTCTACAAACAGCA GCTGAAGGACCACAAATTTTACAAGATGCAGCAAAAACATGTGGTCCTCTACAAACAGCA GCTGAAGGCCCACAAATTTTACAAGATGCAGCAAAAACATGTGGTCCTCTACAAACAGCA GCTGAAGGCCCACAAATTTTACAAGATGCAGCAAAAACATGTGGTCCTCTACAAACAGCA GCTGAAGGCCCACAAATTTTACAAGATGCAGCAAAAACATGTGGTCCTCTACAAACAGCA GCTGAAGGACCACAAATCTTACAAGACGCAGCAAAAACATGTGGTCCTCTACAAACAGCA GCTGAAGGACCACAAATTTTACAAGATGCAGCAAAAACATGTGGTCCTCTACAAACAGCA GCTGAAGGACCACAAATTTTACAAGATGCAGCAAAAACATGTGGTCCTCTACAAACAGCA GCTGAAGGCCCACAAATCTTACAAGACGCGGCAAAAACATGTGGTCCTCTACAAACGGCA
1270
1280
1290
1300
1310

$\ldots|\ldots| \ldots|\ldots| \ldots|\ldots| \ldots|\ldots| \ldots|\ldots| \ldots|\ldots| \ldots \mid \ldots$ TTAGATTTATGGAAAGATATTACTTTTAACTATACTTCTACAGATACAGCTGATTTC TTAGATTTATGGAAAGATATTACTTTTAACTATACTTCTACAGATACAGCTGATTTC TTAGATTTATGGAAAGATATTACTTTTAACTATACTTCTACAGATACAGCTGATTTC TTAGATTTATGGAAAGATATTACTTTTAATTATACTTCTACAGATACAGCTGATTTC TTAGATTTATGGAAAGATATTACTTTTAATTATACTTCTACAGATACAGCTGATTTC TTAGATTTATGGAAAGATATTACTTTTAATTATACTTCTACAGATACAGCTGATTTC TTAGATTTATGGAAAGATATTACTTTCAACTATACTTCTACAGATACAGCTGATTTC TTAGATTTATGGAAAGATATTACTTTCAACTATACTTCTACAGATACAGCTGATTTC TTAGATTTATGGAAAGATATTACTTTCAACTATACTTCTACAGATACAGCTGATTTC TTAGATTTATGGAAAGATATTACTTTCAACTATACTTCTACAGATACAGCTGATTTC 


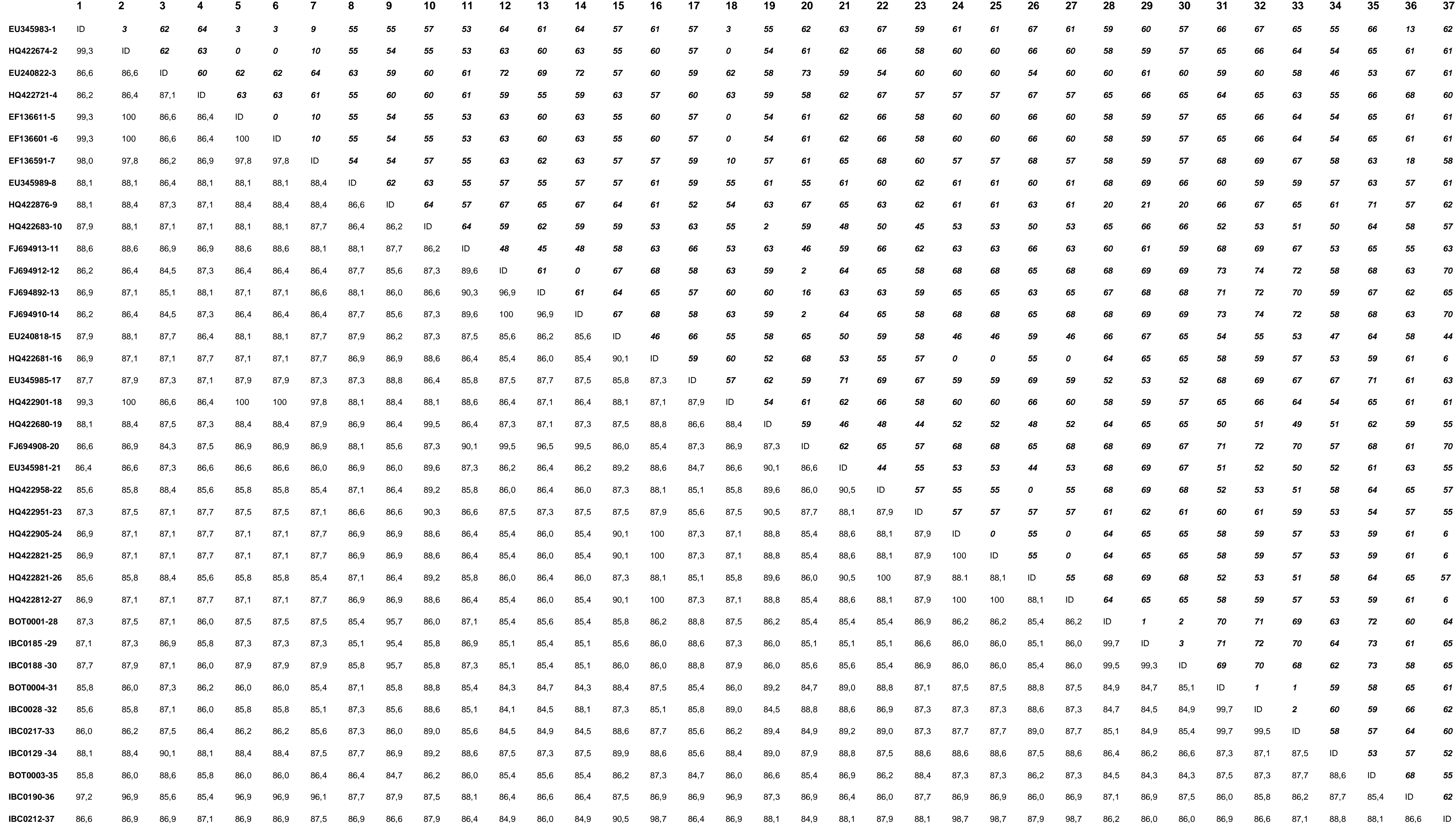

Anexo IV. Matriz de identidade do marcador cox1 das sequências obtidas neste e estudo e das sequências retiradas do banco de dados. Amostras numeradas de acordo com as Tabelas 5,8 e 9 . 


\begin{tabular}{|c|c|c|c|c|c|c|c|c|c|c|c|c|c|c|}
\hline & & 1 & 2 & 3 & 4 & 5 & 6 & $?$ & 8 & 9 & 10 & 11 & 12 & 13 \\
\hline EU3 46010 & - & ID & 9,2 & 71,1 & 82,9 & 76,3 & 75 & 69,8 & 79,0 & 3,9 & 3,9 & 79,0 & 2,6 & 77,7 \\
\hline AF3856841 & $1-2$ & $99,3 \%$ & ID & 79,0 & 90,8 & 84,2 & 84,2 & 77,7 & 84,2 & 11,8 & 11,8 & 84,2 & 10,5 & 85,6 \\
\hline EU240843 & -3 & $94,6 \%$ & $94,0 \%$ & ID & 63,2 & 75,0 & 63,2 & 63,2 & 77,7 & 73,7 & 71,1 & 59,2 & 72,4 & 76,3 \\
\hline$A B 033159$ & - & $93,7 \%$ & $93,1 \frac{4}{8}$ & $95,2 \%$ & ID & 84,2 & 75,0 & 75,0 & 92,1 & 82,9 & 82,9 & 69,8 & 84,2 & 84,2 \\
\hline ABO33160 & - & $94,2 \%$ & $93,6 \%$ & $94,3 \%$ & $93,6 \%$ & ID & 46,0 & 42,1 & 14,4 & 73,7 & 73,7 & 81,6 & 75,0 & 48,7 \\
\hline EU3 45993 & - & $94,3 \div$ & $93,6 \%$ & $95,2 \%$ & $94,3 \%$ & $96,5 \%$ & ID & 6,5 & 43,4 & 72,4 & 72,4 & 65,8 & 73,7 & 46,0 \\
\hline AB095912 & - & $94,7 \%$ & $94,1 \%$ & $95,2 \div$ & $94,3 \%$ & $96,8 \%$ & $99,5 \%$ & ID & 40,8 & 67,1 & 67,1 & 65,8 & 67,1 & 47,4 \\
\hline AB033162 & - & $94,0 \%$ & $93,3 \div$ & $94,1 \%$ & $93,0 \%$ & $98,9 \div$ & $96,7 \%$ & $96,9 \%$ & ID & 76,3 & 76,3 & 84,2 & 77,7 & 46,0 \\
\hline EF 136632 & - & $99,7 \%$ & $99,1 \%$ & $94,4 \%$ & $93,7 \%$ & $94,4 \%$ & $94,5 \%$ & $94,9 \%$ & $94,2 \%$ & ID & 2,6 & 79,0 & 1,3 & 75,0 \\
\hline AB033163 & -1 & $99,7 \%$ & $99,1 \%$ & $94,6 \%$ & $93,7 \%$ & $94,4 \%$ & $94,5 \%$ & $94,9 \%$ & $94,2 \%$ & $99,8 \div$ & ID & 80,3 & 1,3 & 75,0 \\
\hline EU3 46002 & -1 & $94,0 \%$ & $93,6 \%$ & $95,5 \div$ & $94,7 \%$ & $93,8 \%$ & $95,0 \%$ & $95,0 \div$ & $93,6 \%$ & $94,0 \div$ & $93,9 \%$ & ID & 79 & 75,0 \\
\hline DQ095823 & -12 & $99,8 \%$ & $99,2 \%$ & $94,5 \%$ & $93,6 \%$ & $94,3 \div$ & $94,4 \%$ & $94,9 \%$ & $94,1 \%$ & $99,9 \%$ & $99,9 \%$ & $94,0 \%$ & ID & 75,0 \\
\hline EU346014 & -13 & $94,1 \%$ & $93,5 \%$ & $94,2 \div$ & $93,6 \%$ & $96,3 \div$ & $96,5 \%$ & $96,4 \%$ & $96,5 \%$ & $94,3 \%$ & $94,3 \%$ & $94,3 \%$ & $94,3 \%$ & ID \\
\hline U04179 & -1 & $94,0 \%$ & $93,6 \%$ & $94,1 \%$ & $93,6 \div$ & $96,2 \%$ & $96,5 \%$ & $96,3 \%$ & $96,5 \%$ & $94,3 \div$ & $94,3 \div$ & $94,3 \%$ & $94,2 *$ & 99, \\
\hline FJ 694932 & -1 & $93,6 \%$ & $93,0 \%$ & $95,1 \frac{4}{7}$ & $96,3 \%$ & $93,8 \%$ & $94,5 \%$ & $94,5 \%$ & $93,9 \div$ & $93,7 \frac{2}{8}$ & $93,7 \%$ & $94,6 \%$ & $93,6 \%$ & $13,6 \%$ \\
\hline FJ 694947 & -1 & $93,2 \%$ & $92,6 \%$ & $94,1 \%$ & $94,3 \%$ & $93,1 \%$ & $93,8 \%$ & $93,8 \%$ & $92,8 \%$ & $93,3 \div$ & $93,3 \%$ & $95,8 \div$ & $93,2 *$ & $13,6 \%$ \\
\hline FJ694959 & -1 & $94,5 \%$ & $93,9 \%$ & $95,8 \%$ & $95,5 \%$ & $94,7 \%$ & $95,8 \div$ & $95,8 \%$ & $94,5 \%$ & $94,7 \%$ & $94,7 \%$ & $96,5 \%$ & $94,6 \%$ & $94,6 \%$ \\
\hline ABO33165 & -1 & $93,3 \%$ & $92,7 \%$ & $94,3 \div$ & $94,4 \%$ & $93,3 \div$ & $94,0 \%$ & $94,0 \%$ & $93,0 \%$ & $93,4 \%$ & $93,4=$ & $95,8 \%$ & $93,3 \%$ & 93,8 \\
\hline FJ 604935 & $-1 s$ & $93,7 \%$ & $93,1 \%$ & $95,3 \%$ & $94,4 \%$ & $93,2 \%$ & $93,9 \div$ & $94,0 \%$ & $93,3 \%$ & $93,7 \%$ & $93,7 \%$ & $94,1 \%$ & $93,6 \%$ & $93,0 \%$ \\
\hline EU2 40849 & -20 & $93,6 \%$ & $93,0 \%$ & $96,3 \%$ & $95,5 \%$ & $94,3 \div$ & $94,8 \%$ & $94,8 \%$ & $94,2 \%$ & $93,7 \%$ & $93,7 \%$ & $95,2 \%$ & $93,6 \%$ & $94,1 \%$ \\
\hline 2033166 & -21 & $93,5 \%$ & $92,9 \%$ & $96,2 \%$ & $95,5 \%$ & $94,3 \div$ & $94,7 \div$ & $94,7 \%$ & $94,1 \%$ & $93,6 \%$ & $93,6 \%$ & $95,2 \%$ & $93,6 \%$ & 94, \\
\hline EU346004 & -22 & $94,0 \%$ & $93,3 \div$ & $94,6 \div$ & $93,6 \div$ & $95,3 \%$ & $96,8 \div$ & $96,9 \%$ & $95,5 \%$ & $94,0 \%$ & $94,0 \%$ & $93,8 \%$ & $94,0 \%$ & 95, \\
\hline FJ 694934 & -23 & $98,8 \div$ & $98,2 \%$ & $94,1 \frac{1}{8}$ & $93,7 \%$ & $94,0 \%$ & $94,0 \%$ & $94,3 \%$ & $93,7 \%$ & $98,7 \%$ & $98,7 \frac{1}{8}$ & $93,9 \div$ & $98,8 \%$ & $93,7 \%$ \\
\hline FJ 694933 & $-2^{2}$ & $94,4 \%$ & $93,8 \%$ & $96,0 \div$ & $95,6 \%$ & $93,8 *$ & $94,5 \%$ & $94,8 \%$ & $93,9 \%$ & $94,4 \%$ & $94,4 \%$ & $95,1 \%$ & $94,3 \%$ & $3,8=$ \\
\hline FJ694930 & -25 & $94,0 \%$ & $93,4 \%$ & $95,3 \frac{2}{5}$ & $95,1 \%$ & $94,0 \%$ & $95,2 \%$ & $95,2 \%$ & $93,9 \%$ & $94,3 \%$ & $94,3 \%$ & $96,4 \%$ & $94,2 \%$ & $93,9 \%$ \\
\hline EU3 45998 & -26 & $93,6 \%$ & $93,0 \%$ & $95,1 \%$ & $99,6 \%$ & $93,4 \%$ & $94,1 \%$ & $94,1 \%$ & $92,9 \div$ & $93,6 \%$ & $93,6=$ & $94,6 \%$ & $93,5 \%$ & $93,5 \%$ \\
\hline ABO33167 & -27 & $94,2 \%$ & $93,6 \%$ & $96,2 \%$ & $95,8 *$ & $94,3 \%$ & $95,2 \%$ & $95,2 \div$ & $94,0 \%$ & $94,3 \frac{4}{7}$ & $94,3 \%$ & $94,9 \%$ & $94,3 \%$ & $94,3=$ \\
\hline FJ 694945 & -28 & $93,6 \%$ & $93,0 \%$ & $95,6 *$ & $94,6 \%$ & $93,4 \div$ & $94,2 \div$ & $94,2 \%$ & $93,2 \%$ & $93,8 \%$ & $93,8 \%$ & $95,7 \%$ & $93,7 \%$ & $93,3 \div$ \\
\hline FJ694944 & -25 & $93,6 \%$ & $93,0 \%$ & $95,6 \%$ & $94,6 \%$ & $93,4 \%$ & $94,2 \%$ & $94,2 \%$ & $93,2 \%$ & $93,8 \%$ & $93,8 \div$ & $95,7 \%$ & $93,7 \%$ & $93,3=$ \\
\hline IBCO028 & -30 & $93,8 \div$ & $93,2 \%$ & $95,5 \%$ & $96,5 \%$ & $94,1 \%$ & $94,6 \%$ & $94,6 \%$ & $93,8 *$ & $94,0 \%$ & $94,0 \%$ & $95,3 \frac{7}{3}$ & $93,9 \%$ & 94,0 \\
\hline IBC0064 & -31 & $93,8 *$ & $93,2 \%$ & $95,5 \%$ & $96,5 \%$ & $94,1 \%$ & $94,6 \%$ & $94,6 \%$ & $93,8 \div$ & $94,0 \%$ & $94,0 \%$ & $95,3 \%$ & $93,9 \%$ & $94,0 \%$ \\
\hline IBCO245 & -32 & $93,4 \%$ & $92,8 \div$ & $95,1 \frac{7}{7}$ & $96,0 \%$ & $93,7 \%$ & $94,2 \%$ & $94,2 \%$ & $93,4 \%$ & $93,5 \%$ & $93,6 \%$ & $94,9 \%$ & $93,5 \%$ & $93,6 \%$ \\
\hline IBC0040 & -33 & $94,5 \%$ & $93,9 \%$ & $94,2 \%$ & $94,0 \%$ & $96,7 \%$ & $96,7 \%$ & $96,7 \%$ & $96,8 \%$ & $94,7 \%$ & $94,7 \%$ & $94,5 \%$ & $94,6 \%$ & $98,2 \%$ \\
\hline IBC0098 & -36 & $94,4 \%$ & $93,8 \%$ & $94,1 \frac{2}{5}$ & $93,9 *$ & $96,6 \%$ & $96,6 \%$ & $96,6 \%$ & $96,7 \%$ & $94,6 \%$ & $94,6=$ & $94,4 \%$ & $94,6 \%$ & 98,1 \\
\hline IBC0185 & -35 & $94,5 \%$ & $93,9 \%$ & $94,2 \frac{2}{7}$ & $94,0 \%$ & $96,7 \%$ & $96,7 \%$ & $96,7 \%$ & $96,8 \div$ & $94,7 \%$ & $94,7 \%$ & $94,5 \%$ & $94,6 \%$ & 98,2 \\
\hline IBC0129 & $-3 t$ & $94,0 \%$ & $93,3 \div$ & $96,1 \frac{1}{7}$ & $95,8 *$ & $93,6 \%$ & $94,0 \%$ & $94,2 \%$ & $93,4 \%$ & $94,1 \%$ & $94,1 \frac{3}{8}$ & $94,8 \%$ & $94,0 \%$ & $93,5=$ \\
\hline IBC0190 & -37 & $99,0 \%$ & $98,4 \%$ & $94,4 \%$ & $93,3 \%$ & $94,2 \%$ & $94,2 \%$ & $94,3 \%$ & $93,8 \%$ & $99,1 \%$ & $99,1 \frac{\%}{3}$ & $93,6 \%$ & $99,2 \%$ & 94,0 \\
\hline IBCO2 12 & -38 & $93,3 \%$ & $92,7 \%$ & $95,7 \%$ & $95,3 \%$ & $93,4 \%$ & $94,3 \%$ & $94,3 \%$ & $93,3 \%$ & $93,5 \%$ & $93,5=$ & $94,6 \%$ & $93,4 \%$ & 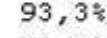 \\
\hline BOTO003 & -35 & $93,9 \%$ & $93,3 \div$ & $96,2 \div$ & $95,7 \%$ & $94,1 \%$ & $94,6 \%$ & $94,6 \%$ & $94,0 \%$ & $94,0 \%$ & $94,0 \div$ & $94,8 \%$ & $94,0 \%$ & \\
\hline
\end{tabular}

Anexo V. Matriz de identidade do marcador rbcLdas sequências obtidas neste estudo e das sequências retiradas do banco de dados.

Amostras numeradas de acordo com as Tabelas 5, 8 e 9. 


\begin{tabular}{|c|c|c|c|c|c|c|c|c|c|c|c|c|c|c|c|c|}
\hline & & 14 & 15 & 16 & 17 & 18 & 19 & 20 & 21 & 22 & 23 & 24 & 25 & 26 & 27 & 28 \\
\hline EU346010 & -1 & 79,0 & 84,2 & 89,5 & 72,4 & 84,2 & 82,9 & 84,2 & 85,6 & 79,0 & 15,8 & 73,7 & 79,0 & 84,2 & 76,3 & 84,2 \\
\hline AF 3856841 & -2 & 84,2 & 92,1 & 97,4 & 80,3 & 96,1 & 90,8 & 92,1 & 93,5 & 84,2 & 23,7 & 81,6 & 86,9 & 92,1 & 84,2 & 92,1 \\
\hline EU240843 & -3 & 77,7 & 64,5 & 77,7 & 55,3 & 75,0 & 61,8 & 48,7 & 50,0 & 71,1 & 77,7 & 0,96 & 61,8 & 64,5 & 50,0 & 57,9 \\
\hline ABO33159 & -4 & 84,2 & 48,7 & 75,0 & 59,2 & 73,7 & 73,7 & 59,2 & 59,2 & 84,2 & 82,9 & 57,9 & 64,5 & 5,2 & 55,3 & 71,1 \\
\hline$A B 033160$ & -5 & 50,0 & 81,6 & 90,8 & 69,8 & 84,2 & 89,5 & 75,0 & 75,0 & 61,8 & 79,0 & 81,6 & 79,0 & 86,9 & 75,0 & 86,9 \\
\hline EU345993 & -6 & 46,0 & 72,4 & 81,6 & 55,3 & 79,0 & 80,3 & 68,4 & 69,8 & 42,1 & 79,0 & 72,4 & 63,2 & 77,7 & 63,2 & 76,3 \\
\hline AB095912 & -7 & 48,7 & 72,4 & 81,6 & 55,3 & 79,0 & 79,0 & 68,4 & 69,8 & 40,8 & 75,0 & 68,4 & 63,2 & 77,7 & 63,2 & 76,3 \\
\hline ABO33162 & -8 & 46,0 & 80,3 & 94,8 & 72,4 & 92,1 & 84,2 & 76,3 & 77,7 & 59,2 & 82,9 & 80,3 & 80,3 & 93,5 & 79,0 & 89,5 \\
\hline EF 136632 & -9 & 75,0 & 82,9 & 84,2 & 69,8 & 86,9 & 82,9 & 82,9 & 84,2 & 79,0 & 13,17 & 73,7 & 75,0 & 84,2 & 75,0 & 81,6 \\
\hline ABO33163 & -10 & 75,0 & 82,9 & 84,2 & 69,8 & 86,9 & 82,9 & 82,9 & 84,2 & 79,0 & 13,17 & 73,7 & 75,0 & 84,2 & 75,0 & 81,6 \\
\hline EU346002 & -11 & 75,0 & 71,1 & 55,3 & 46,0 & 55,3 & 77,7 & 63,2 & 63,2 & 81,6 & 80,3 & 64,5 & 47,4 & 71,1 & 67,1 & 56,6 \\
\hline DQ095823 & -12 & 76,3 & 84,2 & 89,5 & 71,1 & 84,2 & 84,2 & 84,2 & 84,2 & 79,0 & 15,8 & 75,0 & 76,3 & 85,6 & 75,0 & 82,9 \\
\hline EU346014 & -13 & 1,3 & 84,2 & 84,2 & 71,1 & 81,6 & 92,1 & 77,7 & 79,0 & 60,5 & 82,9 & 81,6 & 80,3 & 85,6 & 75,0 & 84,2 \\
\hline v04179 & -14 & ID & 84,2 & 84,2 & 71,1 & 82,9 & 93,5 & 79,0 & 79,0 & 61,8 & 84,2 & 82,9 & 81,6 & 86,9 & 76,3 & 89,5 \\
\hline FJ694932 & -15 & $93,6 \mathrm{v}$ & ID & 85,6 & 60,5 & 84,2 & 65,8 & 63,2 & 64,5 & 84,2 & 85,6 & 56,6 & 65,8 & 50,0 & 55,3 & 72,4 \\
\hline FJ 694947 & -16 & 93,64 & 93,54 & ID & 60,5 & 2,6 & 85,6 & 76,3 & 77,7 & 89,5 & 86,9 & 76,3 & 63,2 & 77,7 & 81,6 & 65,8 \\
\hline FJ694959 & -17 & 94,64 & $95,4=$ & $95,4=$ & ID & 59,2 & 67,1 & 50,0 & 50,0 & 75,0 & 73,7 & 59,2 & 13,17 & 60,5 & 55,3 & 47,4 \\
\hline ABO33165 & -18 & 93,74 & $93,6 \%$ & 99,87 & $95,5 \div$ & ID & 84,2 & 75,0 & 75,0 & 84,2 & 84,2 & 75,0 & 63,2 & 75,0 & 79,0 & 63,2 \\
\hline FJ 604935 & -19 & 92,94 & $95,0=$ & $93,5=$ & $94,9 \div$ & 93,64 & ID & 64,5 & 65,8 & 92,1 & 84,2 & 57,9 & 72,4 & 75,0 & 61,8 & 79,0 \\
\hline EU240849 & -20 & 94,04 & $95,2=$ & 94,25 & 96,28 & $94,3 \%$ & 95,18 & ID & 1,3 & 79,0 & 84,2 & 46,0 & 59,2 & 60,5 & 43,4 & 64,5 \\
\hline 1033166 & -21 & $94,0 *$ & 95,14 & $94,1=$ & $96,2=$ & 94,37 & $95,0 \mathrm{~s}$ & $99,9 \div$ & ID & 79,0 & 85,6 & 47,4 & 60,5 & 61,8 & 44,7 & 65,8 \\
\hline EU346004 & -22 & 95,34 & 93,64 & 93,24 & 94,33 & 93,34 & 93,04 & 94,04 & 94,04 & ID & 80,3 & 73,7 & 80,3 & 86,9 & 75 & 84,2 \\
\hline FJ 694934 & -23 & $93,6 \%$ & $93,5 *$ & 93,41 & 94,48 & 93,63 & 93,37 & $93,6=$ & $93,5=$ & $93,9 *$ & ID & 75 & 77,7 & 84,2 & 79,0 & 86,9 \\
\hline FJ694933 & -24 & 93,74 & $95,7 \notin$ & $94,2 \%$ & 95,54 & $94,3 \div$ & 95,64 & $96,5 \%$ & 96,43 & 94,48 & 94,34 & ID & 67,1 & 59,2 & 35,5 & 71,1 \\
\hline FJ694930 & -25 & 93,83 & 95,04 & 95,28 & 98,74 & 95,24 & 94,58 & $95,5=$ & 95,47 & 93,98 & 94,17 & 94,94 & ID & 67,1 & 63,2 & 48,7 \\
\hline EU345998 & -26 & 93,45 & $96,2=$ & $94,1 \%$ & 95,41 & $94,3 *$ & 94,34 & 95,48 & $95,3 \div$ & 93,44 & $93,6 *$ & 95,54 & 94,94 & ID & 57,9 & 73,7 \\
\hline$A B 033167$ & -27 & 94,25 & $95,8 *$ & $93,8 *$ & $95,84$. & 94,04 & 95,34 & 96,74 & 96,63 & 94,34 & 94,03 & 97,34 & 95,28 & 95,64 & ID & 65,8 \\
\hline FJ 694945 & -28 & 93,24 & $94,5=$ & 95,04 & $96,4=$ & $95,2 \div$ & 94,07 & 95,17 & 95,07 & 93,64 & $93,4 t$ & 94,64 & 96,37 & 94,44 & 95,07 & ID \\
\hline FJ 694944 & -29 & 93,24 & 94,54 & 95,04 & 96,48 & 95,27 & 94,03 & 95,18 & 95,04 & 93,67 & 93,48 & 94,64 & 96,31 & $94,4 t$ & 95,08 & 1 \\
\hline IBCO028 & -30 & $94,0=$ & 97,04 & $94,1 *$ & 96,04 & $94,3=$ & 95,27 & 95,74 & 95,67 & 93,74 & $94,0 *$ & $96,2 *$ & $95,5=$ & 96,34 & 96,34 & $95,2 \div$ \\
\hline IBCO064 & -31 & 94,04 & $97,0=$ & $94,1+$ & $96,0 \leqslant$ & $94,3=$ & 95,24 & 95,73 & 95,64 & 93,78 & 94,04 & 96,24 & 95,54 & $96,3=$ & $96,3=$ & $95,2 \div$ \\
\hline IBCO245 & -32 & $93,5 \%$ & $96,5=$ & 93,74 & $95,6 *$ & $93,9=$ & $94,9=$ & 95,27 & $95,2 \div$ & 93,37 & $93,6 \%$ & $95,8 *$ & 95,27 & $95,8 *$ & $95,8 *$ & $94,8=$ \\
\hline IBCOO40 & -33 & $98,1 \%$ & $94,0 *$ & 93,35 & $94,9=$ & 93,54 & 93,13 & 94,13 & $94,0 \div$ & 95,74 & $94,3=$ & 93,97 & 94,24 & 93,84 & $94,1 \%$ & 93,68 \\
\hline IBCO098 & -34 & 98,17 & $94,0 t$ & 93,34 & 94,91 & $93,4 \geqslant$ & $93,0 *$ & $94,0 \leqslant$ & 94,07 & 95,63 & $94,3 *$ & $94,0 \leqslant$ & $94,1 \geqslant$ & $93,7=$ & 94,04 & $93,5 \%$ \\
\hline IBC0185 & -35 & 98,14 & 94,04 & 93,34 & 94,94 & 93,54 & 93,13 & 94,14 & $94,0 \%$ & 95,74 & $94,3=$ & 93,94 & 94,28 & 93,84 & 94,14 & 93,64 \\
\hline IBCO129 & -36 & 93,48 & 95,64 & 93,94 & 95,48 & 94,04 & 95,14 & $96,6 *$ & 96,57 & 93,98 & $94,0 \div$ & $97,5=$ & 95,17 & 95,78 & 97,43 & 94,91 \\
\hline IBC0190 & -37 & 94,08 & $93,3=$ & $92,9 \div$ & 94,34 & $93,0=$ & 93,24 & $93,5=$ & 93,41 & 93,74 & $98,4=$ & 93,94 & 93,74 & 93,21 & 94,04 & $93,6=$ \\
\hline IBCO2 12 & -38 & 93,33 & 94,87 & 93,68 & 95,08 & $93,8=$ & 94,68 & 96,94 & 96,87 & 93,63 & 93,37 & $96,2 \%$ & $94,6 \%$ & $95,2=$ & $96,2 \%$ & $94,3=$ \\
\hline BOTO003 & -39 & 93,64 & 95,84 & $93,9 \%$ & $95,5 t$ & 94,07 & 95,37 & $96,6 \div$ & $96,5 \div$ & $94,1 \%$ & $93,9 *$ & $96,8 \%$ & 95,04 & $95,5 *$ & 96,84 & $94,7 \mathrm{t}$ \\
\hline
\end{tabular}

Anexo V. Continuação 


\begin{tabular}{|c|c|c|c|c|c|c|c|c|c|c|c|c|}
\hline & & 29 & 30 & 31 & 32 & 33 & 34 & 35 & 36 & 37 & 38 & 39 \\
\hline EU346010 & -1 & 84,2 & 81,6 & 81,6 & 86,9 & 72,4 & 73,7 & 72,4 & 79,0 & 13,1 & 84,2 & 80,3 \\
\hline AF 3856841 & -2 & 92,1 & 89,5 & 89,5 & 94,8 & 80,3 & 81,6 & 80,3 & 84,2 & 21,0 & 96,1 & 84,2 \\
\hline EU240843 & -3 & 57,9 & 59,2 & 59,2 & 64,5 & 76,3 & 77,7 & 76,3 & 51,3 & 73,7 & 56,6 & 50,0 \\
\hline АB033159 & -4 & 71,1 & 46,0 & 46,0 & 0,96 & 79,0 & 80,3 & 79,0 & 55,3 & 84,2 & 61,8 & 56,6 \\
\hline$A B 033160$ & -5 & 86,9 & 77,7 & 77,7 & 82,9 & 43,4 & 44,7 & 43,4 & 84,2 & 76,3 & 86,9 & 77,7 \\
\hline EU345993 & -6 & 76,3 & 71,1 & 71,1 & 76,3 & 43,4 & 44,7 & 43,4 & 79,0 & 76,3 & 75,0 & 71,1 \\
\hline AB095912 & -7 & 76,3 & 71,1 & 71,1 & 76,3 & 43,4 & 44,7 & 43,4 & 76,3 & 75,0 & 75,0 & 71,1 \\
\hline AB033162 & -8 & 89,5 & 81,6 & 81,6 & 86,9 & 42,1 & 43,4 & 42,1 & 86,9 & 81,6 & 84,2 & 79,0 \\
\hline EF 136632 & -9 & 81,6 & 79,0 & 79,0 & 85,6 & 69,8 & 71,1 & 69,8 & 77,7 & 11,8 & 85,6 & 79,0 \\
\hline AB033163 & -10 & 81,6 & 79,0 & 79,0 & 84,2 & 69,8 & 71,1 & 69,8 & 77,7 & 11,8 & 85,6 & 79,0 \\
\hline EU346002 & -11 & 56,6 & 61,8 & 61,8 & 67,1 & 72,4 & 73,7 & 72,4 & 68,4 & 84,2 & 71,1 & 68,4 \\
\hline DQ095823 & -12 & 82,9 & 80,3 & 60,3 & 85,6 & 71,1 & 71,1 & 71,1 & 79,0 & 10,5 & 86,9 & 79,0 \\
\hline EU346014 & -13 & 84,2 & 79,0 & 79,0 & 84,2 & 23,7 & 25,0 & 23,7 & 85,6 & 79,0 & 84,2 & 82,9 \\
\hline 004179 & -14 & 89,5 & 79,0 & 79,0 & 85,6 & 25,0 & 25,0 & 25,0 & 86,9 & 79,0 & 84,2 & 84,2 \\
\hline FJ 694932 & -15 & 72,4 & 39,5 & 39,5 & 46,0 & 79,0 & 79,0 & 79,0 & 57,9 & 84,2 & 68,4 & 55,3 \\
\hline FJ 694947 & -16 & 65,8 & 77,7 & 77.7 & 82,9 & 84,2 & 84,2 & 84,2 & 80,3 & 93,5 & 84,2 & 80,3 \\
\hline FJ694959 & -17 & 47,4 & 39,5 & 39,5 & 57,9 & 67,1 & 67,1 & 67,1 & 60,5 & 75,0 & 65,8 & 59,2 \\
\hline AB033165 & $-1 \theta$ & 63,2 & 75,0 & 75,0 & 60,3 & 85,6 & 86,9 & 85,6 & 79,0 & 92,1 & 81,6 & 79,0 \\
\hline FJ604935 & -19 & 79,0 & 63,2 & 63,2 & 67,1 & 90,8 & 92,1 & 90,8 & 64,5 & 89,5 & 71,1 & 61,8 \\
\hline EU240849 & -20 & 64,5 & 56,6 & 56,6 & 63,2 & 77,7 & 79,0 & 77,7 & 44,7 & 85,6 & 40,8 & 44,7 \\
\hline 1033166 & -21 & 65,8 & 57,9 & 57,9 & 63,2 & 79,0 & 79,0 & 79,0 & 46,0 & 86,9 & 42,1 & 46,0 \\
\hline EU346004 & -22 & 84,2 & 82,9 & 82,9 & 84,2 & 56,6 & 57,9 & 56,6 & 80,3 & 82,9 & 84,2 & 77,7 \\
\hline FJ694934 & -23 & 66,9 & 79,0 & 79,0 & 84,2 & 75,0 & 75,0 & 75,0 & 79,0 & 21,0 & 84,2 & 80,3 \\
\hline FJ 694933 & -24 & 71,1 & 50,0 & 50,0 & 55,3 & 80,3 & 79,0 & 80,3 & 32,9 & 80,3 & 50,0 & 42,1 \\
\hline FJ694930 & $=25$ & 48,7 & 59,2 & 59,2 & 63,2 & 76,3 & 77,7 & 76,3 & 64,5 & 82,9 & 71,1 & 65,8 \\
\hline EU345998 & -26 & 73,7 & 48,7 & 48,7 & 55,3 & 81,6 & 82,9 & 81,6 & 56,6 & 89,5 & 63,2 & 59,2 \\
\hline$A B 033167$ & -27 & 65,8 & 48,7 & 48,7 & 55,3 & 77,7 & 79,0 & 77,7 & 34,2 & 79,0 & 50,0 & 42,1 \\
\hline FJ694945 & -28 & 0 & 63,2 & 63,2 & 68,4 & 84,2 & 85,6 & 84,2 & 67,1 & 84,2 & 75,0 & 69,8 \\
\hline FJ694944 & -29 & ID & 63,2 & 63,2 & 68,4 & 84,2 & 85,6 & 84,2 & 67,1 & 84,2 & 75,0 & 69,8 \\
\hline IBCO028 & -30 & 95,24 & ID & 0 & 6,5 & 75,0 & 75,0 & 75,0 & 47,4 & 82,9 & 61,8 & 50,0 \\
\hline IBCO064 & -31 & 95,28 & 100,04 & ID & 6,5 & 75,0 & 75,0 & 75,0 & 47,4 & 82,9 & 61,8 & 50,0 \\
\hline IBCO245 & -32 & 94,84 & 99,54 & 99,57 & ID & 80,3 & 81,6 & 80,3 & 65,8 & 84,2 & 67,1 & 56,6 \\
\hline IBCOO40 & -33 & 93,64 & 94,34 & 94,34 & 93,94 & ID & 1,3 & 0 & 84,2 & 73,7 & 84,2 & 82,9 \\
\hline IBCO098 & -34 & 93,50 & 94,34 & 94,34 & 93,84 & 99,94 & ID & 1,3 & 84,2 & 72,4 & 84,2 & 84,2 \\
\hline IBC0185 & -35 & 93,60 & 94,37 & 94,31 & 93,94 & $100,0 \mathrm{t}$ & 99,94 & ID & 84,2 & 73,7 & 84,2 & 82,9 \\
\hline IBCO129 & -36 & 94,94 & $96,4=$ & 96,47 & 95,94 & $93,6 \mathrm{t}$ & 93,64 & 93,64 & ID & 82,9 & 55,3 & 42,1 \\
\hline IBCO190 & -37 & 93,60 & 93,70 & 93,74 & 93,34 & 94,44 & 94,51 & 94,44 & 93,74 & ID & 84,2 & 81,6 \\
\hline $\mathrm{IBCO} 212$ & -38 & 94,34 & 95,34 & 95,34 & 94,94 & 93,34 & $93,3=$ & 93,34 & 95,86 & 93,34 & ID & 42,1 \\
\hline Bото003 & -39 & 94,74 & 96,24 & 96,24 & $95,7 *$ & 93,74 & 93,64 & 93,74 & $96,8 *$ & 93,84 & 96,87 & ID \\
\hline
\end{tabular}

Anexo V. Continuação 